University of San Diego

Digital USD

2009-08-01

\title{
The Relationship of Level of Traumatic Exposure, Perceived \\ Stress, and Resilience with Salivary Cortisol and Salivary Alpha- \\ Amylase Diurnal Rhythm in Palestinian Children 10-12 Years \\ Exposed to Chronic War Violence
}

Mohammad R. Asia PhD, RN

University of San Diego

Follow this and additional works at: https://digital.sandiego.edu/dissertations

Part of the Nursing Commons

\section{Digital USD Citation}

Asia, Mohammad R. PhD, RN, "The Relationship of Level of Traumatic Exposure, Perceived Stress, and Resilience with Salivary Cortisol and Salivary Alpha-Amylase Diurnal Rhythm in Palestinian Children 10-12 Years Exposed to Chronic War Violence" (2009). Dissertations. 370.

https://digital.sandiego.edu/dissertations/370

This Dissertation: Open Access is brought to you for free and open access by the Theses and Dissertations at Digital USD. It has been accepted for inclusion in Dissertations by an authorized administrator of Digital USD. For more information, please contact digital@sandiego.edu. 


\section{UNIVERSITY OF SAN DIEGO}

Hahn School of Nursing and Health Sciences

DOCTOR OF PHILOSOPHY IN NURSING

THE RELATIONSHIP OF LEVEL OF TRAUMATIC EXPOSURE, PERCEIVED STRESS, AND RESILIENCE WITH SALIVARY CORTISOL AND SALIVARY ALPHA- AMYLASE DIURNAL RHYTHM IN PALESTINIAN CHILDREN 10- 12 YEARS EXPOSED TO CHRONIC WAR VIOLENCE

\section{By}

Mohammad R. Asia, RN, PhD

A dissertation presented to the

FACULTY OF THE HAHN SCHOOL OF NURSING AND HEALTH SCIENCES

UNIVERSITY OF SAN DIEGO

In partial fulfillment of the requirements for the degree

DOCTOR OF PHILOSOPHY IN NURSING

August 2009

Dissertation Committee

Dr. Anita Hunter, PhD, CPNP, FAAN, Chairperson

Dr. Lois Howland, DPH, M.S., R.N.

Dr. Joseph Burkard, DPNC, CRNA

Dr. Jane Georges, RN, PhD 


\begin{abstract}
Political violence, war, and genocide exist across the world and often the innocent children and civilians become victims. War and long-term violence have potentially harmful psychological and physiological effects on children. There are limited studies on the effect of prolonged armed conflict on the child's physiologic stress responses. The purpose of this study is to investigate the relationships between level of trauma, stress and resilience with salivary cortisol and salivary alpha- amylase (sAA) diurnal patterns in Palestinian children, ages 10-12, living in a long standing war zone. Salivary cortisol, a surrogate marker of hypothalamicpituitary-adrenal axis (HPA) activity, and salivary alpha- amylase, a surrogate marker of sympathetic nervous system (SNS), have been used to explore relationships of studies psychoneurobiological factors and processes related to stress. This study is exceptional in its examination of stress-related processes in a Palestinian child population. Factors as resilience, and stress biomarkers may serve as predictors in identifying children at greatest risk for physical and mental health problems in the face of actual or perceived stress and trauma. Exploring the effects of trauma exposure on perceived stress, resilience, and HPA and SNS markers provided for an examination of biological and behavioral relationships to in developing a theoretical framework and an explanatory model that might provide a guideline for clinical assessment and intervention models among traumatized children.
\end{abstract}




\section{DEDICATION}

I would like to dedicate this dissertation to the memory of all innocent children who have died in wars, children who were injured or traumatized due to war, and my beloved family and friends 


\section{ACKNOWLEDGMENTS}

First, I would like to thank the children and parents who participated in this study. Their dedication and enthusiasm to participate in this scientific research had made my mission easier in the midst of the war related difficulties.

I do appreciate the University of San Diego / Dean's Research Scholar Award that assisted me in purchasing the salivary biomarkers' kits and supplies; the Specialty laboratory Center/ Ramallah team for their extensive work to conduct the assays; and the United Nations Relief and Work Agency (UNRWA) / West Bank / Department of Education administrators and field supervisors, Ain Beit Ilma Elementary Schools' teachers and directors who provided me with permission, and great support for the data collection process on site.

I intensely appreciate Dr. Anita Hunter, my dissertation committee chairperson, for her guidance and invaluable knowledge which had enabled me to successfully complete my doctoral study. Her patience and extreme support have provided me with big lessons for the future.

I would like to address my sincere appreciation for Dr. Lois Howland and Dr. Joseph Burkard who provided me with tremendous knowledge and in depth expertise in the field of stress biomarkers. They helped to enrich the content of this study. My special thanks to Dr. Jane Georges for her strong contribution in the production of a scientific and scholarly paper article. She had broadened my perspectives in the context of scientific inquiry. I highly appreciate Dr. Andrea Hazen for her rich and outstanding expertise in the conduction of this research statistics. Without her efforts, this study wouldn't be appropriately carried out.

- Finally, I would like to thank my wife, children, parents, siblings and friends who had provided me with unlimited support toward the completion of my dissertation research study. 


\section{TABLE OF CONTENTS}

Dissertation introduction...................................................................

Background and significance of the problem ..........................................

Conceptual framework .................................................................

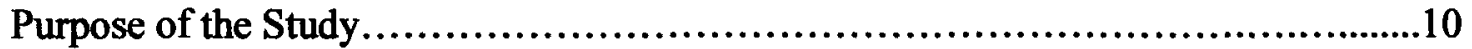

Key variables and definitions....................................................11

Research assumptions and Question............................................13

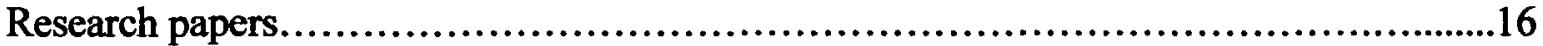

Article one: Research in a war zone..................................................16

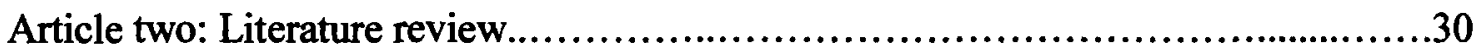

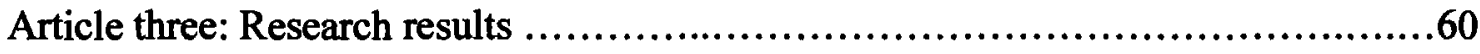

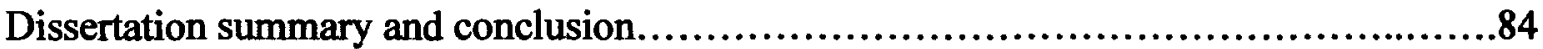

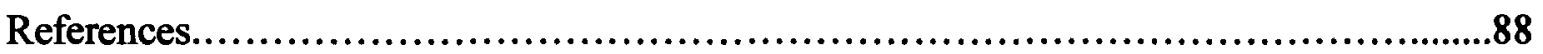

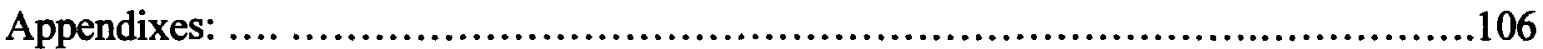

Appendix A: IRB Study Approval .............................................107

Appendix B: Permission to use facility .........................................108

Appendix C: Demographic data form..............................................109

Appendix D: Traumatic stress instrument.......................................110

Appendix E: Perceived stress instrument (child version)...............................111

Appendix F: Perceived stress instrument (parents' version) ....................... 112

Appendix G: H \& H Resilience screening instrument ...............................113

Appendix H: Parent/Guardian Consent ...........................................115

Appendix I: Child Assent Form....................................................118

Appendix J: Instruction for saliva collection.....................................120

Appendix K: Dissertation presentation slides..................................121 


\section{INTRODUCTION}

Background and significance of the problem

\section{Psychobiological impact of war violence on children}

Children might appear to do well under the most horrific circumstances such as war, violence, neglect, poverty, and abuse; however their current and future development remains threatened by these high stress risk factors. Political violence and war conflict is widely spread across the world where civilians, and particularly children, become victims of its ramifications. According to Ursano (2007), armed conflicts exist in more than 25 countries and children's rights are violated in 30 situations around the globe. Warzone traumatic stress predisposes vulnerable children to suffer the most toxic effects of such stressors and hostilities (Parson, 2000). The last decade witnessed the killing of more than two million children in war conflicts and six million children have been permanently disabled or injured (Ursano, 2007) . Over the past 10 years, armed conflicts resulted in 12 million homeless children and over one million orphaned (Papageorgiou, Frangou- Garunovic, Lordanidou, Yule, Smith et al., 2000; Parson, 2000). The prevalence rate of post traumatic stress disorder (PTSD) among survivors of war and mass violence has been estimated as $37.4 \%$ in Algeria, $28.4 \%$ in Cambodia, $17.8 \%$ in Gaza, and $15.8 \%$ in Ethiopia (Jong, Klmpore, Ommeron, El Masri, Araya, Khalid, et al., 2001). The exposure to terrorist attack puts at least $28-35 \%$ people around the world at risk for developing PTSD. While PTSD risk increases for directly exposed individuals, those individuals secondarily exposed were also at substantial risk of developing PTSD after September $11^{\text {th }}$ attack (e.g. more than $40 \%$ of people across USA and twice the baseline rate in residents of lower Manhattan) (Lee, Mohan, \& Janaca, 2002). 
The physiological and psychological results of PTSD and related disorders may include higher health care utilization and medication use; a variety of mental health problems; and psychosocial morbidity such as depression, anxiety disorders, anger, functional impairment, hyperarousal symptoms, substance abuse, social isolation, cognitive impairment, altered HPA, and brain changes in children (Carrion, Weems, \& Reiss, 2007; Creamer, Elliott, Forbes, Biddle, \& Hawthorne, 2006). The impact of war related experiences revealed that traumatized individuals demonstrate a high rate of psychiatric illnesses such as depression, dissociation, somatization, anxiety and neuroendocrine dysregualtion (Kocijan-Hercigonja, Sabioncello, Rijavic, Folenegovic-Smalk, Matijevic, Dunevski, et al. 1996).

Smith, Perrin, Dyregrov and Yule (2003) note that traumatic response in children to war stress is not culture bound. Traumatic reactions have been found among Lebanese children aged 10-16 (Macksound \& Aber, 1996), and Bosnian refugee children between 8-13 years (Papageorgiou et al., 2000). A similar chronic war conflict Northern Ireland in children exposed to traumatic injuries of chronic civic violence showed significant acute stress reactions, PTSD symptomatology, mixed anxiety and depressive reactions, phobic illness, hysteria, anger and conduct disorders(Curran \& Miller, 2001).

Since 1948 Palestinian children living in West Bank and Gaza Strip have been exposed to war, resistance, civil disturbance and paramilitary conflict (Garbarino \& Kostenly, 1996) thus, health professionals in Palestine have raised grave concerns about the long-term physical and psychosocial health problems Palestinian children may face when they reach adulthood. This is evidenced by the current high rate of PTSD symptomatology and associated psychiatric morbidity in these children. Palestinian context is different because children there have been exposed to war for generations with limited incidences of peace and tranquility (Thabet, Abed, \& 
Vostanis, 2004). Previous studies on the prevalence of PTSD among Palestinian children revealed $41 \%$ severe form, $72.8 \%$ mild to moderate form in 6-11 year old children (Thabet \& Vostanis, 1999); and 59\% in children directly impacted during the second Palestinian Uprising(Thabet, Abed, \& Vostanis, 2002). More recently, Palestinian children aged 3-6 years exposed to a wide range of traumatic events demonstrated significant behavioral and emotional problems (Thabet, Karim \& Vostanis, 2006). To date, no studies have examined the relationship between stress and psychobiological health in Palestinian children or adults.

\section{Stress, vulnerability and resilience}

Resilience, the process of overcoming stress and adversity, is complex. The explanatory model of resilience has traditionally been viewed as a normative response to stress in which an individual bends and rebounds without negative consequences, a positive attribute that facilitates stress-resistance, adaptive functioning and developed competence (Bonanno, 2004; Garmzy, 1991; Glantz \& Johnson, 1999; Haase, 1997; Kaplan, 1999; Luthar \& Zigler, 1991; Rutter, 1985). For Davidson (2000), optimally resilient individuals maintain a high level of positive affect and well-being in the context of adversity while also mediating negative effects. Affect regulation involves a complex network of corticolimbic pathways that mediates perception, contextual evaluation, and expression of emotions. Others have criticized the construct of optimum resilience (Kaplan, 1999). Hunter (2001) argues that resilience exists along a continuum from optimal resilience (rebounding with personal growth) to survival resilience (rebounding in any way possible without quitting). Children employing survival resilience may use insulation, isolation, disconnecting, denial, and aggression as defensive tactics to overcome their challenges and adversity (Hunter \& Chandler, 1999). Many of these behaviors, if left unattended, may lead to psychopathological and physical disorders. Other researchers have 
hypothesized that resilience has both a psychosocial and a physiological effect. Survivors of the Oklahoma City bomb blast had significantly higher mean resting heart rates despite their high scores for emotional resilience, suggesting that physiologic assessment may capture long-term consequences of terrorism despite of survivors' emotional resilience years after experiencing trauma(Tucker, Pfefferbaum, North, Kent, Burgin, Parker, et al., 2007).

Family resilience concepts have been emphasized heavily by family scholars in the last 10 years where a family, as one unit, competently overcome adverse social conditions and significant risks of the environment leading to desirable outcome; however, the type and severity of stressors affecting such resiliency process remains under debate (Patterson, 2002). Family distress results from failure to cope with multiple and overwhelming life stressful life conditions and requires an intervention program to build family strength, resilience, and reduce the risk to its vulnerable members (Walsh, 2002). Poverty and violence place the family under stress and weakens its capacity to perform core functions or achieve competent adaptation (Patterson, 2002). Family support is hypothesized to counteract the impact of war trauma effect on vulnerable children; however unhealthy family relationships might lead to unwanted and long term psychological and behavioral consequences. According to Fox, Benson, DeMaris and Wyk (2002) there is an increased literature that shows a strong relationships between economic distress and lack of resources on domestic violence and intimate relationships in the family. In a study on Vietnam veterans who were exposure to high war stress showed that $75 \%$ have been involved in abusive domestic violence resulting in significant behavioral disturbances in their children 15- 20 years later (Rosenheck \& Fontana, 1998). Another study by Weidner, Hutt, Connor and Mendell (1992) suggested that family stress can lead to increased risk of coronary disease risk and aggression in boys during their adulthood while girls will only be predisposed to 
aggressive behaviors. The study concludes that boys are more likely to be affected by adverse environmental influences predisposing them to coronary heart disease in their adulthood (Weidner, Hutt, Connor, \& Mendell, 1992). Another study demonstrated strong evidence that family stressful life events predispose children to multiple physical, mental and emotional illnesses (Blgbee, 1992).

Little research has been conducted to establish the relationship between neurobiology and resilience, especially with children (Curtis \& Cicchetti, 2003; Hunter, 2001b). This study assessed the stress perception, trauma exposure, resilience response, and the physiologic responses to war stress in Palestinian children residing under chronic war violence.

\section{Stress Biology}

Response to social stress includes the activation of two neurobiological systems, the autonomic nervous system and the hypothalamic - pitutary- adrencortical axis. Cannon (1929) described how the sympathetic-adrenomedullary axis governs the initial "fight or flight response. Here the release of catecholamines (epinephrine, norepinephrine and dopamine) stimulate the corticolimbic structures in the brain as well as peripheral effects such as increased heart rate, increased cardiac tone, increased blood flow to skeletal muscles, increased respiratory rate, bronchial dilatation, increased blood glucose and augmentation in basal metabolism. A promising measure of Autonomic stress responsitivity is $\mathrm{SAA}$, an enzyme produced by the oral salivary gland with a primary function to facilitate the digestion of complex macromolecules of carbohydrates into glucose and maltose for easy absorption through the intestinal tract. It also contributes to the maintenance of oral cavity health.

When stimulated by stress the sympathetic nervous system (SNS) releases catecholamines from the adrenal medulla into the blood for peripheral circulation. The 
subsequent release of sAA via stimulation of beta-adrenergic receptors in salivary glands suggest the use of alpha amylase as a noninvasive indirect measure of plasma norepinephrine (Granger, Kivlighan, El-Sheikh, Gordis, \& Stroud, 2007; Nater \& Rohleder, 2009). Studies have shown that SAA has an opposite pattern to cortisol's diurnal rhythm where levels of amylase drops sharply after awakening and increased steadily thereafter with highest levels in the afternoon and evening (Nater, Rohleder, Schlotz, Ehlert, and Kirschbaum, 2007; Rohleder, Nater, Wolf, Ehlert, \& Kirschbaum, 2004). Granger and colleagues (2006) stated that sAA was recognized as a surrogate marker of the Autonomic/sympathetic nervous system since the 1990s; however, it wasn't integrated into the mainstream study of stress psychobiology, health, and social behavior, and never employed to examine biosocial models of stress and vulnerability in the context of child development Granger, Kivlighan, Clancy, Mona, Jacquelyn, Lisonbee, et al. (2006). Previous studies have linked cortisol and sAA activity with acute stress and disease; rare studies have attempted to link sAA with chronic psychological stress (Wolf, Nicholls, \& Chen, 2008). Studies have reported faster peak and recovery time of sAA over the cortisol pattern, and also a difference at baselines (Granger et al., 2007)

Selye (1936) expanded his stress theory by describing the activation of the hypothalamicpituitary-adrencortical axis which results in the secretion of corticotrophin-releasing factor (CRF), adreno-corticotropic hormone (ACTH) and ultimately increased secretion of corticosteroids. Cortisol plays a vital role in carbohydrate metabolism (gluconeogenesis), modulation of the balance between cellular and humoral immunity, modulation of the central cognitive and affective processes, maintenance of the vascular tone and redistribution of blood flow (Edwards et al., 2003). Cortisol diurnal patterns have proven to accurately reflect the HPA axis response in an individual's stress responses. Under normal circumstances, baseline cortisol 
reaches its highest peak within 30 minutes of awakening in order to enable the body respond the daily demands and then steadily declines through the day and evening to its lowest level at night prior to sleep. A normal and steeper cortisol diurnal rhythm is associated with good health outcome while flatter slopes of cortisol are associated with poor health outcomes(Edwards, Hucklebridge, Clow, \& Evans, 2003).The chronic activation of the HPA system in response to acute stress can lead to alteration, maladaptive and even pathological activity of the HPA system (Lopez, Akil, \& Watson, 1999). Prolonged stimulation (chronic hyperocortisolism) or lack of this natural response (hypocortisolism) have both been associated with devastating health problems (Curtis \& Cicchetti, 2003). Chronic hyperocortisolism can cause hypertension, osteoporosis, immunosuppression, insulin resistance, dyslipidemia, dyscoagulation resulting in atherosclerosis and cardiovascular disease (Charney, 2004). The sequela of hypocortisolism appears to alter brain development and inhibit growth factors that might facilitate neural cell death and alter cognitive functioning (Yehuda, Bierer, Schmeidler, Aferiat, Breslau, \& Dolan, 2000).

As Lazarus (1999) asserted, stress and coping are rarely studied in early developmental stages. According to Lynch (2003) there is no literature demonstrating the relationship between exposure to chronic violence and the physiological systems governing hyperarousal vs. hypoarousal. No studies in the literature examine the impact of chronic war violence with the autonomic nervous system. This study explored the effects of trauma exposure on perceived stress, resilience with HPA and SNS markers. The results have provided a beginning framework to identifying clinical assessment tools that can identify those children at greatest physical and psychological risk as a result of their exposure to war trauma. 


\section{Conceptual Framework}

The conceptual framework of this study was based on the Revised Model of Stress, Coping, and Adaptation developed by Lazarus (1994) (see figure 1). The model includes three main relationships between causal antecedents that include the individual's personal variables; his/her environmental variables; and the individual's mediating processes to cope with life stressors that influence the ultimate outcome. As outlined, the model illustrates three levels of analysis that include the social, psychological and physiological level. According to Lazarus \& Folkman (1984), little attention is paid toward the relationships between the coping processes to mediate stress that might affect the social, psychological and physiological short and long term adaptational outcomes. Resilience skills, as developed by Hunter (1999) and Huertes (2001), play a central role in the individual's coping and adaptational processes to mediate the physiological outcomes of chronic stress. Resilience skills are depicted in the $\mathrm{H}$ \& $\mathrm{H}$ Resilience Screening Tool (Huertes, 2000; Hunter, 1999) and measured in the nine subscales as Creativity, Humor, Independence, Initiative, Insight, Relationships, Values orientation, Self - esteem, and Self- Efficacy. 
The Lazarus model (Lazarus 1994) (Figure 1)

\section{$\underline{\text { Antecedents }}$}

Person:

Goals and goal hierarchies

Beliefs about self and world

Personal resources
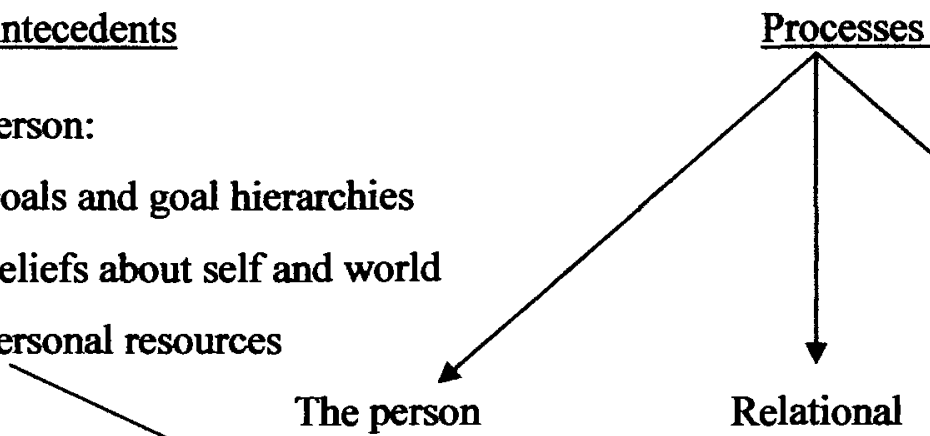

Outcomes

Environment: relationship

Environment $\rightarrow$ appraisa

Harms/losses

meaning their effects;

Threats themes morale, social-

Challenges functioning,

Benefits

The adapted model to reflect variables in this study is:

Antecedents

Person:

Demographic

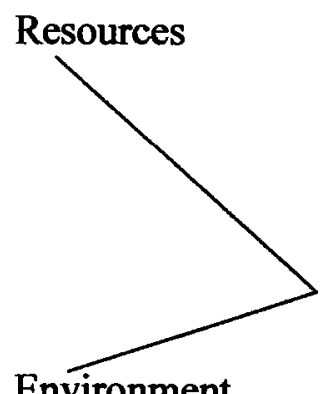

Environment

Traumatic exposure

Parental stress/support
Processes

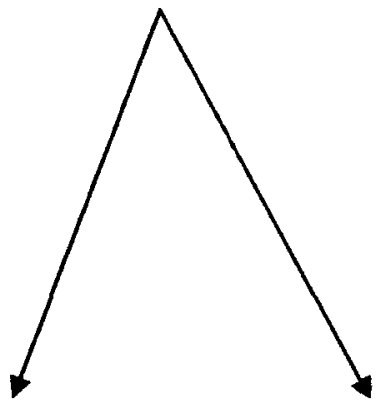

Resilience skills $\rightarrow$ Perceived stress $\rightarrow$ Psychosocial\& Biological stress

Outcomes and health 


\section{Purpose of the Study:}

Examining the hypothalamic- adrenal- axis (neuroendocrine alteration) response with concomitant psychosocial status in children exposed to chronic violence can help identify children at risk for chronic mental and physical health problems. Such insight to understanding the influence and relationships between violence in war zones and its biologic and psychological impact on children can lead to better prevention and treatment of children experiencing chronic traumatic exposure.

The purpose of the study was to investigate the relationships between traumatic experiences, perceived stress, resilience and their potential neuroendocrine diurnal variation in amylase (sAA) and cortisol secretion in Palestinian children, ages 10-12, living under chronic violence. Children often appear to successfully overcome the effects of chronic stress; however, such resilience may hurt them as much as help them. It is important to understand how these children are resilient, what types of resilience skills they possess, and the interrelationship of these factors on salivary cortisol and sAA diurnal rhythms. Such information will be used to develop programs that might improve the child's ability to successfully overcome these adversities, to demonstrate more positive resilience skills, achieve more optimal resilience, and decrease the harmful effects of altered cortisol secretion patterns (Hunter, 2001; Joshi \& O'Dennell, 2003; Kanji, Drummond, \& Cameron, 2007).

A descriptive cross-sectional research design was used to study the relationships between demographics, level of trauma, perceived stress, resilience total scores, and the Palestinian child's cortisol and sAA diurnal rhythm. This research investigated the biological alterations of children living in a war environment and its potential contribution to the child's resilient state. The findings may be helpful to nurses and other stakeholders to better understand 
and intervene with children respond to chronic stress. This study hypothized there was a significant relationship between perceived stress, traumatic experiences, resilient functioning and neuroendocrine alterations in children exposed to chronic war violence. The study specifically aimed to:

(1) Investigate possible correlation between, demographics, level of trauma, perceived stress, resilient functioning with cortisol and SAA diurnal rhythm in Palestinian children 10-12 years exposed to chronic war violence.

(2) Investigate the relationship parental perceived stress had on the child's perceived stress.

(3) Assess the effect of children's exposure to chronic war violence and their resilience.

\section{Key variables and definitions}

The following definitions were used to operationalize the variables in this study:

\section{Independent Variables}

Demographics. Age, gender, family income, and academic performance had been identified as potential moderating variables that might play a vital role in moderating children's stress level, resilience and its outcome (Barr, Boyce \& Zeltzer, 1994).

Level of traumatic exposure. For the purpose of the research, level of traumatic exposure was based on children's total score of traumatizing events witnessed during the military actions in West Bank in the last year. Children answered by "Yes" or "No" for each item presented in the modified Gaza Traumatic Checklist. This instrument was developed by the research department of the Gaza Mental Health Program and consisted of 17 traumatizing events that children in Gaza might have witnessed during the military violence in the last year (AbuHein, Qouta, Thabet, \& El-Sarraj, 1993). The instrument was presented in English and Arabic versions and had an established reliability of 0.90 . For the purpose of this research the checklist 
was modified by the principal investigator to more accurately depict children's traumatizing experiences with the military incursions in the West Bank. It was composed of 26 items that reflected most of the military traumatizing events to which these children might be exposed. The instrument was translated into Arabic and back-translated to ensure consistency of the content between the original and Arabic versions. Reliability of the modified version of the Gaza Traumatic Checklist instrument was assessed during this study.

Perceived stress. According to Dobson and Metcalfe (1983) (perceived) stress is a substantial imbalance between demand and response capability under conditions where failure to meet demand has important (perceived) consequence (Karr \& Johnson, 1987). Stress was measured through Cohen Perceived Stress Scale (PSS) (1983). The children participating in the study were asked to complete the children version of the Perceived Stress Instrument while children parents were asked to complete the parents' version of the Perceived Stress instrument. Both versions of the instrument were composed of a 14 item measure of the degree to which situations in an individual's life were appraised as stressful. The instrument is valid and reliable with reliability coefficient of 0.85 . Both instruments were translated into Arabic and backtranslated to ensure consistency of the content between the original and Arabic versions. Reliability of both versions of the PSS instrument will be assessed during this study.

Resilience. For the purpose of this study, the definition of "resilience" developed by Hunter (2001) will be used. Thus, "resilience" is defined as the process of overcoming adversity. The H\&H Resilience Screening Tool, comprised of 41 questions, was used to measure resilience scores among participating children. This instrument is valid and reliable with reliability coefficient of 0.91 across multiple international arenas and age groups. The instrument had been translated into Arabic, back-translated to ensure consistency of the content between the original 
and Arabic versions, and piloted in a population of Palestinian children ages 9-13 obtaining a reliability coefficient of $r=.87$.

\section{Dependent Variables}

Salivary cortisol diurnal rhythm. For the purpose of this research, cortisol diurnal rhythm was determined based on participants' difference between child's participant awakening and evening salivary cortisol levels detecting normal versus altered HPA Axis cortisol secretion pattern. Cortisol presents an important indicator of the hypothalamic- pituitary- adrenal axis reaction to human's stress and resilience. According to Barr, Boyce\& Zeltzer (1994) these are psychobiological markers that function as mediators if they transform or tranduce the stimulus in a way that leads to the outcome. We examined the morning and evening salivary cortisol levels for each child participant and then computed the difference between both levels.

Salivary Alpha-Amylase (sAA) diurnal rhythm. sAA is a strong biomarker that accurately measures human's autonomic/sympathetic nervous system response to stress. SAA diurnal course was determined through measuring participant's SAA awakening and evening levels and then computed its daily slope pattern for normal versus flattened rhythm outcomes.

\section{Research Assumptions and Questions}

The following research assumptions and questions were explored in this study:

\section{Research assumptions}

1. Children exposed to chronic violence, exist in potentially unhealthy resilience dimensions of emotional insulation or survival. Either of these modalities of overcoming adversity increases the child's risk for mental and physical health problems. 
2. Children exposed to chronic violence do not exhibit the normal physiological cortisol stress response and as such are at increased risk for physical health problems.

3. Parents may influence their child's perception of stress.

\section{Research Questions}

1. What is the relationship of the demographic variables, level of trauma exposure, perceived stress, and resilience, with cortisol and sAA diurnal activity in Palestinian children, ages 1012 , exposed to chronic war violence?

2. What is the relationship of demographic variables, level of trauma exposure, and perceived stress with resilience of Palestinian children?

3. What was the relationship between parents' and their child's perceived stress scores?

\section{Implications}

The outcomes of this research study have relevance to future nursing research as well as other related disciplines in the following ways. First, medical professionals will gain more knowledge of the impact of chronic war violence on the biological pathways in young bodies. This knowledge will then lead to more effective treatment strategies, both behavioral and pharmacological. Second, psychotherapists will gain a deeper understanding of both the short and long-term effects of war on children's psychological development. Third, this increased understanding of both professions will help medical and psychological clinicians better coordinate their treatment plans. Fourth, the findings will guide further research into how violence of any kind affects biological and psychological systems, both in children and adults. Fifth, the findings will give those who work in war zones, (i.e. medical first responders, human rights organizations, peace keeping efforts) more appropriate strategies for intervening with 
young victims of war. Finally, these findings can be used to help families and communities not only help children cope with war-time experiences, but also help them restore the physical and psychological health of their children and in doing so preserve their cultures. In particular, the findings can be easily integrated into both nurses' training programs and continuing education modules. This will lead to enhanced nursing competence and increased efficacy of care for young victims of war, gang violence, and domestic abuse. It will facilitate nursing research on the impact of war on stress biology, and the role of family and community to buffer and maximize coring strategies of war stress on children. 
Research in a War Zone:

Implications for Nurse Researchers

\author{
Mohammad R. Asia, RN, PhD \\ Jane M. Georges, RN, PhD \\ Anita J. Hunter, RN, PhD, FAAN
}




\begin{abstract}
Using a case example of a research study conducted in the Palestinian West Bank during Dec. 2008 to Jan. 2009, the process of conducting research within a war zone is described and analyzed. The contextual factors influencing research in displaced populations within war zones are discussed. Methodological implications for nurse scientists functioning within zones of conflict and their American academic mentors or research partners are analyzed, with the identification of potential barriers and solutions for conducting research in this context.
\end{abstract}


Research in a War Zone:

Implications for Nurse Researchers

\section{Introduction}

This article is situated in the space between methodology and philosophic analysis. Using a case example of a research study conducted in the Palestinian West Bank during Dec. 2008 to Jan. 2009, we propose to describe and analyze the process of conducting research within a war zone. In addition, we seek to address the issues facing American nursing academics who may be either mentoring or partnering in such research endeavors, for whom these experiences may be unfamiliar.

Specifically, the purposes of this paper are to:

- Describe the challenges of conducting nursing research in a displaced population within the context of active armed conflict; specifically, the Palestinian West Bank during December, 2008 through January, 2009;

- Reflect and analyze the philosophical implications for nurse researchers who are members of a displaced population being studied under conditions of violence;

- Discuss methodological implications for nurse scientists functioning within zones of conflict and their American academic mentors or research partners, with the identification of potential barriers and solutions for conducting research in this context. 


\section{Background}

The primary author is a Palestinian who was completing a $\mathrm{PhD}$ in Nursing Science at a university in the United States. The purpose of his doctoral research study was to investigate the relationships between exposure to traumatic experiences, levels of stress, resilience, with salivary cortisol and a-amylase diurnal pattern in Palestinian children, ages 10-12, and their parents, who are living under conditions of chronic violence. This study hoped to answer some of those unanswered questions related to the relationships between the aforementioned variables and the potential neuroendocrine alterations in children living in war environments. Such information can be used to develop programs that might improve the child's ability to successfully overcome these adversities, to demonstrate more positive resilience skills, achieve more optimal resilience, and decrease the harmful effects of altered biomarker patterns (Hunter \& Chandler, 1999; Joshi \& O'Dennell, 2003; Kanji, Drummond, \& Cameron, 2007). The Nablus district in the West Bank of /Palestine was chosen as the site of study because it contains a sample population of children and their parents who have been exposed to a variety of conflict-related stressors throughout their lives.

\section{Challenges of Conducting Research in a War Zone}

The challenges facing this doctoral student mounting a dissertation study were many, but the challenges encountered by those of us who have come from countries outside the U.S. have an added dimension of complexity. Unlike other US-born doctoral students who remain "in place" to begin their data collection, very often we, as international students, return to our countries of origin which are experiencing ongoing conflicts. My decision was to focus my dissertation on the health care needs of Palestinian children which reflected my own lived 
experiences of growing up in Palestine and having worked as a pediatric health teacher and practitioner in that setting. But the actual mechanics of carrying out a study which on its surface appeared straightforward- collecting survey questionnaire data and salivary stress biomarkers' samples- were to become extremely complicated in the context of the events of December, 2008 through January, 2009.

The history of the Israeli-Palestinian conflict is a complex one and beyond the scope of this article. Since 1948, Palestinians have been displaced by ongoing conflicts over land ownership resulting in consequent instability, insecurity, and limited resources. Currently, poverty, violence, high morbidity and mortality, and a limited infrastructure impact the health care needs of four million Palestinians (Horton, 2009). Though the West Bank is not as unstable as Gaza, its citizens have still suffered the same abuses, economic hardship, shortages in water supply, and restrictions on free access to work, health care and family(Batniji et al., 2009; Worth, Metcalfe, Boyd, Worrall, \& Canarutto, 2009).

The Gaza War, part of the ongoing Israeli-Palestinian conflict, started when Israel launched a military campaign in the Gaza Strip on December 27, 2008. On January 3, 2009, the Israeli ground invasion began. It is estimated that 1,314 Palestinians and 13 Israelis died in the conflict, but the actual number of casualties remains a subject of ongoing contention (Bell, 2009) In the days following the ceasefire, the $\mathrm{BBC}$ reported that more than 500,000 Gazans were left without running water and that 4000 homes had been ruined, leaving tens of thousands of people homeless (BBC, 2009). 
Impact on Research: Access to Research Supplies

It was in this context of active war that I began my data collection for my dissertation. Unlike my American counterparts whose most daunting task might be obtaining human subjects approval, I faced a multitude of challenges and constraints. Prior to departure for the West Bank, I had obtained a research grant to purchase the biomarker supplies needed for salivary cortisol and $\alpha$-amylase collection and analysis from a company in Europe. Delivery of the kits was guaranteed to Ramallah, Palestine within 4 days. Unfortunately, the delivery took three months to reach its destination as the supplies had been detained in an Israeli airport under investigation as potential bomb making items. Many people were involved in trying to resolve this problem: my professors, research assistants, another biomarker evaluation center, the biomarkers company, and the embassy of the country from which the package had been shipped. Three months later, the kits and supplies were finally released and undamaged. As with most good news, there was some bad news: I owed an additional \$900. Thus, unexpected and costly delays in accessing research supplies are an integral part of conducting research in a conflict zone. As a researcher, I and my American mentors/research partners needed to be prepared for problem solving at an international level, and develop an alternative plans in crisis situations.

\section{Impact on Research: Access to Study Participants}

Beyond the constraints of getting access to research supplies, however, the issue of geographic constraints became my primary challenge after arrival to perform data collection. Roadblocks, checkpoints, soldiers, and permit checks are integral parts of a military operation conducted in a civilian setting. At the checkpoints, Israeli Defense Forces (IDF) soldiers controlled the movement of people, inspecting every car entering and leaving any Palestinian 
city. These restrictions became significant barriers to the conduct of the research. Nablus, where data was collected, was approximately $25-40$ minute drive from Ramallah, where I, as investigator, was staying. What might have been a short drive between two American cities became an hours-long journey, as I encountered no fewer than 5 Israeli checkpoints obstructing all pathways to Nablus city, with additional mobile checkpoints emerging at any time and in any place along the roads. As violence escalated in late December, 2008, the lack of communication with and unpredictability of access to the data collection site- an elementary school at Nablusbecame extremely stressful. Like any researcher, I wanted to adhere to my protocol for survey completion and specimen collection carefully and not to lose access to this study population. While the surveys had been completed prior to the attack on Dec. 27, the salivary samples' collection was scheduled to begin after this time point. After a delay due to the escalation of violence, I finally was able to connect with the school administrators to schedule a more suitable, safe and stable time in which to collect the salivary biomarkers' samples. The experience of biological specimen collection, timing, storage and delivery continued to be complicated by the conflict, as the specimens had to be placed in the back seat of the car in a special large box and surrounded by ice packs. My principal concern was that soldiers inspecting the car at the checkpoints might suspect the samples were biological weapons or other dangerous materials. The consequences of such a misunderstanding were serious, including imprisonment and confiscation/destruction of the specimens. Throughout the journey, armed soldiers did subject the researcher to questioning at gunpoint. Finally, the specimens were safely delivered to the laboratory where the assays would be performed. While most doctoral students would characterize the data collection phase of their dissertation as (at least) somewhat stressful, I would later characterize this stress as so intense as to feel "life-shortening." 
Ultimately, the study was completed, and 122 children and 203 parents were recruited to participate in the study and completed study materials. I returned to the United States to complete data analysis and finalize my dissertation. However, these empiric "facts" about the completion of my research project are only part of the story. For researchers (especially those of an ethnicity directly involved in the conflict) who actually enter into a conflict zone to perform research, the implications are much broader. And for American nursing academics, who may be either mentoring or partnering in such research endeavors, the issues facing the "in country" researcher may be opaque. Thus, it was considered important to "go deeper" in the understanding of the conduct of research in a war zone by nurse researchers, and perform a reflective/ philosophical analysis as well.

\section{Reflections and Philosophical Implications}

Given the profound impact the process of conducting research in a war zone had on both the researcher and his American mentors, it is appropriate to reflect and analyze the philosophical implications for nurse researchers who may face such experiences in the future. The following reflection/analysis is situated in an emancipatory paradigm, and seeks to examine the power relations inherent in the conduct of research in displaced populations under conditions of violence. The principal researcher's own voice and situatedness as a member of a displaced group is given salience here, as a means of revealing more clearly the social processes sometimes rendered invisible in other descriptions of research methodologies.

The principal researcher would later provide a written narrative account about his experiences during data collection to his professors. Here is an excerpt in which he describes the 
day he finally arrived at Nablus to collect the salivary cortisol samples, only to find that the school was closed due to the rapid escalation of violence:

"I guess this was one of my darkest days - I felt my academic future was in jeopardy as I would not be able to complete my research. I was afraid for my family and myself that there would be a military incursion on Ramallah, I was exhausted and frustrated by the never-ending road checkpoints and military encampments. As I sat in the empty school feeling overwhelmed, the epiphany occurred - this is what my participants might feel like every day. If I could finish this study, I suspected I would have some phenomenal data reflecting this mental and physical stress load because I was sure feeling it. So, I refused to give up."

These reflections show the social "space" that this researcher was functioning within- one of fear of physical violence and a sense of never-ending barriers. Unlike an "outsider" to the social context who enters only to collect data and then departs for a safe environment, this researcher is a highly identifiable member of an ethnic group that is currently the focus of violence. He must simultaneously fulfill the demands of academia to complete his degree- ("I felt my academic future was in jeopardy") - as well as the demands of a dominating military force. Yet it is his very situatedness in this ethnic group that provides the transformative power for him to continue with this study. His sudden epiphany that he has become the object under study- the ethnic minority experiencing violence- gives him the impetus to continue. He has moved from a stance of observer/data collector to being, in a sense, a participant in his own study. The observer/observed polarity had collapsed, and he has entered a space in between. As Bell Hooks (1994) observed, students experiencing a profoundly life-changing educational experience may have a sense of developing a "voice." For this researcher, a voice independent of 
any academic or political authority has emerged. While previously having received what he describes as "excellent" support from his American mentors, it is in the context of his own lived experience, isolated from his mentors, that his voice emerges. He is able to continue and complete his research within his own social space, a space not accessible to his American professors- that of being simultaneously both the object of study and the object of violence. When he does return to the social space of American academia, he describes himself as a "changed" person in many ways: "angry, frustrated, and disheartened," but at the same time, "profoundly" committed to bringing his research study to completion. While many students also experience significant changes in sense of "voice" and commitment as the result of doctoral study, it is the depth and scope of his change that constitute an important issue for American academics who have not had such experiences to recognize.

\section{Methodological Implications}

The methodological implications from this experience for nurse scientists functioning within zones of conflict and their American research partners are manifold. Little documentation exists regarding the actual conduct of research within war zones, including the challenges that must naturally accompany restricted access to research supplies or participants. Even fewer authors have commented on what has become a primary implication from this experience: the space inhabited by the nurse researcher who enters zones of conflict. A further layer of complexity, the investigator as a member of an ethnic group that is currently the focus of violence, has implications for the growing number of nurse researchers globally who are members of cultures located in either ongoing or post-conflict societies. Additionally, American nursing professors- who may be Caucasian, middle class, and have not experienced 
displacement- are now entrusted with long-distance mentoring of these beginning nurse researchers. What lessons have we learned from this unique experience that might benefit nurse researchers faced with similar challenges?

\section{Instrumental Implications}

American researchers are accustomed to planning research studies based on levels of access to supplies and geographic locations usually present in most American cities. Such assumptions must be discarded when planning research in zones of conflict. Even beyond the traditional researcher's lament of "if anything can go wrong, it will," there are unique factors confronted by researchers entering conflict zones. It become incumbent to think pro-actively regarding the way "ordinary" research supplies might be viewed by military personnel in social settings in which military control is being enforced. As a result of his experience, the researcher strongly advises other investigators entering a war zone to either bring the supplies with them in their luggage or purchase them within the country, if possible. While researchers in industrialized countries have come to expect the rapid supply/delivery of goods via international carriers within days, this expectation must be discarded in a zone of conflict.

Free movement through geographic spaces is another assumption held by researchers accustomed to doing research in the U.S. For American researchers, "gaining access" to study participants means obtaining institutional and human subjects permissions. In a militarized zone, "gaining access" becomes a far more complex issue. Regardless of the location, researchers entering a zone of conflict to do research must be prepared to endure extreme time delays and searches of their research materials. And while it may be important to try to forecast the ways in which research materials might be misinterpreted by inspecting authorities, this researcher found 
that not all such interpretations can be predicted. Having as much written documentation as possible of one's own status as a researcher and the identity of the materials being carried- both technical specifications and institutional permissions to use them- is absolutely essential.

\section{Affective Implications}

Prior to leaving for his data collection, the principal researcher recalls feeling he was "ready" to re-enter this volatile environment, after having spent 3 years in the U.S. doing his doctoral coursework. He later describes any feeling of readiness he might have had as "naïve"the cultural transition from American life back to a zone of conflict among his own displaced people was an incredibly stressful event for him. For nursing professors mentoring such doctoral students, it is an extremely important issue. Unlike their U.S. counterparts, international students experiencing "re-entry" back into their own sociopolitical realities have an additional crisis to face as they begin dissertation data collection. The shift from the relative freedom of American daily life to a controlled, militarized environment can be abrupt. Any assumption by a U.S. professor that "they grew up in it, so they're used to it" is incorrect. As this researcher stated, "one never becomes accustomed to war." In addition, the status of being an identifiable member of a specific ethnic group can have an entirely different meaning in the U.S. and in another environment. The politics of difference may place this person at risk for violence in their original setting, a risk not encountered in their lives as American doctoral students.

In addition to anticipating and supporting one's colleagues experiencing the profound cultural shifts described above, it is incumbent on American academic mentors/research partners to recognize that the very process of data collection can be transformative. Most research texts describe data collection- particularly in a quantitative study-as a one-way process. The 
investigator enters the research area, "collects" data, and then departs. We would like to emphasize the relational nature of data collection in all settings, but particularly in zones of conflict in which the investigator shares culture/ethnicity with persons who are experiencing violence. In addition to the instrumental tasks of having participants fill out forms and give biological specimens, the researcher is herself/himself experiencing the same violence. Going through such an experience is unquestionably transformative. Academic mentors and colleagues who are invested in an engaged model of pedagogy which Hooks (1994) describes need to give validation to the experiences reported by their colleague "in country," both during and after their journey. While the lived experience of being an indigenous person returning to a zone of conflict may seem opaque- to the point of incomprehensible- to his or her American counterparts, the active expression of support and willingness to listen are essential. By open acknowledgement that this researcher has entered a social space inaccessible to them, mentors and fellow researchers can provide a starting place for providing the support needed to complete the research project and share these data with the rest of the world.

\section{$\underline{\text { Summary }}$}

We support Cairns' (1994) premise that conducting research on children within political violence is not easy. But we also would also expand upon this premise to add that the stress on the researcher entering the zone of conflict can be both intense and life changing. Conducting research in a war zone carries a tremendous amount of stress, insecurity, danger, financial outlay, and extraordinary risks- with the least risk being not completing the project.

This case example and its analysis constitute a starting point for future work in this area. As Georges (2008) noted, "biopower"- understood as "power over life"- is emerging as a central 
theme in contemporary nursing epistemology. An awareness of the need for nursing research within zones of conflict in which biopower is being enacted is increasing. We foresee the need for additional research into the following issues that also became salient our experiences: the nurse researcher-participant relationship under conditions of violence; the social space in which violence occurs; nurse researchers within that space: the observer-interventionist polarity; and the space "in between" that polarity inhabited by nurse researchers. As nursing research becomes an increasingly globalized endeavor, the need for research within zones of conflict and partnerships with our colleagues who do such research will become of central importance to nursing science. 
Literature review regarding children's perceived stress, resilience, hypothalamic-pituitary-adrenal axis and sympathetic nervous

$$
\text { system activity }
$$

Mohammad R Asia, PhD*, Anita Hunter, PhD (Chair) ${ }^{* *}$, Lois Howland, DrPH (Committee) ${ }^{* * *}$, Joseph Burkard, DNsC (Committee) ${ }^{* * * *}$, Jane Georges, $\mathrm{PhD}$ (Committee)

$$
\text { University of San Diego }
$$

School of Nursing \& Health Sciences 


\begin{abstract}
There is limited research on the effect of prolonged armed conflict on a child's stress levels and physiologic stress responses. Health care providers know that exposure to war and long-term violence have potentially harmful psychological and physiological effects on children. The current state of the science on these variables will be presented. This state of the science review and the resultant analysis laid the foundation for a doctoral research study that explored the relationship between level of trauma, perceived stress, resilience, cortisol and $\alpha$-amylase diurnal rhythm patterns in Palestinian children, ages 10-12, living in a long standing war zone. These psychosocial factors and biomarkers may serve as predictors in identifying children at greatest risk for physical and mental health problems in the face of actual or perceived stress and trauma. Gaining insight into understanding the influence and relationships between violence in war zones and its biologic and psychological impact on children can lead to better prevention and treatment of traumatized children.
\end{abstract}




\section{Introduction}

The following paper is a literature review on various factors that have contributed or could contribute to children's psychosocial and biological responses to extreme stress and violence. This literature review laid the foundation for a doctoral study investigating stress, trauma exposure, resilience, and biomarker responses in Palestinian children ages 10-12.

Over the past decade, much research has been conducted disproving the old position that children could bounce back from anything without incurring negative consequences. Researchers have found that children overcoming stress can either emotionally grow as a result of the experience or can develop defensive coping mechanisms in order to survive the experience (Haase, 2004; Hunter, 2001; Lazarus \& Folkman, 1984). Children living in war zones are even more vulnerable to impairment in normal development; and suffer the toxic effects of traumatic stress, political uprooting, poverty and refugee status that can cause cognitive, emotional, behavioral, and psychobiological changes (Lynch, 2003; Parson, 2000).

In Palestine, where children had been exposed to a war lasting decades, there are grave concerns raised by the health professionals about the long-term physical and psychosocial health problems these children may face when they reach adulthood. There is current evidence of a high rate of post traumatic stress disorder (PTSD) symptomatology and associated psychiatric morbidity (Elbedour, Onwuegbuzie, Ghannam, Whitcome, \& Hein, 2007).

This literature review contains information about the impact of political violence and war trauma on potential child psychobiological alterations and stress adaptation. The role of age, gender and family process in childhood traumatic stress; child vulnerability, risk and resilience; the biological stress response in children, specifically the dysregulation of the HPA functioning and the sympathetic nervous system (SNS) response to stress are presented. 


\section{Stress and adaptation}

Negative stress has been found to disrupt the physiological and emotional homeostasis that could potentiate vulnerable individuals to serious physiological and psychological consequences (Kanji, Drummond, \& Cameron, 2007; Lazarus \& Folkman, 1984; Roberti, Harrington, \& Storch, 2006). One's cognitive appraisal of external and internal stressors significantly influences the adaptational and coping mechanism used to reduce stress and restore homeostasis (Lazarus \& Folkman, 1984). In 1994, Barr, Boyce, and Zeltzer found relationships between childhood morbidities such as respiratory illnesses, psychiatric disorders, depression, and chronic diseases with the child's exposure to stress. Though stress research in the last three decades has determined a significant and persistent relationship between psychosocial adversity and pediatric health disorders, such research in children is limited. As Lazarus (1999) asserted, stress and coping are rarely studied in early developmental stages.

Shalev in 2000 expanded our understanding about traumatic stress in his discussion about the response stages one goes through when exposed to such stress. Stage one, or initial exposure to traumatic stress, may trigger psychobiological changes but this response (fight or flight) is insufficient to cause damage to the central nervous system (CNS). At the second stage, learning and adaptation responses could lead to both positive learning and resolution of stress, or may lead to prolong distress with subsequent development of permanent irreversible CNS changes. Unfortunately, few studies have examined the effects of war on children's psychosocial or physiological responses to stress (Joshi \& O'Dennell, 2003; Thabet, Karim, \& Vostanis, 2006); however, one can hypothesize that if such horrific emotional and physical responses occurs with stress exposure, war trauma should accelerate and exacerbate these reactions especially children traversing developmental stages. 


\section{The psychological and physiological impact of war on children}

Stress triggers the release of cortisol as a normal physiologic response to prepare the mind and body to psychologically and physiologically respond to the stress. However, exposure to chronic stress, such as war, promotes either a prolonged stimulation of cortisol (chronic hyperocortisolism) or a reduction in this response (hypocortisolism) with resultant devastating health problems (Curtis \& Cicchetti, 2003). Continuous cortisol secretion can cause such health problems as hypertension, osteoporosis, immunosuppression, insulin resistance, dyslipidemia, and coagulapathies resulting in atherosclerosis and cardiovascular disease (Charney, 2004); whereas, hypocortisolism disrupts the human regulatory function altering brain development and inhibiting growth factors that might cause neural cell death and alter brain cognitive functioning (Yehuda, Bierer, Schmeidler, Aferiat, Breslau, \& Dolan, 2000). The last decade has found war present in 25 countries around the world, resulting in the death of more than two million children, permanent injuries to six million more children, the homelessness of 12 million children, and over one million orphaned with catastrophic social implications (Papageorgiou, Frangou-Garunovic, Iordanidou, Yule, Smith, \& Vostanis, 2000; Parson, 2000; Ursano, 2007). These survivors are at risk for mental health problems, behavior problems, sleep disorders, somatic problems and altered levels of cognitive functioning (Ladd \& Cairns, 1996), neurobiological alterations, chronic fear \& anxiety leading to the development of cardiovascular, gastrointestinal, visceral pathologic conditions and maladaptive behavior (Gray, 1991)

Research on the impact of war-related experiences revealed that traumatized individuals demonstrated a high rate of psychiatric illnesses such as depression, dissociation, somatization, anxiety and neuroendocrine dysregualtion (Kocijan-Hercigonja, Sabioncello, Rijavic, Folenegovic-Smalk, Matijevic, Dunevski, et al, 1996) with a significant prevalence rate of PTSD 
among survivors of war and mass violence. This prevalence has been estimated at $37.4 \%$ in Algeria, $28.4 \%$ in Cambodia, $17.8 \%$ in Gaza, and $15.8 \%$ in Ethiopia (Jong, Klmpore, Ommeron, El Masri, Araya, Khalid, et al, 2001). The exposure to terrorist attacks places an average of $25 \%$ of people around the world at risk for developing PTSD. Even individuals secondarily exposed to trauma and violence were also at substantial risk of developing PTSD (Lee, Mohan, \& Janaca, 2002). Approximately 30 to $50 \%$ of children with PTSD experience psychological numbing, emotional and thought avoidance to the traumatic events in an effort to protect them against reactions of intense fear and horror (Clark, Pynoos, \& Gobel, 1994). Creamer, Elliott, Forbes, Biddle, and Hawthorne (2006) found the physiological and psychological results of PTSD and related disorders may include higher health care utilization and medication use; a variety of mental health problems and psychosocial morbidity such as depression, anxiety disorders, anger; functional impairment; hyperarousal symptoms; substance abuse such as alcohol, social isolation; and cognitive impairment. An altered Hypothalamic-pitutary-axis (HPA) and brain change in children was mentioned by Carrion, Weems, and Reiss (2007).

According to Smith, Perrin, Dyregrov and Yule (2003), children's response to traumatic stress is not culture bound. Macksound \& Aber (1996) studied 224 Lebanese children 10-16 exposed to multiple war traumas such as shelling or combat (93.6\%), bereavement $(70 \%)$, displacement (67.7\%), witnessing violent acts (45\%), emigration (19.1\%), separation from parents(16.8\%), extreme deprivation(11.8\%), victims of violent acts(14.5\%) and physical injuries (4.5\%). The majority had increased PTSD symptoms and separation from parents accounted for the depressive symptomatology in these children.

Another sample of 95 refugee children between 8-13 years, who had experienced the Bosnian war, found that $47 \%$ scored high on the depression scale, $23 \%$ scored positively for 
anxiety, and $28 \%$ scored high for posttraumatic stress disorder reactions (Papageorgiou et al., 2000). Another Bosnian study assessing the potential for personality changes among traumatized survivors concluded that prolonged trauma resulted in personality changes and was more prevalent in children and younger adolescents who experienced such trauma during critical developmental periods (Weine, Becker, Vojvoda, Hodzic, Sawyer, Hyman, et al., 1998).

The long standing violence in Northern Ireland confirms many of the more recent studies about the effect of war on children. According to Toner (1993), four decades of political violence in Northern Ireland gravely affected the psychological and physical health of the children. The prolonged exposure of children to the violence, the media blitzes, and the presence of security forces exacerbated children's psychiatric morbidity, PTSD symptomatology, poor school performance, anxiety and depression, behavioral problems, and multiple physical health problems (Curran \& Miller, 2001).

The war in Palestine is as long standing as the Northern Ireland conflict. Studies about Palestinian adolescents (Elbedour et al., 2007) and young school-age children (Thabet \& Vostanis, 1999; Thabet, Abed, \& Vostanis, 2002) have found significant psychological distress: PTSD (68.9\% of 230 adolescents, and $>50 \%$ of 200 children ages $6-11$ ), moderate to severe depression, severe anxiety levels, and undesirable coping responses. In a more recent study by Thabet et al., (2006), 309 Palestinian children aged 3-6 years were studied with results indicating that pre-school children exposed to a wide range of traumatic events demonstrated significant behavioral and emotional problems.

Unfortunately, the consequences of war stressors continue in the postwar period and might be carried for the rest of survivor's lives. A study conducted by the International Study Team (2003) to assess the effect of war and sanctions with Iraqi children who were two years 
postwar found these children continued to experience sadness and fear of losing their families and persistent high trauma scores. The study conclude that the psychological impact of war on children does not end when fighting stops (Dyregrov, Gjestad, \& Raundalen, 2002; Dyregrov \& Raundalen, 2003); nor are the effects ameliorated by age, gender, or family support systems.

Age \& gender: The psychosocial maladjustment of war affects children differently, often influenced by their developmental level. According to Joshi \& O'Dennell (2003) the lack of cognitive maturation in preschoolers may be manifested as vague somatic responses, self- blame, and confusion. Fremont (2005) found children under five years of age demonstrated regressive behaviors such as bedwetting, thumb sucking, fear of the dark, repetitive play of trauma content, frightening dreams and difficulty in separating from parents as a response to traumatic events.

Joshi and O'Dennell (2003) also found that school aged children 7-12 years have difficulty fully comprehending the war trauma and, as a result, demonstrate fearfulness, confusion, anxiousness, behavioral regression, somatization, insecurity, guilt, loss of interest in activities, and dissociation. While Fremont (2005) adds that school age children (6-12 years) demonstrate attention problems, poor schooling achievement, anxiety symptoms such as school avoidance, somatic complaints, irrational fears, sleep problems, nightmares, irritability and anger when dealing with war trauma.

Adolescents often develop depression, anxiety and hidden feelings of fear when experiencing trauma (Joshi \& O'Dennell, 2003). According to Fremont (2005) adolescents' (1218 years) response to trauma is similar to adults exhibiting such behaviors: intrusive thoughts, hypervigilance, emotional numbing, nightmares, sleep disturbances, avoidance, substance abuse and depression. 
In their study to examine the impact of chronic exposure of political violence on children behavioral problems and the relationship of age, gender, family and community in moderating its effects, Garbarino and Kostenly (1996), with a sample of 150 Palestinian mothers and their children, revealed that boys exhibited more behavioral problems than girls and younger children displayed more problems than older children. In this study, the child's mother filled the Achenbach Child Behavior Checklist, measuring standard behavioral problems and competencies for children 4-16 years. It was found that the increased number of risks in the child's life was highly associated with an increased number of behavioral problems.

A retrospective study on 6000 Palestinian adolescents was conducted at the end of Palestinian Uprising 1994-1995 (Barber, 2001). It concluded that Palestinian adolescent depression was significantly related to war trauma. Depression was measured with a 6-point self report scale derived from Achenbach \& Edelbrock's Child Behavior Checklist. The study results demonstrated a direct association between war and antisocial behaviors and depression, especially in females. It also showed that social integration in family, education, religion, and peer relationships had a significant moderating effect on the development of youth problems.

\section{Resilience}

Family stress and resilience: Family resilience is defined as the family unit's competency in overcoming adverse social conditions and environmental risks; however, the type and severity of stressors affecting the resilience of a family unit remains under debate (Patterson, 2002). Family distress results from the families', especially the adults', failure to effectively cope with multiple and overwhelming stressful life conditions (Walsh, 2002). Poverty and violent neighborhoods place the family at risk, exacerbating maternal distress, potentiating cognitive and 
behavioral dysfunction in the children, and weakening its capacity to perform core functions and achieve competent adaptation (Patterson, 2002).

Family support is hypothesized to mediate the negative psychosocial responses of children living in a war zone; however, when family relations are strained and adults are not coping effectively with the trauma, then domestic and family violence may be an outcome, as well as unwanted and long term psychological and behavioral problems in the children (Fox, Benson, DeMaris, \& Wyk, 2002) . A study on Vietnam veterans found that $75 \%$ of the veterans had been involved in domestic violence upon their return home and was significantly correlated to the behavioral problems exhibited by their children 15-20 years later (Rosenheck \& Fontana, 1998).

Weidner, Hutt, Connor and Mendell (1992) study found that family stress had greater negative effects on boys in the family, predisposing them to coronary heart disease and aggression in adulthood; while girls were predisposed to aggressive behaviors. Feng, Shaw and Silk (2008) examined the relationship between family risk factors and the developmental of anxiety symptoms among 290 boys (2-10 years) and found that parenting and maternal depression were highly correlated with elevated anxiety symptoms in middle childhood, with subsequent depression occurring later. A study on 43 children from Chile and 20 children from the Middle East, who were refugees in Sweden and had been exposed to war and family dysfunction, revealed that the rate of poor mental health among these children was three times (46\%) higher when compared to the general public (15\%) (Hjerm, Angel, \& Jeppson, 1998).

Vulnerability, risk and resilience. Resilience, the process of overcoming stress and adversity, is complex and substantive research has been conducted on this phenomenon (McGee, 2006). The explanatory model of resilience has traditionally been this is a normative process: a 
response to stress in which an individual bends and rebounds without negative consequences, a positive attribute, stress- resistance, adaptive functioning and competency development (Bonanno, 2004; Garmzy, 1991; Glantz \& Johnson, 1999; J. Haase, 1997; Kaplan, 1999; Luthar \& Zigler, 1991; Rutter, 1985). Children are not immune to adversity. Genetic and environmental factors are important in children's vulnerability to psychosocial stressors (Rutter, 1999; Werner, 1992). The sustainability of competent adaptation to adversity among children has been questioned as children move into higher levels of awareness and understanding about the reality of the world in which they live. Furthermore, the success in one behavioral outcome does not mean the success in others (Luthar \& Cushing, 1999). Resilience can encompass the positive qualities of personal growth as well as the phenomena of emotional insulation and survival overcoming adversity any way possible without quitting (Hinds, Burghen, Haase, \& Phillips, 2006; Hunter, 2001; Hunter \& Chandler, 1999). However survival resilience is an unhealthy adaptation to adversity, and if left unchecked, deepens the insulation, isolation, and disconnecting, numbing, and aggressive/violent reactions to the stressors and may lead to pathopsychosocial and physical problems (Hunter \& Chandler, 1999; Hunter, 2001b).

According to Gore \& Eckenrode (1994) the traditional model of risk and resiliency assumes that high levels of existing protective resources such as personal factors, and environmental resources moderates risk appraisals to engender positive coping and adaptation to significantly counteract the mental health and behavioral impact of risk. However, high levels of protective factors may not be able to completely moderate the risk appraisal when a person is exposed to long-term stress and therefore at higher risk for negative effects on mental and physical health and the achievement of critical developmental tasks (Gore \& Eckenrode, 1994). 
In their 20-year longitudinal study in children of Kauai Island, Werner \& Smith (1982) found that inadequate family emotional support in early and middle childhood was found to promote the development of serious behavioral problems later in life. A study by Simeon and colleagues (2007) found that resilience was strongly associated negatively with childhood trauma, fearful attachment and harm avoidance. Results from a study exploring the physiologic effects on survivors of the Oklahoma City bomb blast showed the survivor group had significantly higher mean resting heart rates despite their high scores for emotional resilience (Tucker, Pfefferbaum, North, Kent, Burgin, Parker, et al., 2007). These studies suggest that physiologic assessment years after exposure to war trauma and violence may show the longterm health effects of terrorism despite a survivor's resilience scores. Therefore assessing the neurobiological contribution to resilient adaptation of children to adversity is important for implementing early prevention and treatment of potential alterations (Curtis \& Cicchetti, 2003; Hunter, 2001b).

\section{Biological stress response}

The biologic stress response is the body's mechanisms for ensuring a rapid physical response to threat. The impact of psychological stress on human physiologic and biologic responses had been documented by Walter Cannon (1932) when he introduced the role of the sympathetic nervous system (SNS) in stress adaptation by the "fight or flight response" and "homeostasis"; and by Hans Selye (1936) who integrated the fight or flight phenomenon as a central component of his general adaptation syndrome that include the activation of the hypothalamic-pitutary adrenal axis (HPA).

The perception of a threatening experience by an individual's brain leads to the activation of the HPA system that initiates the release of corticotrophin-releasing factor (CRF) from the 
hypothalamus, which in turns stimulates production of adreno-corticotropic hormone (ACTH) from the anterior pitutary gland. Stimulation of the ACTH results in secretion of glucocorticoids, most importantly cortisol, from the adrenal glands resulting in a variety of physiologic responses. Cortisol has a vital role in carbohydrate metabolism (gluconeogenesis), modulation of the balance between cellular and humoral immunity, modulation of the central cognitive and affective processes, maintenance of the vascular tone and redistribution of blood flow; which all enhance the body's energy and memory functions to accommodate the body's needs in emergent stressful condition and maintain homeostasis thereafter (Porth, 2005; Souza \& Appel, 1991).

Simultaneously, as the cortical perception of threat stimulates $\mathrm{CRH}$, there is an activation of the SNS through the sympatho-adrenomedullary (SAM) axis. Activation of the SNS results in release of catecholamines - norepinephrine, epinephrine, and dopamine)- a condition known by "flight or flight response" which result in immediate physiologic processes that enhance a person's ability to flee or fight: increased heart rate, increased cardiac tone and blood pressure, increased blood flow to skeletal muscles, increased respiratory rate, bronchial dilatation, increased blood glucose and augmentation in basal metabolism (Bar et al. 1994; Davis \& Granger, 2009). Both systems have feedback mechanisms that allow down-regulation of the stress response. The short term of HPA and SNS response to stress is considered a protective and adaptational process (allostasis); however, long-term up-regulation of both systems (allostatic load) can be damaging and leads in a variety of pathologic conditions related to excessive exposure to glucocorticoids and catecholamines (McEwen \& Seeman, 1999).

\section{Stress and the hypothalamic-pitutary-adrenal axis}

Developmental and gender differences: Previous research findings suggest that the HPA and hippocampus are programmed during early critical childhood development (Quirin, 
Pruessner, \& Kuhl, 2008); furthermore early life experiences can influence the HPA regulation in adulthood (Nicolson, 2004). According to Turner (2005) the outcome of childhood psychological stressors early in life influences the HPA response causing undesirable health outcomes later in life. More work is required to further investigate these links.

Past studies have also concluded that gender, age or sexual maturation related changes in cortisol production may be minimal after the neonatal period (Kerrigan, Veldhuis, Leyo, Iranmanesh, \& Rogol, 1993). These researchers investigated the daily cortisol production and clearance rates of 18 healthy pubertal male participants concluding the following: 1) cortisol production rates are in agreement with other previous studies; however, lower than many previous estimates for cortisol levels; and 2) the increase in serum gonadal level is not associated with alterations in cortisol production or clearance. They tested serum cortisol samples acquired between 8 am and $8 \mathrm{pm}$ in conjunction with a 24-hour urine collection to estimate cortisol excretion. Despite the small sample size of young male participants, the study emphasized that sexual maturation at puberty represented by the rise in serum gonadal level rise has no effect on glucocorticoid secretion and excretion (Kerrigan et al, 1993).

Unfortunately, like other studies on children, there is a lack of consistency in findings related to gender difference in cortisol levels, with findings concluding that girls had a significant greater increase over boys in early morning cortisol (Jessop and Turner, 2007). Nertherton, Goodyer, Tamplin and Herbert (2004) studied 129 healthy children aged 8-16 years, for gender differences in basal cortisol and dehydroepiandrosterone release. They found morning salivary cortisol levels in mid-postpubertal girls were $20-30 \%$ higher than in mid-postpubertal boys, but not in pre-early pubertal girls and boys. Similar findings was found in a prospective cohort study by Rosmalen, Oldehinkel, Ormel, Winter, Buitelaar, \& Verhulst (2005) study with a 
sample of 1768 subject aged 10-12 years, measuring salivary cortisol levels at wakening time, 30 minutes post awakening and at 8pm, concluded that girls had significantly higher levels of AM cortisol than boys but not for the evening samples. Additionally no age related differences was observed. In contrast to finding found in a cross-sectional study by (Kudielka \& Kirschbaum, 2003) on a sample of 179 subjects with ages 4-75 years revealed that Am cortisol levels were not different between males and females, however age related differences in AM cortisol was significant. This study utilized 5 points salivary cortisol sampling, upon awakening, 15, 30, 45 and 60 minutes from awakening. Drawing meaningful conclusions about cortisol with age and gender differences is limited by the cross-sectional design of many studies, small sample size and different methodology used, with inconsistent findings up to date.

Kerrigan and colleagues (1993) showed that the circadian rhythm of cortisol in pubertal boy is similar to that in adults: cortisol levels increase in the morning and decrease steadily throughout the day. An invaluable longitudinal study conducted by Matchock, Dorn and Susman (2007) examined the relationships between the diurnal rhythm of cortisol, testosterone, and dehydroepiandrosterone (DHEA) with pubertal maturation in 60 healthy boys and 60 healthy girls aged 8-14 years. The study found that all three hormones had diurnal fluctuations during the peri-pubertal period. The study concluded that the diurnal thythm of cortisol at pubertal age is characterized by the following: (1) cortisol secretion was relatively stable and didn't increase across the pubertal stages or demonstrate major sex differences, except for significantly lower concentrations at pubertal stage three; (2) higher cortisol levels in the morning than later in the day in both sexes; (3) morning cortisol in boys was higher than girls in ages 9-10 years and reversed later in ages 10-11 years; (4) cortisol was significantly higher in the spring and summer than in the fall; (5) the cortisol acrophase (peak) level occurred later in the day in boys than for 
girls during later puberty; and (6) the cortisol circadian acrophase (peak) occurred significantly earlier than for testosterone and DHEA. Limitation of the study is that the total secretory output of the hormones cortisol wasn't a part of the study which could have provided researchers with a reference about normal cortisol levels in children.

The inconsistent results of gender and age differences in cortisol levels in peripubertal periods necessitates further exploration of such variations so as to enable scientist to differentiate normal versus pathologic cortisol levels for various pediatric age groups. The consistency in findings related to children and adults' cortisol diurnal patterns can support the initiation of future comparative studies that examine a participant's exposure to various adversities in order to gain a better understanding of altered cortisol patterns.

Dysregulation of the HPA functioning: Hypercortisolism and hypocortisolism are primarily the two forms of HPA dysregualtion observed in individual's experiencing acute and chronic stress conditions. Hypercortisolism is state of hyperarousal (high cortisol) or failure to mount a normal response that places the individual at both physical and cognitive functioning risk. Hypocortisolism results when stress is prolonged and stress responsivity is diminished. This state is manifested mainly by the low secretion of morning awakening cortisol (Gunnar \& Vazquez, 2001). According to Heim, Ehlert, \& Hellhammer (2000) the term hypocortisolism have been used to describe low cortisol level, flat daytime cortisol production, and blunted cortisol secretion to environmental stressors.

The activation of the HPA system in response to acute stress is complex and an essential adaptive response; however, chronic stress can lead to alteration, maladaptation and even pathological activity of the HPA system (Lopez, Akil, \& Watson, 1999). According to Curtis \& Cicchetti (2003) the ability to quantify the HPA and its relation to mental disorders may help 
explain the psychophysiological responses to adversity. This may also explain an individual's perceived resilience and higher scores on the resilience scales when in fact they are practicing a more negative resilience adaptation (emotional insulation or survival) than positive. The chronic response to stress resulting in hyperocortisolism or hypocortisolism can produce a damaging effect on neurons (Curtis \& Cicchetti, 2003; Levine \& Ursin, 1991). Carrion, Weems, Ray, Glaser, Hessel and Reiss (2002) asserted that the last 15 years had witnessed multiple debates and controversial results when studying the physiologic response of the HPA axis in children experiencing, stress, and trauma and PTSD symptoms.

According to Shirtcliff and Essex (2008), hypocortisolism and hyperocortisolism have been linked with the development of such mental health disorders as depression, anxiety and conduct disorders in studies with children in transitioning into adolescence and adulthood. In their longitudinal study, Shirtcliff and Essex (2008) explored the relationship between basal cortisol (waking, afternoon, and bedtime over three days) and, its diurnal rhythm, with mental health disorders in 294 preadolescent and adolescent children in two Waves: $5^{\text {th }}$ and $7^{\text {th }}$ grade. Results of the study showed that at 5th grade, low basal cortisol was associated with concurrent mental health symptom severity. However, longitudinally, it was adolescents with high cortisol at 5 th grade who were at risk for increasing mental health symptoms by 7 th grade. Flat diurnal rhythms in 5th grade were related to levels of symptom severity at both 5th and 7th grades." Findings of the study suggest these results are not "inconsistent" but support the conclusions that hypoarousal and hyperarousal are associated with mental health disorders. This may mean that cortisol is a nonspecific marker for predicting mental health problems in adolescence (Shirtcliff \& Essex, 2008). 
Hypercortisolism: Dysregulation and chronic activation in cortisol can lead to deleterious impact on cognitive functioning, autoimmune disorders, cancer, Alzheimer's disease, melancholic depression and suppression of growth factors (Porth, 2005). According to Sapse (1997), studies have proven that high cortisol precedes diseases and is not a result of them; deriving an assumption that high cortisol plays a major role in the development of those diseases. High cortisol has been seen in diseases with known causes (e.g., infections, types of cancers, ulcers, myocardial infarction, diabetes, arthritis, strokes/cardiovascular accidents, AIDS), diseases with unknown causes (e.g., amyotrophic lateral sclerosis, multiple sclerosis, myasthenia gravis, Parkinson, skin conditions), and in mental health dysfunction (e.g., depression, alcoholism, substance abuse, anorexia nervosa, heavy smoking, posttraumatic stress disease, aging/Alzheimer's) (Sapse, 1997). Hypercortisolism has been found in patients with major depressions, where cortisol levels remained high throughout the day and evening hours in those patients (Gunnar \& Vazquez, 2001).

In a study by Carrion and colleagues (2002), with fifty-one children with a history of trauma and PTSD, a significant higher level of cortisol was evident in those children when compared to the control groups. Girls in this study with PTSD had significantly higher cortisol levels than boys with PTSD. The study concluded that heightened adrenal activity depicted by children's high cortisol level is a worrisome physiologic response of children with history of trauma and PTSD symptoms (Carrion et al., 2002). Another longitudinal study conducted by Carrion and colleagues (2007) with 15 children with PTSD concluded that PTSD severity and neurotoxicity of glucocorticoids can reduce the hippocampus volume over time leading to cognitive impairment in children. The study conclusions suggested that high levels of cortisol 
induced by chronic stress and traumatic experiences can lead to hippocampal toxicity and destruction (Carrion et al., 2007).

Corroborating findings were evident in a longitudinal two-year study conducted by Peffer, Altemus, Heo, \& Jiang (2006) with bereaved children from the September $11^{\text {th }}$ terror attacks. The study revealed that morning and evening cortisol levels were consistently higher among bereaved than non-bereaved children. Kertes, Gunnar, Madsen and Long (2008) examined the long-term effects of adoption and early deprivation in a sample of 164 children, ages 7-11 years, with various degrees of pre-adoption deprivation experiences. In this study two salivary samples were taken 30 minutes post waking up and another sample 30 minutes before bedtime over 3days. Deprived care was measured based on a total score of three measures to include age at adoption, duration of institutional care, and parent- rated neglect and abuse. The study showed that "deprived care" predicted growth delay which in turn predicted higher early morning cortisol. The study findings suggested that children with short stature had higher morning cortisol levels and a large diurnal cortisol decrease even several years after adoption (Kertes et al., 2008).

Hypercortisolism has also been linked to immune system dysregulation. According to Truckenmiller, Bonneau, \& Norbury, (2006), studies in the past 15 years have explored stressrelated immune response, but only with adult participants. They add that elevation of cortisol in response to stressors can affect and weaken the primary and memory CD8+ cytotoxic T lymphocyte (CTL) responses - a response vital to fight intracellular pathogens such as viruses, tumors as well as some bacteria and parasites. Cortisol impairs the efficiency of antigen presentation to the dendritic cells and affects its role to generate primary and memory $\mathrm{T}$ cells responses. Neurotransmitters such as catecholamines and stress hormones are substantially 
elevated during stress affecting immunodulation processes and ultimately the immune system's function (Granger, Dreschel, \& Shirtcliff, 2003). The biologic effects of cortisol are antiinflammatory and immunosuppression; however, its indirect effect is the inhibition of the intracellular mediators' bradykinin and prostaglandin that result in a decline of lymphocyte proliferation and redistribution of the $\mathrm{T}$ lymphocyte in the bone marrow and dysregulation of immune function (Barr et al., 1994).

It is evident that research indicates there is a direct effect of stress and prolonged high cortisol levels on the body's natural defenses and physiologic functioning across all ages; however, the most significant negative effects appear to be in the physically and cognitively developing child. Scholars and practitioners need to consider preventive strategies to minimize the effects of pathologic stress responses.

Hypocortisolism: Acute exposure to stressful events leads to the activation of the HPA axis, while chronic exposure to stress tends to reduce the reactivity of the HPA system to acute stress (Moss, Vanyukov, Yao, \& Kirillova, 1999). Hypocortisolism in conjunction with stress related conditions have been also observed among children with PTSD, neglect, abuse, severe \& chronic stress presenting a challenge to the basic concept of stress and neuroendocrinology (Heim et al., 2000). According to Gunnar, Bruce, \& Hickman (2001), hypocortisolism may be related to impaired brain development and cognitive functioning which poses a risk for child development. Gunnar and Vazquez (2001) add that the combination of a low cortisol level and high heart rate following a traumatic event has predicted the development of PTSD. The notion that hypocortisolism is associated with PTSD is controversial when studies discussed earlier indicated a high correlation between elevated cortisol levels and PTSD. 
Studies have supported the alteration, dysfunction, low adrenal gland output and enhanced feedback inhibition of the HPA axis in PTSD (Yehuda, 2002). In a study by KocijanHercigonja and colleagues (1996) with 91 traumatized Croatian and Bosnian subjects found alterations in serum hormone was evident in those with severe trauma. Researchers in this study utilized the Comell Index (COR-NEX2) rather than PTSD diagnostic measure to assess the severity of war related trauma. It consisted of 101 self- reported questions on variety of psychiatric and psychosomatic symptoms. One blood sample was taken to assess the level of serum hormones among subjects with various psychological responses. Results indicated that levels of cortisol and prolactin were significantly decreased in individuals who expressed severe psychological responses.

Another study with 12 Bosnian war refugees with DSM-IV diagnosed PTSD and 13 control patients without PTSD collected four salivary samples (shortly after awakening, at 30, 45 , and 60 minutes post awakening) to assess the morning cortisol response among the subjects. Results contended there was no cortisol response upon awakening and significantly lower daytime cortisol levels compared to the control group (Rohleder, Joksimovic, Wolf, \& Kirschbaum, 2004).

Similar findings was found in a two and a half year longitudinal study on five healthy participants to assess the impact of war related stress on HPA revealed that prolonged psychosocial war-induced stress is significantly associated with low morning cortisol and reduced response to ACTH (Zarkovic, Stefanova, Ciric, Penezic, Kostic, Sumarac-Dumanovic, et al., 2003). On the other hand, a recent study by Eckart, Engler, Riether, Kolassa, Elbert, \& Kolassa (2009), exploring the cortisol diurnal patterns in 60 male refugees' participants in Uganda traumatized by the Rwandan genocide in 1994 , revealed no difference in cortisol pattern 
between participants with and without PTSD. The study also showed a strong correlation between the number of traumatic experience and the severity of PTSD symptomatology (Eckart et al., 2009). In this study, researchers had used the posttraumatic diagnostic scale (PSD, 1997) which is different than the most common PTSD diagnostic measures (DSM III or DSM IV) but found to be a valid and reliable measure with other African population. These inconsistent results on individuals with PTSD may be related to differences in research design or methodology. Further controlled studies are needed.

Other studies also showed the high association of hypocortisolism with adverse life circumstances. A study examining the cortisol response to an anticipated stressor among preadolescent sons of substance abusing fathers showed a significant decrease in cortisol reactivity to acute stress (Moss et al., 1999). A study with healthy participants aged 18-37 years, assessing the impact of adverse events in childhood on cortisol reactivity using the Trier Social Stress Task (traumatic experiences checklist), showed that individuals with a history of adverse events had a significantly blunted cortisol response compared to individuals to individuals with no adverse life events (Elzinga, Roelofs, Tollenaar, Bakvis, Pelt, \& Spinhoven, 2008). In this study, a traumatic experiences checklist to assess subjects' adverse lifetime experiences was used. Another study by Gunnar and colleagues (2009), investigating the impact of early life stress on cortisol activity among internationally adopted children 10-12 years, found that diminished cortisol activity was observed among children with moderate but not severe early life stress experiences. The authors concluded that child individualized differences had moderated the impact of severe early life stress (Gunnar, Frenn, Wewerka, \& Ryzin, 2009).

Disruption in normal cortisol diurnal pattern: Flattened cortisol diurnal rhythm is a form of hypocortisolism reflecting a disordered response of the HPA response to individual's 
stress and adaptation mechanism. Many studies support the notion of hypocortisolism in chronic traumatic stress exposure; unfortunately, there are enough variations in findings that more research is needed to more clearly describe cortisol responsivity to chronic stress. In addition, future studies should use the longitudinal approach in exploring the responsivity of the adrenal glands to acute stressors in children with history of traumatic and chronic stress conditions.

Under normal circumstances, cortisol has been shown to follow a circadian pattern with a sharp increase in cortisol concentration 30-45 minutes after awakening, enabling the body to respond to the act of waking, followed by a steady linear decline in its levels until reaching nadir following the onset of sleep around midnight. (Gunnar et al., 2001; Kelley, Young, Sweeting, Fisher, \& West, 2008). The loss of normal diurnal variation in cortisol levels is defined as a lower early morning cortisol and a diminished change between morning and evening cortisol levels that result in a "flatter" slope of change. Flatter cortisol patterns are mainly caused by a low awakening cortisol; however, some studies have shown individuals with higher evening cortisol rhythm without associated decreased morning level that also results in a decrease in diurnal slope (Gunnar\& Vazquez, 2001; Heim et al., 2000). Normal cortisol diurnal rhythm is associated with good health outcomes; while flatter slopes of cortisol are associated with poor health outcomes (Edwards, Hucklebridge, Clow, \& Evans, 2003) and poor prognosis among breast cancer patients ( Spiegel, Giese-Davis, Taylor \& Kraemer, 2006).

Assessing the impact of psychosocial risk factors and resources on the cortisol diurnal rhythm among 257 middle-aged Swedish men and women was conducted by Sjogren, Leanderson, and Kristenson (2006). They concluded that flatter diurnal patterns were related to higher psychosocial risks such as depression, exhaustion and cynicism while a more normal 
steeper diurnal pattern was related to psychosocial resources such social support, higher self esteem, and coping.

An important study conducted by Adam and Gunnar (2001) on 70 middle-class healthy mothers investigated the relationship between home and work demands with mothers' psychological variables (relationships functioning) and their cortisol response. The results discovered the following: 1) positive relationships functioning was associated with normal cortisol secretion patterns; 2) greater working hours and increased number of children in the household were associated with lower morning cortisol level and less steep decline in cortisol level in the evening; and 3) the flatter cortisol slope was due to the low morning cortisol level rather than an increase in the evening level.

A two-day study by Smyth, Ockenfels, Gorin, Cately, Porter, Kirschbaum, Hellhammer\& Stone (1997) assessed the relationship between cortisol cycle and upper respiratory tract infections with 109 healthy employed and non-employed participants, and demonstrated that participants with flat cortisol cycles reported more symptoms of upper respiratory tract infections. Consistent findings have been reported in another study with 34 healthy participants over two consecutive days. The study showed that participants with flatter cortisol diurnal rhythm profiles and lower awakening cortisol secretion reported more upper respiratory tract infections symptoms (Edwards et al., 2003).

A longitudinal study with 104 patients with metastatic breast cancer concluded that patients with metastatic breast cancer, whose diurnal cortisol rhythm flattened or was abnormal, had earlier mortality. The study also showed that patients with flattened cortisol profiles had significantly lower morning and higher evening cortisol levels (Sephton, Sapolsky, Kraemer, \& Spiegel, 2000). Consistent with these findings were the results of a study by Abercrombie, 
Giese-Davis, Stephton, Epel, Turner-Cobb, \& Spiegel (2004) with 17 women with metastatic breast cancer and 31 healthy women that found women with metastatic breast cancer had significantly flatter diurnal cortisol patterns than women in the control group. Likewise a study conducted by Spiegel and colleagues (2006) with 99 women with breast cancer found that women with metastatic breast cancer presented flattened diurnal cortisol rhythm with high cortisol suppression resistance when dexamethasone was administered. In this study flatter daytime cortisol was a result of elevated evening cortisol and not due to a lower waking cortisol level.

Studying the cortisol slope formulates another important mean to assessing the HPA responsitivity under chronic stress. This methodology may require lesser number of cortisol samples and may reduce the cost of the research. There are scarce studies exploring the flattened cortisol response in children under stress.

\section{Stress and the autonomic nervous system}

A promising dimension to measuring acute stress response is the use of salivary $\alpha$ amylase (sAA) as a surrogate marker of the sympathetic nervous system responsitivity (Kivlighan \& Granger, 2006). Granger, Kivlighan, Clancy, Mona, Jacquelyn, Lisonbee, et al. (2006) stated that SAA has been viewed as a surrogate marker for activation of the autonomic/sympathetic nervous system (SNS) since the 1990s; however, only recently has it been used to further explore the areas of stress psychobiology. It has not been employed to examine biopsychosocial models of stress and vulnerability in the context of child development (Granger et al., 2006).

Stimulating the SNS in response to stress leads to the release of catecholamines such as norepinephrine from the adrenal medulla into the blood and peripheral circulation which 
activates the release of SAA via stimulation of beta-adrenergic receptors in salivary glands. Thus the use of SAA as a noninvasive indirect measure of plasma norepinephrine should be considered (Granger, Kivlighan, El-Sheikh, Gordis, \& Stroud, 2007; Nater \& Rohleder, 2009). Salivary alpha amylase (sAA) is an enzyme produced by the oral salivary gland whose primary function is to facilitate the digestion of complex macromolecules of carbohydrates and starch into glucose and maltose for easier absorption through the intestinal tract. In a double blind study by Stegern and colleagues (2006), investigating the effect of non-selective beta blockers on the secretions of sAA with 30 healthy participants, it was concluded there was a significant lowering effect of beta blockers on sAA levels compared to a placebo. The study indicates that SAA may be a strong and sensitive measure of the sympathetic and beta-adrenergic activity in humans (Stegern, Rohleder, Everaerd, \& Wolf, 2006). Keller \& El-Sheikh (2009) assessed the relationship between sAA and children externalizing stress symptoms with a sample of 36 girls and 28 boys at $3^{\text {rd }}$ grade and later at $5^{\text {th }}$ grade. This longitudinal study revealed that SAA and externalizing behavior were related. An important study by Chatterton and colleagues (1997) on the impact of potential engagement in life threatening event (skydiving) on the hormonal and psychological responses in a group of healthy volunteers revealed that SAA resembled previous findings of urinary catecholamines and plasma norepinephrine response to the same event.

Other studies confirmed the validity of SAA as an indirect measure of the SNS responsivity to stress however rejecting its direct correlation with plasma catecholamines responsitivity to the same condition. A study by Nater, Marca, Florin, Moses, Langhans, Koller, et al. (2006) evaluating the relationship of sAA with plasma catecholamines (norepinephinerine, epinephrine) using the Trier Social Stress Test with 30 male participants, revealed a significant sAA response to psychosocial stress conditions indicating its validity and reliability as an acute 
stress biomarker. However the study found a negative correlation of sAA stress responsivity and levels of plasma catecholamines contradicting previous studies (Nater et al., 2006). Similar findings have been found by Ehlert and colleagues (2006) when they studied the correlation between plasma norepinephrine and epinephrine to sAA response after an intravenous injection with yohimbine in 13 healthy male participants. The study showed that no meaningful relationship exists between plasma norepinephrine, epinephrine and SAA. It was explained that sAA secretion may reflect the central norepinephrine release instead of the peripheral norepinephrine secretion suggesting that SAA can be used as an indirect indicator of the central sympathetic nervous system. Another study investigated whether salivary amylase can serve as a valid indicator of the SNS in response to stress. Rohdhler and colleagues (2004) studied 12 healthy participants, using the Trier Social Stress Test, and found an increase in sAA in response to the acute psychological stress correlated with the increase in norepinephrine; however, the findings were inconclusive for SAA to be used as a predictor for SNS activity (Rohleder, Nater, Wolf, Ehlert, \& Kirschbaum, 2004).

The diurnal pattern of $\mathrm{sAA}$ is opposite of the diurnal pattern of cortisol secretion. Nater and colleagues (2007) state there is a significant decreased level of sAA in the first 60 minutes after awakening which steadily increases toward the afternoon and evening. This was corroborated by Rohleder and colleagues (2004) with 17 healthy participants who also found that sAA had an opposite diurnal pattern to cortisol where levels of amylase were lowest after awakening and increased steadily thereafter with highest levels in the afternoon and evening.

Previous studies had linked cortisol and sAA activity with acute stress; however, there are limited studies examining the link between sAA and chronic psychological stress (Wolf, Nicholls, \& Chen, 2008). In their attempt to investigate the relationship of chronic stress with 
the basal activity of cortisol and sAA, Wolf and colleagues (2008) studied 47 children with chronic asthma compared to a 45 healthy children control group. This study showed that: 1) sAA and cortisol had different diurnal patterns; 2) healthy children with chronic home life stress and low parental education demonstrated flatter cortisol pattern; 3) children with asthma didn't show any difference in cortisol trajectories; 4) children with asthma who had higher chronic home life stress and lower parental education status had lower SAA levels during the day compared with healthy children. Another study measuring the impact of chronic psychological process on the HPA and SNS by Rohleder and colleagues (2008) examined these relationships with 56 young women utilizing "shame" experiences as a chronic psychological reference. Results of study showed that shame wasn't associated with overall daily cortisol secretion; yet, in contrast, sAA results showed a high association with shame trait. This suggests that HPA activation in this study was limited to acute experiences of shame.

Review of the literature on SAA reveals it is an invaluable indicator of the sympathetic nervous system activity in variety of acute stress condition; however, there is limited examination in natural settings and chronic stress exposure in adult and children age groups to stress. Future studies are needed to explore the impact of age, body mass index, and psychiatric conditions on basal sAA activity and their role in the prediction of future diseases (Rohleder \& Nater, 2009).

\section{Conclusion}

In summary, the literature on the impact of children's chronic exposure to war and its psychobiological associations were reviewed. Though the psychosocial implications of stress on children have been thoroughly studied and discussed over the past century, the biological 
contributions and implications of chronic war stress on children has been assessed in a very limited capacity.

There remains great debate and conflicting results when studying the biologic response on the role of the HPA axis in children experiencing stress, trauma, and PTSD symptoms. There are conflicting results of studies exploring the effects of hyperocortisolism versus hypocortisolism. Furthermore, very limited studies have illuminated the HPA role at a current and chronic exposure of war stress in children.

The responsitivity of the autonomic nervous in chronic stressful environments among children had also been studied in a very limited form and never been studied in the context of stressful war conditions. There is limited literature documenting the relationship between neurobiology and resilience.

There is a lack of complementary studies on both psychological and biological dimensions of stress physiology among resilient children under chronic war stress exposure. As Kanji et al., (2007) asserted resilience protective factors may facilitate an individual's surviving the horrors of war; however, continued research is needed to better understand those protective processes and their role in improving one's health and well being. Identification of the psychological and biological correlates in association with resilience can provide bidirectional understanding of resilient functioning and assist in the prevention and treatment of stress-related psychopathology (Yehuda, Flory, Southwick \& Charney, 2006).

Finally, there is a vital need to further explore the effect of children's exposure to chronic violence on cortisol and sAA diurnal patterns so as to expand understanding of the psychobiological response of children under war adversity, identify predictive markers for early identification and interventional modalities with children at risk for chronic mental and physical 
health problems, and to implement appropriate interventions to ameliorate the harmful results of war traumatic stress.

It is evident from the literature that there is significant potential detrimental impact of chronic war stress on children's psychobiological development and future wellbeing. Sensitive, timely, culturally appropriate investigations with children, across gender and age, are necessary so care providers can begin to ameliorate the devastating short and long-term effects of war on children. 
Research Results Article 60

Relationships of Traumatic Exposure, Perceived Stress and Resilience with Salivary Cortisol and alpha-amylase Diurnal Pattern in Palestinian Children

Mohammad Asia, RN, PhD; Anita Hunter, APRN, PhD; Lois Howland, RN, DrPH; Joseph

Burkard, CNA, DNsC; Jane Georges, RN, PhD; Andrea Hazen, PhD 


\begin{abstract}
Objective: To explore the relationships among levels of traumatic exposure (LTE), child perceived stress (CPSS) scores, child resilience scores (CRS) and salivary cortisol \& salivary alpha- amylase (sAA) diurnal pattern in Palestinian children aged 10-12 years exposed to chronic war violence. Additionally, the relationships of father perceived stress scores (FPSS) and mother perceived stress scores (MPSS) with CPSS were examined. Methods: The participants were 122 children and their parents (101 mothers, 102 fathers), recruited from a small town in West Bank/Palestine where people had been exposed to recent significant trauma. Children were measured for their level of traumatic exposure, perceived stress, and resilience; while parents were measured for their perceived stress. Thirty-seven child subjects delivered two salivary samples for cortisol and sAA analysis; one sample taken upon child's awakening and a second sample taken at bedtime. Relationships of cortisol and SAA with other study variables were explored. Results: Participants reported high LTE $(\mathrm{M}=11.02, \mathrm{SD}=4.48)$ and high CPSS $(M=31.42, \mathrm{SD}=7.43)$. There was a significant positive correlation between CPSS and AM cortisol production in children $(r=.35, \mathrm{p}<.05)$. CPSS was strongly correlated with FPSS $(r=.36$, $\mathrm{p}<.001)$ and MPSS $(\mathrm{r}=.36, \mathrm{p}<.001)$ respectively and with trauma scores $(\mathrm{r}=.39, \mathrm{p}<.001)$. No significant correlations were found between sAA levels and study variables; however $38 \%$ of participants, primarily those who were 11 years of age, showed a reversed sAA diurnal pattern. The overall diurnal pattern of cortisol and sAA remained normal. Regardless of trauma scores, perceived stress, sAA, or cortisol production, participants scored high on the resilience scale, indicating a fairly adaptive response to the trauma exposure. Three male outlier participants reported significant higher AM cortisol levels, higher LTE, CPSS, MPSS, and FPSS scores indicating a potential impact of exposure to war violence on their cortisol production.
\end{abstract}




\section{Introduction}

A growing body of work suggests that exposure of children to adverse war circumstances threatens their current and future development. Children exposed to such childhood adversity might increase their risk of developing mental health problems, posttraumatic stress disorder (PTSD), emotional and behavioral disorders, physical and psychobiological disorders (De Bellis, 2001; Elzinga, Roelofs, Tollenaar, Bakvis, Pelt, \& Spinhoven, 2008; Joshi \& O’Dennell, 2003; Kocijan-Hercigonja, Sabioncello, Rijavic, Folenegovic-Smalk, Matijevic, Dunevski, et al., 1996; Ladd \& Cairns, 1996). However variables such as family, social, and community support, age, and severity of adversity are expected to mediate the impact of trauma (Fremont, 2005). Little research has been conducted to establish the relationship between neurobiology and resilience, especially with children (Curtis \& Cicchetti, 2003; Hunter, 2001b). Prior studies on Palestinian children confirmed the existence of the aforementioned psychiatric and behavioral disorders (Elbedour, Onwuegbuzie, Ghannam, Whitcome, \& Hein, 2007; Thabet, Abed, \& Vostanis, 2002, 2004; Thabet, Karim, \& Vostanis, 2006; Thabet \& Vostanis, 1999); however, information on potential biological consequences of such adversity is not yet available.

Response to psychological stress includes the activation of two neurobiological systems, the autonomic (sympathetic/parasympathetic) nervous system and the hypothalamic-pituitaryadrenal axis (HPA). Cannon $(1915,1932)$ described how the sympathetic-adrenomedullary axis governs the initial "fight or flight stress response leading to the release of catecholamines epinephrine, norepinephrine and dopamine and how the body maintain homeostasis thereafter.

Selye (1936) expanded the stress theory (general adaptation syndrome) by describing the activation of the HPA axis which results in the secretion of corticotrophin-releasing factor (CRF), adrenocorticotropic hormone (ACTH) and ultimately increased secretion of 
corticosteroids (Souza \& Appel, 1991). Cortisol diurnal patterns have proven to accurately reflect the HPA axis response in an individual's stress responses. Under normal circumstances, baseline cortisol reaches its highest peak within 30-45 minutes post awakening in order to enable the body respond the daily demands and then steadily declines through the day and evening to its lowest level at night prior to sleep (Gunnar, Bruce, \& Hickman, 2001; Kelly, Young, Sweeting, Fischer, \& West, 2008). HPA dysregualtion, hyper- or hypocortisolism, has been observed in individual's experiencing chronic stress conditions (Smyth, Ockenfels, Groin, Catley, Porter, Kirschbaum, et al., 1997).

Hypercortisolism (high circulating levels of cortisol) is state of hyperarousal or failure to mount a normal response that places the individual at both physical and cognitive functioning risk. High cortisol precedes the development of diseases and has been associated with infectious diseases, amyotrophic lateral sclerosis, multiple sclerosis, myasthenia gravis, depression, alcoholism, substance abuse, anorexia nervosa, heavy smoking, cancers, ulcers, myocardial infarction, diabetes, arthritis, psychological disorders, strokes/cardiovascular accidents, Parkinson, skin diseases, posttraumatic stress disease, aging/Alzheimer's and AIDS (Sapse, 1997). Further high levels of cortisol have been associated with hypertension, osteoporosis, immunosuppression, insulin resistance, dyslipidemia, dyscoagulation resulting in atherosclerosis and cardiovascular disease (Charney, 2004).

Hypocortisolism results when stress is prolonged and stress responsivity is diminished. This state is manifested by low cortisol level, flat daytime cortisol production, and blunted cortisol secretion to environmental stressors (Heim, Ehlert, \& Hellhammer, 2000). Chronic stress can lead to alteration, maladaptation and even pathological activity of the HPA system (Lopez, Akil, \& Watson, 1999). The sequelae of hypocortisolism appear to alter brain 
development, inhibit growth factors that might facilitate neural cell death and alter cognitive functioning (Yehuda, Bierer, Schmeidler, Aferiat, Breslau \& Dolan, 2000). Hypocortisolism in conjunction with stress related conditions have been also observed among children with PTSD, neglect, abuse, behavioral problems in schools, and chronic stress (Heim et al., 2000).

A normal and steeper cortisol diurnal rhythm is associated with good health outcome while flatter slopes of cortisol are associated with poor health outcomes (Edwards, Hucklebridge, Clow, \& Evans, 2003). In children, flat cortisol diurnal pattern had been associated with neglected, maltreated children, dwarfism, lack of school performance, maladaptation and lack of coping, insecure maternal attachment, infants with colic, orphaned children, and with physical disorders such as fibromyalgia, chronic fatigue syndromes, and asthma (Adam \& Gunnar, 2001; Gunnar \& Vazquez, 2001).

Early life experiences can influence the HPA axis regulation in adulthood (Nicolson, 2004) suggesting that the HPA and the hippocampus are programmed during early critical childhood development (Quirin, Pruessner, \& Kuhl, 2008). Previous studies have concluded that gender, age or sexual maturation related changes in cortisol production may be minimal after the neonatal period (Kerrigan, Veldhuis, Leyo, Iranmanesh, \& Rogol, 1993). The outcome of early childhood psychological stressors have been evidenced to affect the HPA response to cause undesirable health outcomes later in life; however, much more work is required to further investigate those links (Turner, 2005).

A promising dimension to measuring acute stress response is the use of salivary alphaamylase (sAA) (Lee, Mohan, \& Janaca, 2002) as a surrogate marker of the SNS responsiveness (Kivlighan \& Granger, 2006). Granger, Kivlighan, Clancy, El-Sheikh, Jacquelyn, Lisonbee et al. (2006) stated that SAA has been viewed as a surrogate marker for activation of the SNS since the 
1990s; however, only recently has it been used to further explore the areas of stress psychobiology. It has not been employed to examine biopsychosocial models of stress and vulnerability in the context of child development (Granger et al., 2006). The release of catecholamines from the adrenal medulla into the blood for peripheral circulation with the subsequent release of SAA, via stimulation of beta-adrenergic receptors in salivary glands, suggest the use of sAA as a noninvasive indirect measure of plasma norepinephrine (Granger, Kivlighan, El-Sheikh, Gordis, \& Stroud, 2007; Nater \& Rohleder, 2009). Since sAA has an opposite pattern to cortisol diurnal rhythm, where levels of sAA dropped sharply after awakening and then increased steadily thereafter with highest levels in the afternoon and evening (Gunnar et al., 2001; Kelly et al., 2008; Rohleder, Nater, Wolf, Ehlert, \& Kirschbaum, 2004), this assessment in conjunction with cortisol may help identify if an abnormal stress biomarkers' diurnal pattern exists and differentiate between acute versus chronic stress response.

No studies have examined the impact of chronic war violence with the SNS; however plenty of studies examined the HPA in the context of PTSD. Previous studies have linked cortisol and sAA activity with acute stress and disease; however, rare studies have attempted to link sAA with chronic psychological stress (Wolf, Nicholls, \& Chen, 2008). According to Lynch (2003) there is no literature demonstrating the relationship between exposure to chronic violence and the physiological systems governing hyper-arousal versus hypo-arousal. It is important to investigate the relationship of stress and psychobiological health in Palestinian children in the midst of high rates of PTSD and psychiatric disorders. Using a psychobiological framework, the effects of trauma exposure on perceived stress, resilience, HPA and SNS diurnal activity were explored. Conclusions might provide a guideline for clinical assessment and intervention models among traumatized children. 


\section{Method}

\section{Participants}

The study took place at Ain Beit Elma camp Nablus district, Palestine, between December 2008, and January 2009. Approval from and a letter of support by United Nations Relief and Work Agency (UNRWA) / West Bank to conduct the study in their district schools was obtained; as well as IRB approval from the University of San Diego. A total of 150 children and their parents (300) were recruited to participate in the study. Data collection workshops were conducted at Ain Beit Elma elementary boys' school for the male participants and at Ain Beit Elam elementary girls' school for the female participants. A total of six workshops (three in each school), with approximately 35 parents and 20 children participants in each workshop were conducted. Informed consent for parents and assent forms for children were obtained prior to data collection. Children completed a demographic instrument and three other instruments to measure Child Resilience Score (CRS), Level of Traumatic Exposure (LTE) and Child's Perceived Stress Score(CPSS); while parents completed one instrument to measure Father Perceived Stress Score (FPSS) and Mother Perceived Stress Score (MPSS).

A random sample of 48 children was selected to participate in the collection of morning and bedtime salivary samples. Children and their parents were taught the proper salivary sample collection, timing, storage, and sample delivery, and were provided with all required supplies as well as an instruction sheet. Participants were non-English speakers and all the forms, instruments and instruction sheet were translated and back-translated into Arabic language. Inclusion criteria for child participants were: a) Palestinian ethnicity (child should be born and raised in Palestine); b) between the ages of 10 and 12 years; c) able to read, write and speak Arabic. The exclusion criteria for a child participants for the stress biomarkers' analysis were: a) 
participants with mouth wounds or gum disease; b) participants who smoke; c) participants who consumed any meal or drinks prior to the test; d) participants on beta blockers or beta adrenergicagonists; e) participants who had exercised prior to the test.

\section{Measures}

Demographic Questionnaire. Demographic variables were potential moderating variables that could play a vital role in affecting children's stress level, resilience and its outcome (Barr et al., 1994). Data collected from the child participant consisted of four questions regarding the participants' age, gender, schooling performance, and family income.

Level of Traumatic Exposure: Gaza Traumatic Exposure Checklist (GTEC). LTE was measured by a modified version of the Gaza Traumatic Exposure Checklist (GTEC). This instrument was originally developed in 1993 to assess level of children's exposure to traumatizing events resulting from the Israeli military operations in Gaza Strip (Abu Hein, Qouta, Thabet, \& El Saraj, 1993). Originally the checklist consisted of 17 traumatizing events that the child in the Gaza district was exposed to within the past year. The instrument was presented in an Arabic version that is well understood by Palestinian children 10-12 years old. The original instrument had an established internal consistency reliability of 0.90 (Thabet et al., 2004). Due to the difference in the type of military operations and war violence experienced by Palestinian children in the West Bank, the GTEC was modified to accommodate such disparities. Therefore nine items were added to the original instrument. Those item included the exposure to direct physical injury; detainment at home or at a military barrier; beating and humiliation; deprivation from water, food, electricity, or toileting; destruction of personal belonging; direct threat to be killed; danger during street shootings; arrest and imprisoning; and Prevention from going to or coming back from school. The modified version consisted of 26 items and included 
four levels of traumatic events ranging between indirect exposure to violence (e.g., watching dead bodies on television) to direct exposure to violence (e.g., being a victim or witnessing bodily harm to another by gun fire, bombings, knifing, or other sources). Children answered each statement of the checklist with a "yes" or "no" response. Children were also asked to report any other traumatic events they had experienced that were not covered in the instrument. The GTEC was analyzed as a total score as well as a categorical score (score lower than 5= Mild traumatic exposure, 5-9 score $=$ Moderate traumatic exposure, a score of 10 or more $=$ High traumatic exposure) (Thabet et al., 2004). The Cronbach's alpha of the instrument for this study was .80 .

Child and Parents Perceived Stress: Cohen Perceived Stress Scale (PSS). Child perceived stress score (CPSS), father perceived stress score (FPSS) and mother perceived stress score (MPSS) were assessed by using the Perceived Stress Scale developed by Cohen, Kamarck and Mermelstein (1983). This instrument is a 14-item self-report measure by which individuals appraise the degree to which situations are stressful. The instrument is based on Lazarus's theory of stress appraisal, providing a direct measure of the level of stress experienced by the respondent. The PSS was designed for use with community samples with at least a junior high school education. Participants report the prevalence, within the last month, of each stressful item using a five-point Likert scale $(0=$ Never, $1=$ Almost never, $2=$ Sometimes, $3=$ Fairly often, and $4=$ Very often). Scores were obtained by reversing responses (e.g., $0=4,1=3,2=2,3-1 \& 4=0$ ) to the six positively stated items (items $4,5,6,7,9 \& 10$ ) and then summing across all scale items. Total scores can range from 0 to 56 , with higher scores indicating greater stress. The PSS is not a diagnostic instrument. There are only comparisons between people in a given sample or over time among the same people. Internal consistency of the items in previous studies ranged 
between 0.84 to 0.86 , and test - retest reliability was 0.85 (Cohen et al., 1983; Roberti, Harrington \& Storch, 2006).

To adjust the language and vocabulary for children 10-12 years, two Palestinian third grade English teachers reviewed the instrument and provided suggestions to make it more understandable for children in this age group. Such grade level revision improves the ability of the children's version of the instrument to measure the child participant's perceived stress score (CPSS). The parent version of the instrument remained as presented in the original version of Cohen et al.'s (1983) instrument.

Both the child's and parent' version of the PSS instrument were translated to Arabic by the principal investigator and two other expert reviewers who are fluent in both languages (English and Arabic) and familiar with Palestinian adults and children's vocabulary. The Arabic versions of the PSS Instrument were back-translated to English by two different expert reviewers and the principal investigator to ensure that the translated terms actually reflected the meanings in the original instruments. Children completed the Arabic child-modified version of the PSS instrument, and parents completed the translated original version of the PSS instrument. Cronbach's alpha reliability in this study for the CPSS, FPSS and MPSS instruments were .63, .77 , and .68 respectively. This finding was congruent with Watson, Logan and Tomar (2008) reported Cronbach's alpha of .68 for the PSS scale in their study. Though these instruments had not been piloted in this population, the reliability coefficients were all at acceptable levels; however further assessment for reliability is recommended.

\section{Child Resilience: Hunter and Hurtes Resilience Screening Instrument (H\&HRSI).} Child's resilience (CRS) was assessed by the H\&H Resiliency Screening Instrument that had been developed by Hunter \& Hurtes (2001). The instrument is composed of 41 items that 
measure the overall concept of resilience and has nine subscales (Creativity, Humor, Independence, Initiative, Insight, Relationships, Values Orientation, Self- Esteem and SelfEfficacy) that assess resilience skills. The scale is designed to be self-administered with respondents being required to judge whether he/she "strongly disagree, disagree, neutral, agree and strongly agree" to each statement. Reliability and validity testing of this instrument has been completed with over 500 male and female participants between 8-16 years of age across a variety of international populations: Caucasian, Asian, African heritage children in inner city, urban, and rural areas in the United States, Taiwan, Greece, Ghana, Uganda and Northern Ireland. The alpha coefficient reliability for the total score ranged between $0.89-.0 .93$ and with an overall $\mathrm{r}=0.91$ (Hunter \& Hurtes, 2001).

To assess the content validity of the instrument among Palestinian children, a pilot study was conducted prior to its use in this formal study. The $\mathrm{H} \& \mathrm{H}$ instrument was translated into Arabic by the principal investigator and two other expert reviewers who are all fluent in both English and Arabic language. The instrument was then evaluated for its readability for Palestinian children by teacher experts in Palestine. After comparing the responses of reviewers, suggestions for language changes were implemented. The Arabic version of the $\mathrm{H} \& \mathrm{H}$ instrument was then back-translated to English by two different expert reviewers and the principal investigator to ensure that the translated terms actually reflect the meanings of the original instrument. Reliability and content validity of the Arabic version of the $\mathrm{H} \& \mathrm{H}$ instrument was then piloted in Palestine with a group of 75 children ages 9-13 through a mixed methods approach using semi- structured interview question presented in a focus group format. The results found that the instrument's reliability was .87 . Validity of the instrument was confirmed from the focus group sessions as children perceived the questionnaire was easy to understand and complete. Future 
instrument testing needs to continue to consider the grade-level of the participants and be sure the comprehension of terms is appropriate to that grade-level. In the formal study, the Cronbach's alpha reliability for the CRS instrument was .86 .

Saliva sampling and preparation for biomarker assay. Children and parents were instructed to provide two salivary samples. One sample was taken within 10 minutes after awakening and a second sample one hour prior to the child's sleep at night. According to Kraemer, Davis, Yutsis, Neri, Thompson, Taylor and Spiege (2006) two time points (salivary samples at awakening and 9:00 PM) can provide a good estimate for the daily salivary cortisol slope. Participants were asked not to eat, drink, exercise or brush their teeth but to rinse the mouth with only tap water prior to delivering the samples. Participants were also instructed to chew on the cotton roll provided by the Salimetrics Oral Swab Collection device for one minute and then refrigerate the samples within 30 minutes, using a coded Salimetrics Storage Tube recording the wakening time and collection time. Salivary samples were collected at the participant's school. The samples were surrounded with iced bags in a Salimetrics Cryostorage Boxes and immediately transported to the Specialty Laboratory Center (CLC) at Ramallah City/Palestine where centrifugation and assays for salivary cortisol and sAA were conducted. At the laboratory salivary samples were frozen at $-20^{\circ} \mathrm{C}$ until assayed. On the day of assay, salivary samples were brought to room temperature, thawed completely, and centrifuged at 1500 $\mathrm{xg} @ 3000 \mathrm{rpm}$ for 15 minutes. The manufacturer's methodology in the assay of salivary biomarkers was strictly followed.

Salivary cortisol measurement. Salivary cortisol samples were assayed using a high sensitivity Salivary Cortisol Enzyme Immunoassay, manufactured by (Salimetrics, State College, PA) specifically designed and validated for the quantitative in vitro diagnostic measurement of 
salivary cortisol. The assay had a lower limit of sensitivity of $.007 \mu \mathrm{g} / \mathrm{dl}$, range of sensitivity from .007 to $1.8 \mu \mathrm{g} / \mathrm{dl}$, and average intra-and inter-assay coefficients of variation of less than $5 \%$ and $10 \%$. The normal salivary cortisol range identified by Salimetrics was $0.08-0.83 \mu \mathrm{g} / \mathrm{dl}$ or $(2.2-22.9) \mathrm{nmol} / \mathrm{L}$.

Salivary alpha-amylase (SAA) measurement. Participants' samples were assayed for sAA using the (Salimetrics, State College, PA) kinetic reaction assay kit specifically designed for the measurement of salivary sAA activity. This method utilized a chromagenic substrate, 2chloro-p-nitrophenol, linked with maltotriose. The enzymatic action of $\alpha$-amylase on this substrate yields 2-chloro-p-nitrophenol, which can be spectrophotometrically measured at 405 $\mathrm{nm}$ using a standard laboratory plate reader. The amount of $\alpha$-amylase activity present in the sample is directly proportional to the increase in absorbance at $405 \mathrm{~nm}$. Alpha amylase activity in the sample was determined in $\mathrm{U} / \mathrm{ml}$ using a standard manufacturer formula: [Absorbance difference per minute $\times$ total assay volume $(328 \mathrm{ml}) \times$ dilution factor $(2000)] /$ [millimolar absorptivity of 2-chloro- p- nitrophenol (12.9) $\times$ sample volume $(.008 \mathrm{ml}) \times$ light path (.97)]. The intra-assay Coefficient of Variation (CV) for the mean of 30 replicates tests was $2.5-7.5 \%$. Interassay variation computed for the mean of average duplicates for 16 individual runs was less than 6\%. The normal salivary $\alpha$-amylase range identified by Salimetrics was $3.1-423.1 \mathrm{U} / \mathrm{ml}$

\section{Data Analysis}

Cortisol and alpha-amylase. After obtaining the AM and PM salivary samples, the difference between both measures (Time $1=$ awakening level minus Time $2=$ bedtime level) was computed in order to determine the cortisol and sAA diurnal pattern for each participant. Participants who demonstrated a positive difference in salivary cortisol levels were viewed as having a more normal cortisol diurnal pattern; while participants with a negative difference in 
cortisol levels were viewed as having a flattened and or reversed cortisol pattern. Conversely participants with positive difference between sAA measures (Timel minus Time2) were interpreted as having a flatter or reversed diurnal pattern and as having a normal sAA pattern when the difference between the levels was negative.

Perceived stress, resilience, and traumatic exposure. Data analysis was carried out with SPSS version 15.0. Independent variables of level of traumatic exposure, child perceived stress, child's resilience, father perceived and mother perceived stress were treated as continuous variables. Salivary cortisol and sAA morning (AM) and bedtime (PM) levels, and the difference in levels were also treated as continuous variables. Demographic variables were treated either as continuous or categorical. Descriptive statistics (means and standard deviations for continuous variables, and frequencies and percentages for categorical variables) were calculated for all study variables. T-tests and ANOVA tests were used to examine the bivariate relationships of cortisol and SAA measures with demographic variables. Pearson's correlation was used to examine the bivariate relationships between the independent continuous variables and cortisol and sAA.

\section{RESULTS}

\section{Subjects}

Table 1 describes the study sample. Participants were122 children (58 girls [47.5\%], 64 boys [52.5\%]), with a mean age of 11.2 years; $79 \%$ were doing well in school and $67 \%$ came from families with moderate incomes. Data were also obtained from 102 fathers and 101 mothers of the children. The rest of recruited sample from both children and parents were excluded due to their inability to attend the data collection workshops or due to their incomplete data in their instruments. Only 37 of the 48 randomly selected participants were able to provide sufficient 
morning and bedtime salivary sample to conduct AM and PM cortisol and SAA analysis.

Participants reported the delivery of morning samples within 25 minutes from awakening.

Means, ranges and standard deviations of study variables are presented in Table 1 below.

Table 1

Means and Standard Deviations of Study Variables

\begin{tabular}{|c|c|c|c|c|}
\hline Variable & $\mathrm{N}$ & Range & Mean & $\mathrm{SD}$ \\
\hline Child age & 122 & $10-12$ & 11.0 & .81 \\
\hline Child Stress Score & 122 & $7-51$ & 31.42 & 7.43 \\
\hline Father Stress Score & 102 & $6-46$ & 31.42 & 8.10 \\
\hline Mother Stress Score & 101 & $10-55$ & 29.94 & 7.16 \\
\hline Resilience Score & 115 & $84-188$ & 145.53 & 18.25 \\
\hline $\begin{array}{c}\text { Traumatic Exposure } \\
\text { Score }\end{array}$ & 121 & $2-24$ & 11.02 & 4.48 \\
\hline $\begin{array}{c}\text { Cortisol AM Level } \\
\mu \mathrm{g} / \mathrm{ml}\end{array}$ & 37 & $.15-1.28$ & .41 & .24 \\
\hline $\begin{array}{c}\text { Cortisol PM Level } \\
\mu \mathrm{g} / \mathrm{ml}\end{array}$ & 37 & $00-.11$ & .02 & .02 \\
\hline $\begin{array}{c}\text { Cortisol Difference } \\
\mu \mathrm{g} / \mathrm{ml}\end{array}$ & 37 & $.13-1.24$ & .39 & .25 \\
\hline $\begin{array}{c}\alpha \text { - Amylase AM Level } \\
U / \mathrm{ml}\end{array}$ & 37 & $15.09-312.58$ & 86.40 & 54.81 \\
\hline $\begin{array}{c}\alpha \text { - Amylase PM Level } \\
\mathrm{U} / \mathrm{ml}\end{array}$ & 37 & $12.46-243.38$ & 116.19 & 56.76 \\
\hline $\begin{array}{c}\alpha-\text { Amylase Difference } \\
\mathrm{U} / \mathrm{ml}\end{array}$ & 37 & $-195.82-199.10$ & -29.37 & 74.95 \\
\hline
\end{tabular}




\section{Cross-sectional associations of cortisol results with study variables}

As shown in Table 1, participants' AM cortisol levels ranged between $.15-1.28 \mu \mathrm{g} / \mathrm{dl}$ or (4.1- 35.3) $\mathrm{nmol} / \mathrm{L}$. The mean cortisol difference (AM-PM) was $.39 \mu \mathrm{g} / \mathrm{dl}$. Of importance was the finding for three male participants (8.1\%) whose AM cortisol levels exceeded the manufacturer Salimetrics (2009) expected range; these three children reported high scores for CPSS and LTE, as well as high MPSS and FPSS scores. Further discussion of these findings will follow.

As shown in Table 2, there was a significant correlation between child perceived stress scores (CPSS) and AM cortisol level $(\mathrm{r}(37)=.35, \mathrm{p}<.05)$ and between CPSS and cortisol difference, $(\mathrm{r}(37)=.33, \mathrm{p}<.05)$. AM cortisol was strongly correlated with cortisol difference $(\mathrm{r}=$ $.99, \mathrm{p}<.001$ ), indicating the overall normal diurnal pattern among child participants. A significant positive correlation between child's AM cortisol levels and MPSS (r (37)=.37, p <.05), as well as between cortisol difference and MPSS ( $\mathrm{r}(37)=.38, \mathrm{p}<.05)$, were found. Except for the three children previously identified, there were no overall significant associations between CRS, LTE, FPSS, gender, age, schooling achievement and household income with AM cortisol or cortisol difference.

There was a significant gender difference on PM cortisol $(t(35)=3.04, p<.01)$. Boys had higher mean $\mathrm{PM}$ cortisol level $(\mathrm{M}=.03, \mathrm{SD}=.03)$ than girls $(\mathrm{M}=.01, \mathrm{SD}=.01)$. There was no significant PM cortisol difference with age, schooling achievement and household income. PM cortisol was not significantly correlated with CRS, CPSS, MPSS, FPSS, or LTE. All study samples showed high AM cortisol and lower PM cortisol levels and reflected a normal cortisol diurnal pattern, suggesting that these children in the face of war trauma appeared to be adapting 
fairly well physically. This suggests future exploratory studies on why and what contributes to their physiological adaptation?

Table 2

Correlations between Child Traumatic Exposure, Child Perceived Stress, Resilience, Father Perceived Stress, Mother Perceived Stress, and Cortisol \& Amylase diurnal Secretion in

\section{Children}

\begin{tabular}{|c|c|c|c|c|c|c|c|c|c|c|c|c|}
\hline & & 1 & 2 & $\overline{3}$ & 4 & 5 & 6 & 7 & 8 & 9 & 10 & 11 \\
\hline 1 & Cortisol AM & - & .13 & $.99^{* * *}$ & .01 & .021 & -.17 & $.35^{*}$ & .20 & $.37^{*}$ & .03 & .19 \\
\hline 2 & Cortisol PM & & - & .04 & .29 & .24 & .03 & .20 & .08 & .02 & .03 & -.17 \\
\hline 3 & Cortisol AM-PM & & & - & -.04 & .19 & -.17 & $.33^{*}$ & .19 & $.38^{*}$ & .03 & .21 \\
\hline 4 & Amylase Am & & & & - & .09 & $.66^{* * *}$ & .08 & .09 & .22 & .03 & -.18 \\
\hline 5 & Amylase PM & & & & & - & $-.69 * * *$ & .25 & -.18 & -.15 & -.15 & -.18 \\
\hline 6 & Amylase AM-PM & & & & & & - & -.14 & .21 & .26 & .14 & .04 \\
\hline 7 & Child Stress Score & & & & & & & - & $.36^{* * *}$ & $.36^{* * *}$ & -.04 & $.39 * * *$ \\
\hline 8 & Father Stress & & & & & & & & - & $.65^{* * *}$ & .08 & $.33^{* * *}$ \\
\hline 9 & Mother Stress & & & & & & & & & - & .02 & $.41 * * *$ \\
\hline 10 & Resilience Score & & & & & & & & & & - & -.05 \\
\hline 11 & Trauma Score & & & & & & & & & & & - \\
\hline
\end{tabular}

Note: ${ }^{*} \mathrm{p}<.05 * * \mathrm{p}<.01 * * * \mathrm{p}<.001$ 


\section{Cross-sectional associations of $\mathbf{S A A}$ levels with study variables}

Table 1 also reports the sAA levels for the study participants. The mean score AM sAA level for study participants was $86.40 \mathrm{U} / \mathrm{ml}$ and $116.19 \mathrm{U} / \mathrm{ml}$ for the PM level; a result that is close to the Salimetrics (2009) adult mean sAA level of $92.4 \mathrm{U} / \mathrm{ml}$. Though within normal range, $38 \%$ of the 37 participants had positive sAA AM to PM difference, with an overall mean difference of $-29.37 \mathrm{U} / \mathrm{ml}$. This indicates that some participants demonstrated higher AM than PM sAA levels indicating a reversed diurnal pattern. Morning sAA levels were also found to significantly differ across age groups $(F(2,34)=3.29, \mathrm{p}<.05)$. Children aged 11 years had higher mean $\mathrm{AM}$ sAA $(M=114.14, \mathrm{SD}=75.16)$ than children aged 10 years $(\mathrm{M}=61.13, \mathrm{SD}=$ 33.44) and children aged 12 years $(M=86.05, S D=36.99)$. Sixty percent of the participants 11 years of age also exhibited this reversed diurnal pattern, suggesting potential higher stress demands exerted on this specific age group. No significant associations found between sAA measures and CPSS, LTE, CRS, FPSS, MPSS, and other demographic variables. Results of the sAA levels shows there is more of an abnormal stress response in Palestinian children exposed to trauma than is evidenced by the cortisol response.

\section{Association of cortisol and $S A A$ results}

As shown in Table 2, there were no significant correlations found between SAA AM level, PM level and Time1-Time2 difference with cortisol AM level, PM level or cortisol difference Time1-Time2. However, generally higher AM cortisol and positive cortisol difference were negatively associated with AM sAA and negative Time1-Time2 difference in sAA levels reflecting the normal diurnal pattern and relationship of these biomarkers. Additionally, no 
significant relationships were evident between the $38 \%$ participants with reversed sAA pattern and cortisol difference. Since prior research has indicated that flat or reversed cortisol responses could be associated with chronic stress and reverse sAA is associated with acute stress, these results do not help differentiate the acute from chronic stress response in Palestinian children exposed to trauma.

\section{Cross-sectional associations of traumatic exposure (LTE), perceived stress (CPSS, MPSS,} FPSS), and resilience (CRS)

The correlations among child traumatic exposure, child and parental perceived stress, and resilience are presented in Table 2. Children reported high LTE scores $(M=11.02, S D=4.48)$. The association between CPSS and LTE was medium and statistically significant(r $(119)=.39$, $\mathrm{p}<.001$ ); children with greater traumatic events exposure had higher stress scores.

CRS were significantly associated with gender $(t(113)=2.76, p<.01)$. Boys had higher mean resilience scores $(M=150.05, S D=16.09)$ than girls $(M=140.93, S D=19.29)$. Though both groups had resilience scores within the healthy range, boys appeared to be adapting to the war trauma better than the girls. Results also showed a medium and significant association between FPSS with CPSS and LTE $(\mathrm{r}(100)=.36, \mathrm{p}<.001 ; \mathrm{r}(99)=.33, \mathrm{p}<.01)$ respectively. There was also a medium and significant association between MPSS with CPSS and LTE (r (99) =.36, $\mathrm{p}<.001 ; \mathrm{r}(98)=.41, \mathrm{p}<.001)$ respectively. Father and mother perceived stress were strongly and significantly associated $(\mathrm{r}(93)=.65, \mathrm{p}<.001)$. These results indicate that children's exposure to traumatic events and higher parental stress levels had a significant impact on children increased perceived stress responses. 


\section{Discussion}

The purpose of this study was to explore relationships of traumatic exposure, perceived stress and resilience with cortisol and sAA diurnal pattern in Palestinian children exposed to chronic war stress. This study's findings demonstrate that a significant relationship exists between the child's perceived stress scores (CPSS) scores and AM cortisol level, suggesting there could be a significant effect of stress on children. This has the potential to lead to future physiologic or psychosocial problems (Carrion, Weems, \& Reiss, 2007; Curtis \& Cicchetti, 2003; Levine \& Ursin, 1991). Before such conclusions can be made, it is important to understand that higher levels of AM cortisol in some participants could be related to normal individual variation in AM cortisol production influenced by the individual's adrenal sensitivity, capacity, cortisol binding, or methodological difficulties in assessing perceived stress (Hallhammer, Wust, \& Kudielka, 2009). The levels could also be affected by the day of the week, time of measurement, and time since awakening (Kelly et al., 2008).

Salivary cortisol and sAA generally reflected opposite diurnal patterns in this study and this is consistent with the state of the science that demonstrates cortisol diurnal pattern is distinct from sAA patterns (Davis \& Granger, 2009; Granger et al., 2007, Rohleder et al., 2004). Further, results from this study support findings from previous research that showed no differences in AM cortisol with age across pubertal stages in males (Kerrigan et al., 1993), and no major differences with age or gender (Matchock, Dom, \& Susman, 2007). However other studies showed no differences in AM cortisol with gender only (Kudielka \& Kirschbaum, 2003; Groschl, Rauh, \& Dorr, 2003; Tornhage, 2003), and no differences in AM cortisol levels with age only (Rosmalen, Oldehinkel, Ormel, Winter, Buitelaar, \& Verhulst (2005). 
It was found that $38 \%$ of the participants in this study had reversed sAA diurnal patterns. No correlations were found in this study between SAA with LTE, CRS and CPSS scores or gender, household income and schooling performance. However child's age influenced the sAA response in this study, with highest AM sAA among 11-year-olds. The scarce number of studies exploring SAA levels and diurnal pattern among children in different age groups, especially under chronic stress conditions, has made it difficult to compare our study findings. Those younger than 11 and older than 11 did not demonstrate abnormalities which begs the question as to what is it at age 11 that is such a stress in this population? Certainly further research is needed.

Nater, Rohleder, Schlotz, Ehlert, and Kirschbaum (2007) found higher levels of sAA levels in their participants with higher chronic stress scores as measured by the Chronic Stress Screening Scale (CSSS). This may be a measure to use in a future study when trying to differentiate sAA response in acute versus chronic stress exposure. Higher $\alpha$-amylase levels have been observed in experienced and competent competitors (Kivlighan \& Granger, 2006); individuals with chronic shame trait experience (Rohleder, Chen, Wolf, \& Miller, 2008), in addition to its high reactivity in variety of acute stressful experiences. However lower levels of sAA during the day was observed in children with asthma and chronic life stress compared with higher levels in healthy children (Wolf et al., 2008).

The association with reversed SAA pattern with normal cortisol diurnal pattern in this study suggests that studying SAA is important to consider in future stress related studies. According to the literature, reversed sAA slopes may be a more sensitive test of physiological stress; thus, despite the lack of abnormal cortisol diurnal patterns in this study population, the abnormal sAA response in some of the study participants indicates these children may be feeling more stress than was originally perceived. 
However, the significant finding from this study was the fact that the majority of children had normal cortisol diurnal patterns despite their high level of stress; as well as fairly positive resilience scores meaning the majority of children appeared to be managing war stress better than originally assumed. Subjects of the study reported high levels of traumatic exposure yet believed they were fairly resilient. Boys perceived themselves as more resilient than girls. Previous studies on the impact of political violence on Palestinian children showed that girls acquired antisocial behaviors and depression (Barber, 2001) with social integration in family, education, religion, and peer relationships serving as the modifier for their problems. There are conflicting findings in various studies indicating girls are more resilient than boys (Brajకa-Žganec, 2005; Garbarino \& Kostenly, 1996; Hunter, 2001). Were the findings in this study unique to this population of participants? One might conclude that children may acquire higher resilience due to their gender roles; however one can't exclude methodological errors.

Higher CPSS was strongly correlated with parental stress and trauma exposure. Mothers' perceived stress response had greater negative impact on the children's AM cortisol than the fathers' perceived stress. This may be related to longer periods of contact children had with their mothers every day thus aiding in the child's ability to see and feel the mother's anxiety. Furthermore both FPSS and MPSS were also strongly correlated with level of child traumatic exposure which indicates the strong impact of war violence on both parents, potentially causing aggravation of stress levels in children. This gives the impression that family dynamics can be disrupted by war conditions. Family resilience is the unit that can help overcome adverse stresses (Patterson, 2002), but which can become dysfunctional in the face of overwhelming life conditions (Walsh, 2002). Children with higher cortisol levels, perceived stress and traumatic exposure are at increased risk of developing childhood as well as adulthood physical, cognitive, 
psychiatric, behavioral and psychobiologic disorders (Barber, 2001; Feng, Shaw, \& Silk, 2008;

Weidner, Hutt, Connor, \& Mendell, 1992). Health care providers working with families exposed to war and long-term violence need to help mothers cope with this stress in healthier ways so they can help support their children through the crisis; as well as need to find ways to help the family unit remain functional in the wake of war challenges.

Though the majority of the participants appeared to be adapting to the stress of war fairly well, there were three young boys who were not. The screening tools used (perceived stress, parental stress, cortisol response, and trauma exposure) helped to identify these three children who are at significant risk for future physiological and psychological dysfunction. These three boys had unusually high levels of AM cortisol, perceived stress scores, and traumatic exposures scores; as well as high scores for both mother and father's perceived stress. Using reliable screening tools would be important for providers who need to quickly identify children who would be at greatest risk for negative health outcomes from long-term exposure to war violence. There were only three children identified as such in this study; thus further research is obviously necessary to ascertain whether these three outliers really reflected the negative physical and psychosocial response to war stress or was it a methodological error.

The cross-sectional design of this study and the limited number of participants and cortisol sampling can limit the study's validity and generalizability; thus further research with a larger sample is important before evidence-based practice changes can be made. The study was also limited by the absence of control group and the lower reliability level for the child perceived stress instrument. Further exploration to why the PSS instrument was not performing well and or using a different instrument to capture perceived stress in Palestinian children may be helpful; controlling for participant's delivery of salivary sampling could prevent the loss of 11 samples 
and avoid potential misinterpretation of the results; and finally, replicating the study with a larger sample size might provide invaluable foundation for further studies and clinical application among similar study populations.

\section{Conclusion}

The overall study results revealed that Palestinian children in this sample were adapting fairly well physically and psychosocially to their chronic exposure to war and violence. Further work needs to be done to delineate the cortisol and SAA responses to help understand chronic and acute stress responses among children living in a war zone. Further study is also needed to assess children living in such environments to identify the best screening tools to uncover children at greatest risk for poor adaptation to such stress exposure. Developing, implementing, and assessing the effectiveness of interventions to help families, especially mothers, buffer the adversity of war conditions so they can better help their children is vital. Further longitudinal studies, with a larger sample and with more controlled methodologies, are needed to explore the SNS and HPA responsiveness of children, across various ages. The results of this study are just the beginning.

\section{Acknowledgements}

We would like to thank the University of San Diego / School of Nursing for purchasing the salivary biomarkers' kits and supplies, the Specialty laboratory Center/ Ramallah team for their extensive work to conduct the assays, and the United Nations Relief and Work Agency (UNRWA) / West Bank / Department of Education administrators, field supervisors and school's directors who supported the data collection process on site. We would like to thank the children and their families for their kind participation in the study. 
Dissertation Summary and Conclusion 84

Dissertation Summary and Conclusion 


\section{Summary and Conclusion}

Several research assumptions were made before the completion of the research study: 1) Children exposed to chronic violence, exist in potentially unhealthy resilience dimensions of emotional insulation or survival. Either of these modalities of overcoming adversity increases the child's risk for mental and physical health problems. 2) Children exposed to chronic violence do not exhibit the normal physiological cortisol stress response and as such are at increased risk for physical health problems. 3) Parents may influence their child's perception of stress.

The conclusions found that children are exhibiting healthier than unhealthy resilience responses in the face of war trauma; thus were adapting better psychologically than originally assumed. Secondary data analysis will be conducted to ascertain what resilience skills might be contributing to this populations' resilience response. The conclusions also confirmed that parental stress perception significantly influences the child's stress response, with mother's perception having the greatest impact.

Conclusions also found that the majority of children in this population exposed to chronic violence were exhibiting normal diurnal cortisol and SAA responses; thus were adapting better physically than originally assumed. War adversity did appear to have a potential impact on increased morning cortisol secretion. The association of our subjects with reversed alphaamylase pattern with normal cortisol diurnal pattern suggests that studying alpha-amylase is an important to consider in future stress related studies.

The study was limited by the cross-sectional design with the limited number of participants and cortisol sampling; the low reliability for the child perceived stress instrument; and the uncontrolled home setting for participant's delivery of salivary sampling that lead to the loss of 11 salivary samples all affect the study's validity and generalizability. 
The completion of this doctoral dissertation contributed to the submission of three articles for publication. The first article is a case study approach describing the unique experience of a researcher conducting a research in a war zone. The contextual factors influencing the research with displaced populations within a war zone were discussed. The second article is a literature review on the state of the science related to political violence and war trauma on potential child psychobiological alterations and stress adaptation; the role of age, gender and family process in childhood traumatic stress; child vulnerability, risk and resilience; the biological stress response in children, specifically the dysregulation of the HPA functioning and the sympathetic nervous system (SNS) response to stress. The third article is the research results article discussing the research process and the specific results presented at the beginning of this conclusion. All three articles have added to the state of the science in nursing and other healthcare disciplines.

\section{Implications}

The implications of this research study have relevance to future nursing research as well as other related disciplines in the following ways. Clinically, medical professionals may gain more insight into the short and long-term effects of chronic war violence on the biological pathways in young bodies. This knowledge may then lead to more effective treatment strategies. Though providers need to assess war impacts, this study indicates that children appear to be adapting better than expected. Assessing parental stress response would be important since this study found that parental stress had a significant impact on the child's stress response.

In the area of research, the findings from this research supports previous research work on the impact war can have on the stress biomarkers diurnal secretion and adds to the state of the science, specifically in the arena of pediatrics. More research is needed in assessing children's' biological and psychological response to stress. Other research has found significant incidences 
of PTSD; this study did not assess that psychological dimension. Using PTSD in combination with biomarker (stress and other neuroendocrine response) testing might uncover important information that could help in the early identification of children at risk. This study found some biomarker variations in gender response and age response (especially the 11-year-old) which certainly requires further investigation. Intervention studies designed to foster family resilience, or improve maternal coping are important to develop and assess their efficacy in improving the supportive environment for children that may help decrease the PTSD and pathophysiological responses to war. Further research among Palestinian children is obviously necessary to ascertain whether cortisol outliers and reversed sAA diurnal pattern really reflected the negative physical and psychosocial response to war stress or was it a methodological error. Further longitudinal studies, with a larger sample, more reliable screening instruments and with more controlled methodologies, is needed to explore the SNS and HPA responsitivity of children, across various ages

The study's impact on the educational preparation of nursing and medical providers is important. Current news reports and the emphasis at most military hospitals are about the impact of PTSD on military personnel and the victims of war. More education of healthcare providers lacks adequate information about this phenomenon and how to intervene to decrease its incidence. Enhancing this educational component could positively affect the future of violence victims (regardless of the type of violence to which they are exposed) as earlier identification, prevention, and/or therapeutic interventions are implemented. 
References 


\section{References}

Abercrombie, H. C., Giese-Davis, J., Stephton, S., Epel, E. S., Turner-Cobb, J. M., \& Spiegel, D. (2004). Flattened cortisol rythms in metastatic breast cancer. Psychoneuroendocrinology, $29,1082-1092$.

Abu-Hein, F., Qouta, S., Thabet, A., \& El-Sarraj, E. (1993). Trauma and mental health of children in Gaza. British medical Journal, 306, 1130-1131.

Adam, E. K., \& Gunnar, M. R. (2001). Relationship functioning and home and work demands predict individual differences in diurnal cortisol patterns in women.

Psychoneuroendocrinology, 26, 189-208.

Barber, B. K. (2001). Political violence, social integration, and youth functioning: Palestinian youth from the intifada. Journal of Community Psychology, 29(3), 359-280.

De Bellis, M. D. (2001). Developmental traumatology: the psychobiological development of maltreated children and its implications for research, treatment, and policy. Development and Psychopathology, 13, 539-564.

Barr, R. G., Boyce, W. T., \& Zeltzer, L. K. (1994). The stress-illness association in children: A perspective from the biobehavioral interface. In R. J. Haggerty, L. R. Sherrord, N. Garmezy \& M. Rutter (Eds.), Stress, risk, and resilience in children and adolescents (pp. 182-224). New York: Cambridge University Press.

Batniji, R., Rabaia, Y., Nguyen-Gillham, V., Giacaman, R., Sarraj, E., Punamaki, R.-L., et al. (2009). Health in the Occupied Palestinian Territory 4: health as human security in the occupies territory. The Lancet, 373, 1133-1143.

BBC. (2009). Scale of Gaza Destruction Emerges. Retrieved June 13, 2009, from http://news.bbc.co.uk/2/hi/middle_east/7836869.stm 
Bell, B. (2009). Counting casualties of Gaza's war. Retrieved June 13, 2009, from http://news.bbc.co.uk/2/hi/middle_east/7855070.stm

Blgbee, J. L. (1992). Family stress, hardiness, and illness: a pilot study. Family Relations, 41(2), 212-217.

Bonanno, G. A. (2004). Loss, Trauma, and Human Resilience. American Psychopathologist, $59(1), 20-28$.

Brajša-Žganec, A. (2005). The long-term effects of war experiences on children's depression in the Republic of Croatia. Child Abuse \& Neglect, 29(1), 31-43.

Cairns, E. (1994). Children and political violence: an overview. International Journal of Behavioral Development, 17(4), 669-674.

Cannon, W. B. (1915). Bodily changes in pain, hunger, fear and rage: an account of recent researches into the function of emotional excitement. New York: Appleton.

Cannon, W. B. (1932). The wisdom of the body. New York: The Norton Library.

Carrion, V. G., Weems, C. F., Ray, R. D., Glaser, B., Hessl, D., \& Reiss, A. L. (2002). Diurnal salivary cortisol in pediatric posttraumatic stress disorder. Biological Psychiatry, 51(7), $575-582$.

Carrion, V. G., Weems, C. F., \& Reiss, A. L. (2007). Stress predicts brain changes in children: a pilot Longitudinal Study on Youth Stress, Posttraumatic Stress Disorder, and the Hippocampus. Pediatrics, 119, 509-516.

Charney, D. S. (2004). Psychobiological mechanisms of resilience and vulnerability: Implications for Successful Adaptation to Extreme Stress. American Journal of Psychiatry, 161, 195-216. 
Chatterton, R. T., JR., K. M. V., Lu, Y.-C., \& Hudgens, G. A. (1997). Hormonal response to psychological stress in men preparing for skydiving. Journal of Endocrinology and Metabolism, 82(8), 2503-2509.

Clark, D. C., Pynoos, R. S., \& Gobel, A. E. (1994). Mechanism and process of adolescent bereavement. In R. J. Haggerty, L. R. Sherrod, N. Garmezy \& M. Rutter (Eds.), Stress, risk, and resilience in children and adolescents (pp. 100-146). New York: Cambridge University Press.

Cohen, S., Kamarck, T., \& Mermelstein, R. (1983). A global measure of perceived stress. Journal of Health and Social Behavior, 24(4), 385-396.

Creamer, M., Elliott, P., Forbes, D., Biddle, D., \& Hawthorne, G. (2006). Treatment for combatrelated posttraumatic stress disorder: tow- year follow- up. Journal of Traumatic Stress, $19(5), 675-685$.

Curran, P. S., \& Miller, P. W. (2001). Psychiatric implications of chronic civilian strife or war: Northern Ireland. Advances in Psychiatric Treatment, 7, 73-80.

Curtis, W. J., \& Cicchetti, D. (2003). Moving research on resilience into 21 st century: Theoretical and methodological considerations in examining the biological contributors to resilience. Development and Psychopathology, 15, 773-810.

Davidson, R. J. (2000). Affective style ,psychopathology,and resiience:Brain mechanisms and plasticity. American Psychologist, 55, 1196-1214.

Davis, E. P., \& Granger, D. A. (2009). Developmental differences in infant salivary alphaamylase and cortisol in response to stress. Psychoneuroendocrinology, in press.

Dyregrov, A., Gjestad, R., \& Raundalen, M. (2002). Children exposed to warfare: a longitudinal study. Journal of Traumatic Stress 15(1), 59-68. 
Dyregrov, A., \& Raundalen, M. (2003). Threats in the life of Iraqi children. New Directions for Youth Development, 98, 111-118.

Eckart, C., Engler, h., Riether, C., Kolassa, S., Elbert, T., \& Kolassa, I.-T. (2009). No PTSDrelated differences in diurnal cortiol profiles of genocide survivors. Psychoneuroendocrinology, 34, 523-531.

Edwards, S., Hucklebridge, F., Clow, A., \& Evans, P. (2003). Components of the diurnal cortisol cycle in relation to upper respiratory symptoms and perceived stress. Psychosomatic Medicine, 65, 320-327.

Ehlert, U., Erni, K., Hebisch, G., \& Nater, U. (2006). Salivary $\alpha$-amylase levels after yohimbine challenge in healthy men. The Journal of Clinical Endocrinology \& Metabolism, 91(12), $5130-5133$.

Elbedour, S., Onwuegbuzie, A. J., Ghannam, J., Whitcome, J. A., \& Hein, F. A. (2007). Posttraumatic stress disorder, depression, and anxiety among Gaza Strip adolescents in the wake of the second Uprising( Intifada). Child Abuse \$ Neglect, 31, 719-729.

Elzinga, B. M., Roelofs, K., Tollenaar, M. S., Bakvis, P., Pelt, J. v., \& Spinhoven, P. (2008). Diminished cortisol response to psychosocial stress associated with lifetime adverse events: A study among healthy subjects. Psychoneuroendocrinology, 33, 227-237.

Feng, X., Shaw, D. S., \& Silk, J. S. (2008). Developmental trajectories of anxiety symptoms among boys across early and middle childhood. Journal of Abnormal Psychology, 117(1), $32-47$.

Fox, G. L., Michael L. Benson, DeMaris, A. A., \& Wyk, J. V. (2002). Economic distress and intimate violence: testing family stress and resources theories. Journal of Marriage and the Family, 64(3), 793-807. 
Fremont, W. P. (2005). Childhood reactions to terrorisms-induced trauma. Psychiatric Times, 22(10).

Garbarino, J., \& Kostenly, K. (1996). The effects of political violence on Palestinian children's behavior problems: a risk accumulation model. Child Development, 67, 33-45.

Garmzy, N. (1991). Resilience in children's adaptation to negative life events and stressed environment. Pediatric Annual, 20, 459-466.

Gary, T. S. (1991). Limbic pathways and neurotransmitters as mediators of autonomic and neuroendocrine responses to stress. In M. R. Brown, G. F. Koob \& C. Rivier (Eds.), Stress Neurobiology and Neuroendocrinology (pp. 73-89). New York: Marcel Dekker.

Georges, J. M. (2008). Bio-power, Agamben, and emerging nursing knowledge. Advances in Nursing Science 31(1), 4-12.

Glantz, M. D., \& Johnson, J. L. (1999). Resilience and Development, Positive Life Adaptation. New York: Kluwer Academics/Plenum Publishers.

Gore, S., \& Eckenrode, J. (1994). Context and process in research on risk and resilience. In R. J. Haggerty, L. R. Sherrod, N. Garmezy \& M. Rutter (Eds.), Stress, risk, and resilience in children and adolescents (pp. 19-63). New York: Cambridge University Press.

Granger, D. A., Dreschel, N. A., \& Shirtcliff, E. A. (2003). Developmental psychoneuroimmunolgy. In D. Cicchetti \& E. F. Walker (Eds.), Neurodevelopmental Mechanisms in Psychopathology (Vol. 13, pp. 293-322). New York: Cambridge University Press.

Granger, D. A., Kivlighan, K. T., Clancy, B., Mona, E.-S., Jacquelyn, M., Lisonbee, J. A., et al. (2006). Integrating the measurement of salivary $\alpha$-amylase into studies of child health, 
development and social relationships. Journal of Social and Personal Relationships, 23(2), 267-290.

Granger, D. A., Kivlighan, K. T., El-Sheikh, M., Gordis, E. B., \& Stroud, L. R. (2007). Salivary $\alpha$ - amylase in biobehavioral research: recent development and applications. New York Academy of Sciences, 1098, 122-144.

Groschl, M., Rauh, M., \& Dorr, H.-G. (2003). Circadian rhythm of salivary cortisol, 17ahydroxyprogestrone, and progesterone in healthy children. Clinical Chemistry, 49, 16881691.

Gunnar, M. R., Bruce, J., \& Hickman, S. e. (2001). Salivary cortisol response to stress in children. Everyday Biological Stress Mechanism, 22, 52-60.

Gunnar, M. R., Frenn, K., Wewerka, S. S., \& Ryzin, M. J. V. (2009). Moderate versus severe early life stress: association with stress reactivity and regulation in 10-12-year-old children. Psychoneuroendocrinology, 34, $62-75$.

Gunnar, M. R., \& Vazquez, D. M. (2001). Low cortisol and a flattening of expected daytime rhythm: Potential indices of risk in human development. Development and Psychopathology, 13, 515-538.

Haase, J. (1997). Hopeful teenagers with cancer: living courage. Reflections, 32(1), 20.

Haase, J. E. (2004). The adolescent resilience model as aguide to interventions. Journal of Pediatric Oncology Nursing, 21, 289-299.

Hallhammer, D. H., Wust, s., \& Kudielka, B. M. (2009). Salivary cortisol as a biomarker in stress research. Psychoneuroendocrinology, 34, 163-171.

Heim, C., Ehlert, U., \& Hellhammer, D. H. (2000). The potential role of hypocortisolism in the pathophysiology of stress-related bodily disorders. Psychoneuroendocrinology, 25, 1-35. 
Hinds, P. S., Burghen, E. A., Haase, J. E., \& Phillips, C. R. (2006). Advances in defining, conceptualizing, and measuring quality of life in pediatric patients with cancer. Oncology Nursing Forum, 33(1), 23-29.

Hjerm, A., Angel, B., \& Jeppson, O. (1998). Political violence, family stress and mental health of refugee children in exile. Scand J Soc Med, 26(1), 18-25.

Hook, B., (1994). Teaching to transgress: education as the practice of freedom. In (pp. 11). New York: Routledge Publishing CO.

Horton, R. (2009). The occupied Palestinian territory: peace, justice, and health. The Lancet, 373(9666), 784-788.

Hunter, A. J. (2001). A cross -cultural comparison of resilience in adolescents Journal of Pediatric Nursing, 16(3).

Hunter, A. J. (2001b). What is resilience? Book review of resilience and development: Positive life adaptations by Glantz \& Johnson. Contemporary Psychology, 46(4), 420-422.

Hunter, A. J., \& Chandler, G. E. (1999). Adolescent resilience. Journal of Nursing Scholarship, 31(3), 243-247.

Hunter, A. J., \& Hurtes, K. P. (2001). Measuring resilience in youth: the resiliency attitudes and skills profile. Unpublished.

Jessop, D. S., \& Turner, J. M. (2008). Measurement and meaning of salivary cortisol: a focus on health and disease in children. Stress, 11(1), 1-14.

Jong, J. T. d., Klmpore, I. H., Ommeren, M. V., Masri, M. E., Araya, M., Khalid, N., et al. (2001). Lifetime events and posttraumatic stress disorder in 4 postconflict settings. Journal of the American Medical association, 286(5), 555-562. 
Joshi, P. T., \& O'Dennell, D. A. (2003). Consequences of child exposure to war and terrorism. Clinical Child and Family Psychology Review, 6(4).

Kanji, Z., Drummond, J., \& Cameron, B. (2007). Resilience in Afghan Children and their families: a review. Pediatric Nursing, 19(2), 30-33.

Kaplan, H. B. (1999). Toward an understanding of resilience: a critical Review of Definitions and Models. In M. D. Glantz \& J. L. Johnson (Eds.), Resilience and Development , Positive Life Adaptations (pp. 17-83). New York: Kluwer Academic/Plenum Publishers.

Karr, S. K., \& Johnson, P. L. (1987). Measuring children's stress: An evaluation of methods. Paper presented at the Annual meeting of the National Association of School Psychologist, New Orleans.

Keller, P. S., \& El-Sheikh, M. (2009). Salivary alpha amylase as a longitudinal predictor of children's external-izing symptoms: respiratory sinus arrhythmia as a moderator of effects. Psychoneuroendocrinology, 34, 633-643.

Kelly, S. J., Young, R., Sweeting, H., Fischer, j. E., \& West, P. (2008). Levels and confounders of morning cortisol collected from adolescents in a naturalistic (school) setting. Psychoneuroendocrinology, 33(9), 1257-1268.

Kerrigan, J. R., Veldhuis, J. D., Leyo, S. A., Iranmanesh, A., \& Rogol, A. D. (1993). Estimation of daily cortisol production and clearance rates in normal pubertal males by deconvolution. Journal of Clinical Endocrinology and Metabolism, 76(6), 1505-1510.

Kertes, D. A., Gunnar, M. R., Madsen, N. J., \& Long, J. D. (2008). Early deprivation and home basal cortisol levels: a study of internationally adopted children. Development and Psychopathology, 20, 473-491. 
Kivlighan, K. T., \& Granger, D. A. (2006). Salivary $\alpha$-amylase response to competition: relation to gender, previous experience, and attitude. Psychoneuroendocrinology, 31, 703-714. Kocijan-Hercigonja, D., Sabioncello, A., Rijavec, M., Folenegovic-Smalk, V., Matijevic, L., Dunevski, I., et al. (1996). Psychological condition hormone levels in war trauma. Psychiatry Research, 30(5), 391-399.

Kraemer, H. C., Giese-Davis, J., Yutsis, M., Neri, E., Gallaber-Thompson, D., Taylor, B., et al. (2006). Design decisions to optimize the reliability of daytime cortisol slopes in an older population. American Association for Geriatric Psychiatry, 14(4), 325-333.

Kudielka, B. M., \& Kirschbaum, C. (2003). Awakening cortisol responses are influenced by health status and a wakening time but not by menstrual cycle.

Psychoneuroendocrinology, 28, 35-47.

Ladd, G. W., \& Cairns, E. (1996). Children: ethnic and political violence. Child Development, 67, 14-18.

Lazarus, R. S. (1999). Stress and Emotion. New York: Springer Publishing Company.

Lazarus, R. S., \& Folkman, S. (1984). Stress, Appraisal and Coping. New York: Springer Publishing Company.

Lee, A., Mohan, I., \& Janaca, A. (2002). Post-traumatic stress disorder and terrorism. Current Opinion in Psychiatry, 15(6), 633-637.

Levine, S., \& Ursin, H. (1991). What is stress? In M. R. Brown, G. F. Koob \& C. Rivier (Eds.), Stress neurobiology and neuroendocrinology (pp. 3-21). New York: Marcel Dekker.

Lopez, J. F., Akil, H., \& Watson, S. J. (1999). Neural circuits mediating stress. Biological Psychiatry, 46, 1461-1471. 
Luthar, S. s., \& Cushing, G. (1999). Measurement issues in the empirical study of resilience. In M. D. Glantz \& J. L. Johnson (Eds.), Resilience and Development: Positive Life Adaptations (pp. 129-160). New York: Kluwer Academic/Plenum Publishers.

Luthar, S. S., \& Zigler, E. (1991). Vulnerability and competence: A review of research on resilience in childhood. American Orthopsychiatric, 61(1).

Lynch, M. (2003). Consequences of child exposure to community violence. Clinical Child and Family Psychology Review, 6(4), 265-274.

Macksound, M. S., \& Aber, J. L. (1996). The war experience and psychosocial development of children in Lebanon. Child Development, 67, 70-88.

Maguire, A. M., \& Cowell, C. T. (2007). Salivary cortisol to assess the hypothalamic-pitutaryadrenal axis in healthy children under 3 years old. J. Pediatr. (Rio J.), 83(4), 382-386.

Matchock, R. L., Dorn, L. D., \& Susman, E. J. (2007). Diurnal and seasonal cortisol, testosterone, and DHEA in boys and girls during puberty. Chronobiology International, 24(5), 969-990.

McEwen, B. S., \& Seeman, T. (1999). Protective and damaging effects of mediators of stress: elaborating and testing the concepts of allostasis and allostatic load. Annual New York Academy of Sciences, 89(6), 30-47.

McGee, E. M. (2006). The Healing circle: Resiliency in nurses. Issues in Mental Health Nursing, 27, 43-57.

Moss, H. B., Vanyukov, M., Yao, J. K., \& Kirillova, G. P. (1999). Salivary cortisol responses in prepubertal boys: the effects of Parental substance abuse and association with drug use behavior during adolescence. Society of Biological Psychiatry, 45, 1293-1299. 
Nater, U. M., Marca, R. L., Florin, L., Moses, A., Langhans, W., Koller, M. M., et al. (2006). Stress-induced changes in human salivary alpha- amylase activity-association with adrenergic activity. Psychoneuroendocrinology, 31, 49-58.

Nater, U. M., \& Rohleder, N. (2009). Salivary alpha-amylase as a non-invasive biomarker for the sympathetic nervous system: current state of research. Psychoneuroendocrinology, 34, 486-496.

Nater, U. M., Rohleder, N., Schlotz, W., Ehlert, u., \& Kirschbaum, C. (2007). Determinants of the diurnal course of salivary alpha-amylase. Psychoneuroendocrinology, 32, 392-401.

Netherton, C., Goodyer, I., Tamplin, A., \& Herbert, J. (2004). Salivary cortisol and dehydroepiandrosterone in relation to puberty and gender. Psychoneuroendocrinology, $29(2), 125-140$.

Nicolson, N. A. (2004). Childhood parental loss and cortisol levels in adult men. Psychoneuroendocrinology, 29(8), 1012-1018.

Papageorgiou, V., Frangou-Garunovic, A., Iordanidou, R., Yule, W., Smith, P., \& Vostanis, P. (2000). War trauma and psychopathology in Bosnian refugee children. European Child \& Adolescent Psychiatry, 9, 84-90.

Parson, E. R. (2000). Understanding children with war-zone traumatic stress exposed to the world's violent environment. Journal of Contemporary Psychotherapy, 30(4).

Patterson, J. M. (2002). Integrating family stress and family stress theory. Journal of Marriage and the Family, 64(2), 349-360.

Pfeffer, C. R., Altemus, M., Heo, M., \& Jiang, H. (2006). Salivary Cortisol and Psychopathology in Children Bereaved by the September 11, 2001 Terror Attack. Biological Psychiatry, $10,1016-1024$. 
Porth, C. M. (2005). Pathophysiology concept of altered health states (seventh edition ed.): Lippincott Williams \& Wilkins.

Quirin, M., Pruessner, J. C., \& Kuhl, J. (2008). HPA system regulation and adult attachment anxiety: Individual differences in reactive and awakening cortisol. Psychoneuroendocrinology, 33, 581-590.

Roberti, J. W., Harrington, L. N., \& Storch, E. A. (2006). Further psychometric support for the 10- item version of the perceived stress scale. Journal of College Counseling, 9, 135-147. Rohleder, N., Chen, E., Wolf, J. M., \& Miller, G. E. (2008). The psychobiology of trait shame in young women: extending the social self preservation theory. Health Psychology, 27(5), $523-532$.

Rohleder, N., Joksimovic, L., Wolf, J. M., \& Kirschbaum, C. (2004). Hypocortisolism and increased glucocorticoid sensitivity of pro-inflammatory cytokine production in Bosnian war refugee with posttraumatic stress disorder. Biological Psychiatry, 55, 745-751.

Rohleder, N., \& Nater, U. M. (2009). Determinants of salivary $\alpha$-amylase in humans and methodological considerations. Psychoneuroendocrinology, 34, 469-485.

Rohleder, N., Nater, U. M., Wolf, J. M., Ehlert, U., \& Kirschbaum, C. (2004). Psychosocial stress-induced activation of salivary alpha-amylase: an indicator of sympathetic activity? Annual New York Academy of Sciences, 1032, 258-263.

Rosenheck, R., \& Fontana, A. (1998). Transgenerational effect of abusive violence on the children of Vietnam combat veterans. Journal of Traumatic Stress, 11(4), 731-742.

Rosmalen, J. G. M., Oldehinkel, A. J., Ormel, J., Winter, A. F. d., Buitelaar, J. K., \& Verhulst, F. C. (2005). Determinants of salivary cortisol levels in 10-12 year old children; a 
population- based study of individual diffrences. Psychoneuroendocrinology, 30, 483495.

Rutter, M. (1985). Resilience in the face of adversity: protective factors and resistance to psychiatric disorders. British Journal of Psychiatry, 147, 598-611.

Rutter, M. (1999). Resilience concepts and findings: implications for family therapy. Journal of Family Therapy, 21, 119-144.

Salimetrics. (2009 A). Expanded range high sensitivity salivary cortisol enzyme immunoassay kit [Electronic Version]. Retrieved April 9, 2009 from http://www.salimetrics.com/assets/documents/products-and-services/salivaryassays/ER\%20Cort\%20Research\%20Kit\%20Insert,\%208x11,\%20with\%20controls,\%20 5-5-09.pdf.

Salimetrics. (2009 B). Salivary $\alpha$ - amylase assay kit. April 9, 2009, from http://www.salimetrics.com/assets/documents/products-and-services/salivaryassays/Amylase\%20Kit\%20Insert,\%208x11,\%205-5-09.pdf

Sapse, A. T. (1997). Cortisol, high cortisol disease and anti-cortisol therapy. Psychoneuroendocrinology, 22, S3-S10.

Selye, H. (1936). A syndrome produced by diverse nocuous agents The Journal of neuropsychiatry and clinical neurosciences $138,32$.

Sephton, S. E., Sapolsky, R. M., Kraemer, H. C., \& Spiegel, D. (2000). Diurnal cortisol as a predictor of breast cancer survival. Journal of the National Cancer Institute, 92(12), 9941000.

Shalev, A. Y. (2000). Biological responses to disasters. Psychiatric Quarterly, 17(3), 277-288. 
Shirtcliff, E. A., \& Essex, M. J. (2008). Concurrent and longitudinal association of basal and diurnal cortisol with mental health symptoms in early adolescence. Development Psychobiology, 50, 690-703.

Simeon, D., Yehuda, R., Cunill, R., Knutelska, M., Putnam, F. w., \& Smith, L. M. (2007). Factors associated with resilience in healthy adults. Psychoneuroendocrinology, 32, 1149-1152.

Sjogren, E., Leanderson, P., \& Kristenson, M. (2006). Diurnal cortisol levels and relations to psychosocial factors in a population sample of middle-aged Swedish men and women. International Journal of Behavioral Medicine, 13(3), 193-200.

Smith, P., Perrin, S., Dyrgrov, A., \& Yule, W. (2003). Principal components analysis of the impact of event scale with children in war. Personality and Individual Differences, 34, 315-322.

Smyth, J. M., Ockenfels, M. C., Gorin, A. A., Cately, D., Porter, L. S., Kirschbaum, C., et al. (1997). Individual differences in the diurnal cycle of cortisol. Psychoneuroendocrinology, 22(2), 89-105.

Souza, E. B. D., \& Appel, N. M. (1991). Limbic pathways and neurotransmitters as mediators of autonomic and neuroendocrine responses to stress. In M. R. Brown, G. F. Koob \& C. Rivier (Eds.), Stress Neurobiology and Neuroendocrinology (pp. 91-117). New York: Marcel Dekker.

Spiegel, D., Giese-Davis, J., Taylor, C. B., \& Kraemer, H. (2006). Stress sensitivity in metastatic breast cancer: Analysis of hypothalamic-pitutary-adrenal axis.

Psychoneuroendocrinology, 31, 1231-1244. 
Stegern, A. v., Rohleder, N., Everaerd, W., \& Wolf, O. T. (2006). Salivary alpha amylase as a marker for adrenergic activity during stress: effect of betablockade. Psychoneuroendocrinology, 31, 137-141.

Thabet, A. A. M., Abed, Y., \& Vostanis, P. (2002). Emotional problems in Palestinian children living in a war zone: a cross-sectional study. Lancet, 359, 1801-1804.

Thabet, A. A. M., Abed, Y., \& Vostanis, P. (2004). Comorbidity of PTSD and depression among refugee children during war conflict. Journal of Child Psychology and Psychiatry, 45(3), 533-542.

Thabet, A. A. M., Karim, K., \& Vostanis, p. (2006). Trauma exposure in pre-school children in war zone. British Journal of Psychiatry, 188, 154-158.

Thabet, A. A. M., \& Vostanis, P. (1999). Post-traumatic stress reactions in children of war. The Journal of child psychology and psychiatry and allied disciplines, 40, 385-391.

Toner, I. J. (1993). Children and political violence in Northern Ireland: From riots to reconcilliation. In L. A. Leavitt \& N. A. Fox (Eds.), The psychological effects of war and violence on children (pp. 215-230): Hillsdale, N. J: L. Erlbaum Associates.

Tornhage, C.-J. (2003). Reference values for morning salivary cortisol concentrations in healthy school-aged children. Journal of Pediatric Endocrinology \& Metabolism, 15, 197-204.

Truckenmiller, M. E., Bonneau, R. H., \& Norbury, C. C. (2006). Stress presents a problem for dendritic cells: Corticosterone and the fate of $\mathrm{MCH}$ class 1 antigen processing and presentation. Brain, Behavior, and Immunity, 20, 210-218.

Tucker, P. M., Pfefferbaum, B., North, C. S., Kent, A., Burgin, C. E., Parker, D. E., et al. (2007). Physiologic reactivity despite emotional resilience several years after exposure to terrorism. The American Journal of Psychiatry, 164, 230-235. 
Turner, J. M. (2005). Psychological and stress hormone correlates in early life: a key to HPAaxis dysregulation and normalization. Stress, 8(1), 47-57.

Ursano, R. J. (2007). Children of war and opportunities for peace. Journal of the American Medical Association, 298(5), 567-568.

Walsh, F. (2002). A family Resilience Framework: innovative practice applications. Family Relations, 51(2), 130-137.

Watson, J. M., Logan, H. L., \& Tomar, S. L. (2008). The influence of active coping and perceived stress on health disparities in a multi-ethnic low income sample. BMC Public Health, 8(41).

Weidner, G., Hutt, J., Connor, S. L., \& Mendell, N. (1992). Family stress and coronary risk in children. Psychometric Medicine, 54, 471-479.

Weine, S. M., Becker, D. F., Vojvoda, D., Hodzic, E., Sawyer, M., Hyman, L., et al. (1998). Individual change after genocide in Bosnian survivors "of ethnic cleansing": assessing personality dysfunction. Journal of Traumatic Stress, 11(1), 147-153.

Werner, E. E. (1992). The children of Kauai: resiliency and recovery in adolescence adulthood. Journal of Adolescent Health, 13, 262-268.

Werner, E. E., \& Smith, R. S. (1982). Vulnerable but invincible: A longitudinal Study of Resilient Children and Youth. USA: R. R. Donnelley and sons, Inc.

Wolf, J. M., Nicholls, E., \& Chen, E. (2008). Chronic stress, salivary cortisol, and $\alpha$-amylase in children with asthma and healthy children. Biological Psychology, 78, 20-28.

Worth, D., Metcalfe, S., Boyd, J., Worrall, A., \& Canarutto, P. (2009). Health and human rights in the Palestinian West Bank and Gaza. The Lancet, 373(9660), 295-296. 
Yehuda, R. (2002). Current status of cortisol in post-traumatic stress disorder. Psychiatric Clinics of North America, 25, 341-368.

Yehuda, R., Bierer, L. M., Schmeidler, J., Aferiat, D. H., Breslau, I., \& Dolan, S. (2000). Low Cortisol and Risk for PTSD in Adult Offspring of Holocaust Survivors American Journal of Psychiatry, 157, 1252-1259.

Yehuda, R., Flory, J. D., Southwick, S., \& Charney, D. S. (2006). Developing an agenda for translational studies of resilience and vulnerability following trauma exposure. New York Academy of Sciences, 1071, 379-396.

Zarkovic, M., Stefanova, E., Ciric, J., Penezic, Z., Kostic, V., Sumarac-Dumanovic, M., et al. (2003). Prolonged psychological stress suppresses cortisol secretion. Clinical Endocrinology, 59, 811-816. 
Appendixes 106

Appendixes 


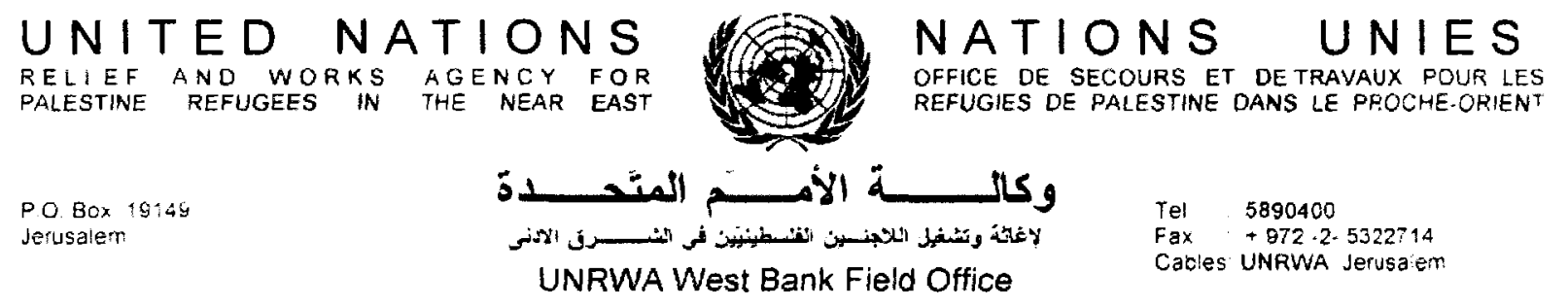

$153-466$

16 September. 2008

Dear Mr. Mohammad Asia,

1 would like to inform you that your dissertation study "Relationships of level of traumatic experienees, perceived stress, and resilience with eortisol diurnal rhythm among Palestinian children has been approved to be conducted at Nablus L.NRWA district schocls.

We are looking forward to see your important study findings and its contribution in developing future stress relief programs.

With Best Regards. 


\section{Demographic Data form}

Number(code):

1. I am A. Male-_-_-_-B. Female--_-_-_-_-

2. My age is A. 9 years--...-..-

B. 10 years----------

C. 11 years---------

D. 12 years --.-.-.-

E. 13 years---------

3. My academic performance is: A. Excellent-

4. My family income: A. High and adequate---------

B. Average but enough----.----

C. Very poor and inadequate---.--..-- 


\section{Traumatic stress events}

Please mark in front of each statement by $(\mathrm{X})$ for any traumatic experience that you have exposed to in the last several months resulting from the Israeli army incursion to your town:

\begin{tabular}{|c|l|l|l|}
\hline & \multicolumn{1}{|c|}{ Traumatic event } & Yes & No \\
\hline 1. & Hearing killing of father, brother, a friend or close relative & & \\
\hline 2. & Hearing shelling of the areas close to your town by heavy artillery & & \\
\hline 3. & Hearing arrest or kidnapping of someone & & \\
\hline 4. & Witnessing the arrest of your father, brother or any family member & & \\
\hline 5. & Witnessing killing of a friend or a close relative & & \\
\hline 6. & Witnessing killing of a father, brother, or a close relative & & \\
\hline 7. & Witnessing shooting of a friend & & \\
\hline 8. & Witnessing shooting of a father, brother, a friend or a close relative & & \\
\hline 9. & Witnessing your own home demolition & & \\
\hline 10. & Witnessing your neighbor's house demolition & & \\
\hline 11. & Witnessing firing by tanks and heavy artillery at neighbors homes & & \\
\hline 12. & Witnessing firing by tanks and heavy artillery at your own home & & \\
\hline 13. & Watching mutilated bodies and wounded people on television & & \\
\hline 14. & Witnessing assassination of street fighters & & \\
\hline 15. & Exposed to physical injury due to random shooting & & \\
\hline 16. & Exposed to detainment at home & & \\
\hline 17. & Exposed to beating and humiliation & & \\
\hline 18. & Exposed to deprivation from water, food, electricity, or toileting & & \\
\hline 19. & Exposed to shooting to get you scared & & \\
\hline 20. & Exposed to destruction of your personal belonging during incursion & & \\
\hline 21. & Exposed to threat to be killed & & \\
\hline 22. & Exposed to threat by killing a family member & & \\
\hline 23. & Exposed to severe danger during street shootings & & \\
\hline 24 & Exposed to detainment for couple of hours by a military barrier & & \\
\hline 25. & Exposed to arrest and imprisoning & & \\
\hline 26. & Prevented from going to your school or coming back to your home & & \\
\hline
\end{tabular}

Please mention any other traumatic experience not listed above: 1 . . 


\section{Perceived stress instrument (Child version)}

Instructions: The questions in this instrument ask you about your feelings and thoughts during the last couple of months. Please indicate your response by placing an " $\mathrm{X}$ " marks in front each statement representing how often you felt or thought a certain way.

\begin{tabular}{|c|c|c|c|c|c|c|}
\hline No. & Statements & Never & $\begin{array}{l}\text { Almost } \\
\text { Never }\end{array}$ & $\begin{array}{l}\text { Some- } \\
\text { times }\end{array}$ & $\begin{array}{l}\text { Fairly } \\
\text { often }\end{array}$ & $\begin{array}{l}\text { Very } \\
\text { often }\end{array}$ \\
\hline 1. & $\begin{array}{l}\text { How often have you been upset because of something that happened } \\
\text { unexpectedly? }\end{array}$ & & & & & \\
\hline 2. & $\begin{array}{l}\text { How often have you felt that you were unable to control the important } \\
\text { things in your life? }\end{array}$ & & & & & \\
\hline 3 & How often have you felt nervous and "stressed"? & & & & & \\
\hline 4 & How often have you solved an upsetting problem? & & & & & \\
\hline & How often have been able to understand changes in your life? & & & & & \\
\hline 6. & $\begin{array}{l}\text { How often have you felt confident about your ability to handle your } \\
\text { personal problems? }\end{array}$ & & & & & \\
\hline 7 & How often have you felt that things were going your way? & & & & & \\
\hline 8. & $\begin{array}{l}\text { How often have you found that you were not able to do the things that } \\
\text { you had to do? }\end{array}$ & & & & & \\
\hline 0 & How often have you been able to handle problems in your life? & & & & & \\
\hline 10 & How often have you felt happy? & & & & & \\
\hline & How often have you been angry because you can't change things? & & & & & \\
\hline 12. & $\begin{array}{l}\text { How often have you found yourself thinking about things you have to } \\
\text { do? }\end{array}$ & & & & & \\
\hline & How often have you been able to spend your time as you would like? & & & & & \\
\hline 14. & $\begin{array}{l}\text { How often have you felt frustrated by problems at home, school, and } \\
\text { neighborhood? }\end{array}$ & & & & & \\
\hline
\end{tabular}




\section{Perceived stress instrument (parents' version)}

Instructions: The questions in this instrument ask you about your feelings and thoughts during the last couple of months. Please indicate your response by placing an " $X$ " mark in front each statement representing how often you felt or thought a certain way.

\begin{tabular}{|c|c|c|c|c|c|c|}
\hline No. & Statements & Never & $\begin{array}{l}\text { Almost } \\
\text { Never }\end{array}$ & $\begin{array}{l}\text { Some- } \\
\text { times }\end{array}$ & $\begin{array}{l}\text { Fairly } \\
\text { often }\end{array}$ & $\begin{array}{l}\text { Very } \\
\text { often }\end{array}$ \\
\hline 1. & $\begin{array}{l}\text { How often have you been upset because of something that happened } \\
\text { unexpectedly? }\end{array}$ & & & & & \\
\hline 2. & $\begin{array}{l}\text { How often have you felt that you were unable to control the important } \\
\text { things in your life? }\end{array}$ & & & & & \\
\hline & How often have you felt nervous and "stressed"? & & & & & \\
\hline 4. & $\begin{array}{l}\text { How often have you dealt successfully with day to day problems and } \\
\text { annoyances? }\end{array}$ & & & & & \\
\hline 5. & $\begin{array}{l}\text { How often have you felt that you were effectively coping with } \\
\text { important changes that were occurring in your life? }\end{array}$ & & & & & \\
\hline 6. & $\begin{array}{l}\text { How often have you felt confident about your ability to handle your } \\
\text { personal problems? }\end{array}$ & & & & & \\
\hline & How often have you felt that things were going your way? & & & & & \\
\hline 8. & $\begin{array}{l}\text { How often have you found that you could not cope with all the things } \\
\text { that you had to do? }\end{array}$ & & & & & \\
\hline 0 & How often have you been able to control irritations in your life? & & & & & \\
\hline 10 & How often have you felt that you were on top of things? & & & & & \\
\hline 11. & $\begin{array}{l}\text { How often have you been angered because of things that happened that } \\
\text { been outside of your control? }\end{array}$ & & & & & \\
\hline 12. & $\begin{array}{l}\text { How often have you found yourself thinking about things that you } \\
\text { have to accomplish? }\end{array}$ & & & & & \\
\hline & How often have you been able to control the way you spend your time? & & & & & \\
\hline 14. & $\begin{array}{l}\text { How often have you felt difficulties were piling up so high that you } \\
\text { could not overcome them? }\end{array}$ & & & & & \\
\hline
\end{tabular}




\section{H \& H RESILIENCE SCREENING TOOL Copyright @ 2001 A.J. Hunter \& K.P. Hurtes}

For the following statements, please circle the number that best describes you and your feelings:

\begin{tabular}{|l|l|l|l|l|l|}
\hline & $\begin{array}{l}\text { Strongly } \\
\text { Disagree }\end{array}$ & Disagree & Neutral & Agree & $\begin{array}{c}\text { Strongly } \\
\text { Agree }\end{array}$ \\
\hline 1. I know what I want to be when I grow up. & 1 & 2 & 3 & 4 & 5 \\
\hline 2. I want to be like the adults I know & & & & & \\
\hline 3. Most adults like me. & & & & & \\
\hline $\begin{array}{l}\text { 4. The rules I have to follow are the same } \\
\text { ones everyone else has to follow }\end{array}$ & & & & & \\
\hline 5. I like myself & & & & & \\
\hline 6. I am happy most of the time & & & & & \\
\hline 7. I try to learn something from each problem & & & & & \\
\hline $\begin{array}{l}\text { 8. I feel most people can be trusted } \\
\text { 9. I have someone I can depend on to help me } \\
\text { solve my problems }\end{array}$ & & & & & \\
\hline 10. My family will be there when I need them & & & & & \\
\hline 11. My friends know they can count on me. & & & & & \\
\hline $\begin{array}{l}\text { 12. When someone tells me my work is not } \\
\text { good, I try harder next time. }\end{array}$ & & & & & \\
\hline $\begin{array}{l}\text { 13. I can deal with whatever happens in the } \\
\text { future }\end{array}$ & & & & & \\
\hline $\begin{array}{l}\text { 14. Once I know what I want, I don't let } \\
\text { anything stop me from getting it. }\end{array}$ & & & & & \\
\hline 15. I learn from my mistakes & & & & & \\
\hline $\begin{array}{l}\text { 16. I can tell how people are feeling when I } \\
\text { look at their face }\end{array}$ & & & & & \\
\hline $\begin{array}{l}\text { 17. I can imagine the consequences of my } \\
\text { actions. }\end{array}$ & & & & & \\
\hline 18. I know when I am good at something. & & & & & \\
\hline $\begin{array}{l}\text { 19. I'm prepared to deal with the } \\
\text { consequences of my action }\end{array}$ & & & & & \\
\hline $\begin{array}{l}\text { 20. I can say "no" to things I don't want to } \\
\text { do. }\end{array}$ & & & & & \\
\hline $\begin{array}{l}\text { 21. I can change my behavior to match the } \\
\text { situation. }\end{array}$ & & & & & \\
\hline $\begin{array}{l}\text { 22. My ability to laugh makes it easier to deal } \\
\text { with tough situations. }\end{array}$ & & & & & \\
\hline 23. I can change my surroundings & & & & \\
\hline $\begin{array}{l}\text { 24. When something goes wrong, I can tell if } \\
\text { it was my fault. }\end{array}$ & & & & & \\
\hline
\end{tabular}




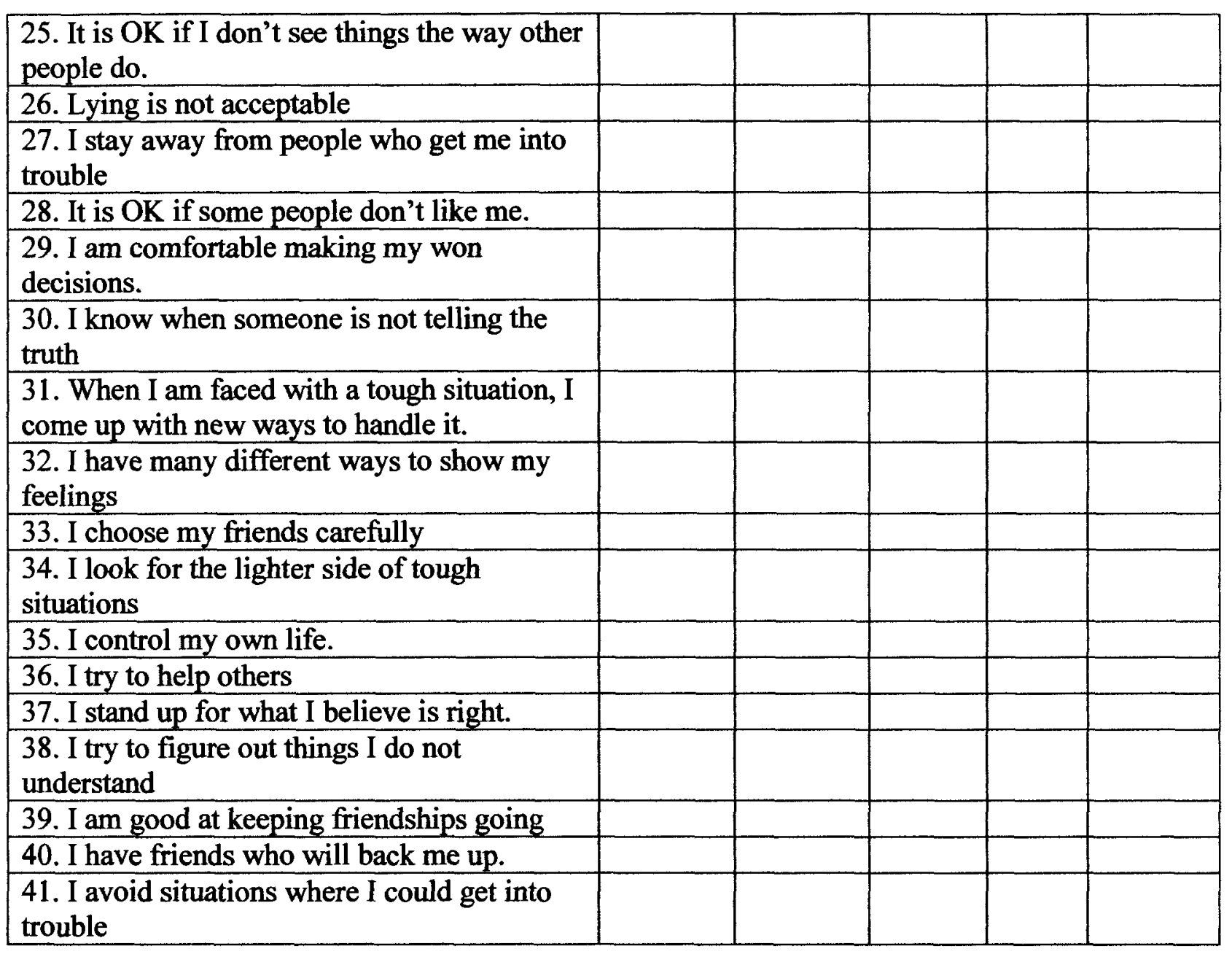


Appendix H: Parent/Guardian Consent 115

\section{PARENT/GUARDIAN CONSENT}

Relationship of level of traumatic experiences, perceived stress, and resilience with cortisol\& alpha-amylase diurnal rhythm in Palestinian children 10-12 years exposed to chronic war violence

Dear Parent or Guardian,

You and your child are being asked to be a part of a research study that looks at children's physiologic response to trauma and stress. This research study is being conducted by Mohammad Asia, a registered nurse, as part of his doctoral dissertation at the University of San Diego, School of Nursing. This study is not being sponsored by the UNRWA Nablus district schools. You and your child do not have to participate if you don't want to. Nothing about your child's schooling, grades, your family's access to social services or health care or anything else will change if you decide not to do this.

\section{What you are being asked to do:}

- You and your child will attend a workshop that will be held in a large classroom at Ain Beit Elma elementary boy's school for boy participants or at Ain Beit Elma elementary girl's school for girl participants. It will last about an hour and a half. Other children and their parents from your town will attend this workshop.

- You will be asked to fill one research instrument that asks you questions about your perceived stress in the last couple of months. This will take about 5 minutes.

- There is also a fifty percent chance that your child might be invited to participate in an extra activity in which your child will be asked to deliver a morning and bedtime salivary samples. Those saliva samples will be tested for a hormone response called cortisol that is released when people are exposed to stress. If your child is randomly chosen for this extra activity, Mohammad will provide you and your child with a thorough education and training on the appropriate method to collect those samples and will provide all the supplies required for this collection at the end of the workshop.

What your child will be asked to do:

- To attend the workshop with you

- To complete 5 forms that Mohammad will give your child: 1) a permission form (called an "Assent Form") for him or her to read and sign; 2) a brief questionnaire that asks 
about his/her gender, age, schooling performance and family income; 3) another that asks about the types of traumatizing experiences that occurred in the last couple of months; 4) another that asks about his/her feelings of stress; and 5) the last that asks about your child's response to stress and overcoming stress.

- The whole process will take about 30 minutes. The forms are presented in a version for kids to understand. It might take kids a bit longer (up to 30 minutes) to fill these out, but Mohammad will be there to help them. Your child will be reminded that he or she can stop anytime they want to, or decide they just don't want to do this. There will be a restroom close by, and Mohammad will give your child a chance to take a break and visit the restroom or relax after finishing the forms.

- You and your child may be asked to stay for another 30 minutes session if he/she was selected to collect a morning and bedtime salivary samples. You and your child will receive education on how to collect those samples and Mohammad will provide you and your child the needed supplies for saliva collection. A written protocol on how to collect those samples at home will be provided before you leave the workshop.

- Your child will be asked to bring the samples back to their schools the following day.

\section{You and your child's participation in this studv are:}

Voluntary. You and your child do not have to do any of this. Nothing about your child's grades, his/her schooling, or family's access to social services or health care if you choose not to do this. You and your child can decide at any time to quit.

Confidential. No names will be recorded or attached to the survey forms or data. All consent/assent forms will be stored separately from data. Only code numbers will be used on data forms. All data will be kept in a locked file cabinet and only Mohammad Asia will have access. All data and forms will be destroyed within 5 years. The results will be reported on a group basis, and neither your child's identity nor his or her school will ever be identified in reporting the results.

Potential Risks. If you or your child becomes tired while filling out the forms or participating in the study, you or your child can take a break and rest. Sometimes when adults are asked things about psychosocial issues like their perceived stress, they feel emotions like anxiety. Also, 
sometimes kids feel anxious or sad when asked about their traumatic events and its related stress. If you or your child would like to discuss these feelings, you can call the Public Mental Health Clinic at (04-293-9022) and the Palestinian Red Crescent Mental Health Department at (04250-1973).

Further Information. If you would like to know more about this research study before, during, or after your child's participation in it-You can call Mohammad Asia (0598) 218-160 or e-mail him at pediatric2000@yahoo.com. You can also call Nisreen Jamil at (054) 306-4373. You can also call his professor, Dr. Anita Hunter, at (011972 619)260-7609 or e-mail her at ahunter@sandiego.edu.

I have read and understand this form, and consent to the research it describes to me. I have received a copy of this consent form for my records. 


\section{Child Assent Form}

Relationship of level of traumatic experiences, perceived stress, and resilience with cortisol\& alpha amylase diurnal rhythm in Palestinian children 10-12 years exposed to chronic war violence

My name is Mohammad Asia. I am a doctoral student in nursing at the Hahn School of Nursing and Health Science at the University of San Diego. I am inviting you to help me with my research project. I am studying kids that are your age to try and find out how much you're traumatic experiences, stress, and ability to overcome that stress are affecting your health.

The part I need your help with doing 2 things:

1. Completing some questionnaires. A questionnaire is a survey, like on TV where they ask people what they think about stuff. It's not like a test at school. You don't need to feel embarrassed if you can't answer the questions, or just don't want to. Nobody is going to grade it. Nobody will know that it's your questionnaire, because your name will not be on it, just a number. You will be asked stuff about you, and then asked other stuff about the traumas you have seen and the feelings you have when you are stressed or face adversities, as well as questions about how you deal with that stress. It will probably take 30 minutes to fill out these forms. If you decide there are questions you don't want to answer, that is perfectly OK. You can skip them. No one will be mad at you. I will not share any information that you give me with anyone. Any papers that I collect from you will be locked up in a safe place so that no one can see them except me. At some point I may talk to other nurses and doctors at meetings and write about what I find in magazines for doctors and nurses, but I will never use your names or the name of your school.

2. The second thing I might ask you to do is to collect two saliva samples at home. I will teach you and your parents how to do this. All you will need to do is to chew a piece of cotton once in the morning and again at night. If you decide you don't want to do this, or changed your mind, it is ok. No one will be mad at you. 
You do not have to help me with this project. You can say "No, thank you," and it will not affect your grades at school or any of your family benefits. No one will be mad or disappointed in you if you don't want to work with me on this research project.

If you do decide to work with me and get tired answering the questions, you can take time to rest. You don't have to answer any questions or give me any information that you don't want to give me. If you want to quit, you can do that too. Sometimes when kids think about stuff like the trauma they have seen and the stress they feel, they get upset or nervous. If you feel that way, be sure to let your parent/guardian know. They or you can call the Public Mental Health Clinic at (04-293-9022) and the Palestinian Red Crescent Mental Health Department at (04-2501973 ) any time. If you have any questions about this study your parents know how to contact me.

By signing my name here, I am saying: Yes, I want to do this.

Signature of Participant

Please print your name on this line. 
Relationship of Level of Traumatic Experiences, Perceived Stress, Resilience with Cortisol \& alpha- amylase Diurnal Rhythm STUDY

Principal Investigator: Mohammad Asia

University of San Diego, Hahn School of Nursing and Health Sciences

\section{INSTRUCTIONS FOR COLLECTING SALIVA SPECIFIMENS}

We are measuring the cortisol hormone using saliva specimens. You are going to collect one morning saliva specimen shortly after awakening and another saliva specimen before you go to bed. To properly collect the specimens, you should:

\section{Sample \#1}
a. Wake up between 6:00 and 8:00 a.m.
b. Do not eat or drink anything before collecting the specimen
c. First, after you wake up, RINSE your mouth with plain water (tap water)
d. Second, remove the cotton roll from the plastic saliva collection cylinder you were given and place it in your mouth.
e. Third, chew on the cotton roll but DO NOT SWALLOW for at least one minute (the cotton rolls will take up the saliva in your mouth as you chew)
f. Fourth, return the chewed roll to the cylinder and firmly close the tube with the stopper. Put the date, time and number 1 on the tube. Store the tube in the refrigerator not the freezer.

\section{Sample \#2}

a. Before you go to bed collect the second sample.

b. DO NOT EAT OR DRINK ANYTHING for one hour prior to collecting sample.

c. Follow the same procedure as above

i. Rinse your mouth with tap water,

ii. Remove the cotton roll,

iii. Chew the cotton roll for one minute and then return it to the plastic saliva collection cylinder.

iv. Put the date, time and number 2 and store in the refrigerator also and not the freezer.

3. Bring both specimens to your school in the following day. We will be waiting in your school to take them.

4. Please call the researcher's study phone number if you have to change the date of the study or otherwise have any questions (study phone number: 0958-218-160)

Thank you so much for your participation 
Relationships of Traumatic Exposure, Perceived Stress, Resilience with Cortisol \& Salivary a-Amylase diumal pattern in Palestinian Children 10- 12 years

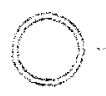

BY

MOHAMMAD R. ASIA RN, PHDC

COMMITTEE:

DRS. HUNTER, HOWLAND, BURKARD, GEORGES

CONSULTANT: DR. HAZEN

\section{What is the problem?}

- Exposure of children to war adversity might increase their risk of developing mental health problems, PTSD, emotional and behavioral disorders, physical and psychobiological disorders (Bellis, 2001; Elzinga et al., 2008; Joshi \& O'Dennell, 2003).

- However variables such as family, social \& community support, age, are expected to mediate the impact of trauma (Fremont, 2005). May not enough to buffer war adversity.

u Prior studies on Palestinian children confirmed the existence of the aforementioned psychiatric and behavioral disorders (Elbedour et al, 2007; Thabet, Abed, \& Vostanis, 2002, 2004); however, potential biological consequences of such adversity is not yet available. 


\section{War and Traumatic Stress/ Background}

- Lebanese children: Macksound \& Aber (1996) study, revealed PTSD in most subjects and depression related to parental separation.

a Bosnian studies: Personality changes (Weine et al., 1998); PTSD 28\%, 47\% depression, 23\% anxiety disorders (Papageorgiou et al., 2000); hypocortisolism in two studies ( Hercigonja et al., 1996); (Rohleder et al., 2004).

Palestine studies: PTSD (68.9\% of 230 adolescents, and $>50 \%$ of 200 children ages 6-11), moderate to severe depression, severe anxiety levels, and undesirable coping responses (Elbedour et al., 2007; Thabet \& Vostanis, 1999; Thabet et al., 2002) .Thabet et al., (2006)behavioral and emotional problems in young 3-6 years.

- Children 7-12 years(concrete thinking) exhibit fearfulness, confusion, anxiousness, behavioral regression, somatization, insecurity, guilt, dissociation, loss of interest in activities\& school when exposed to war trauma(Joshi\& O'Dennell , 2003)

\section{Resilience\& vulnerability}

o Resilience can encompass the positive qualities of personal growth as well as the phenomena of emotional insulation and survival - overcoming adversity any way possible without quitting (Hinds, Burghen, Haase, \& Phillips, 2006; Hunter, 2001; Hunter \& Chandler, 1999).

o survival resilience is an unhealthy adaptation to adversity, and if left unchecked, deepens the insulation, isolation, and disconnecting, numbing, and aggressive/violent reactions to the stressors and may lead to pathopsychosocial and physical problems (Hunter \& Chandler, 1999; Hunter, 2001b). 


\section{Biological stress response}

$\checkmark$ stress - activation of two neurobiological systems, the Autonomic (Sympathetic/Parasympathetic) nervous system and the Hypothalamic Pitutary- Adrencortical axis (HPA).

a Cortisol diurnal patterns - the HPA axis response in an individual's stress responses within 30-45 minutes of awakening and then steadily declines through the day and evening to its lowest level at night prior to sleep (Gunnar et al., 2001; Kelly et al., 2008). $\longrightarrow$

acute stress response - salivary $a$-amylase as a surrogate marker of the sympathetic nervous system responsivity (Kivlighan \& Granger, 2006).

salivary $\alpha$-amylase has an opposite diurnal pattern where levels of $\alpha$ amylase dropped sharply after awakening and then increased steadily thereafter with highest levels in the afternoon and evening( Rohleder, Nater et al., 2004)

\section{HPA dysregulation}

\section{HPA dysregualtion}

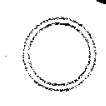

a High cortisol precedes the development of diseases and has been associated with infectious diseases, autoimmune conditions, mental health, and behavioral disorders (Charney, 2004; Sapse, 1997).

a hypocortisolism appear to affect brain development, inhibit growth factors that might facilitate neural cell death and alter cognitive functioning (Yehuda, et al., 2000); found in children with PTSD, neglect, abuse, behavioral problems in schools, and those exposed to chronic stress (Heim et al., 2000).

a flat cortisol diurnal pattern had been associated with neglected, maltreated children, dwarfism, lack of school performance, maladaptation and lack of coping, mother's of insecure attachment, infants with colic, orphaned children, physical disorders such as fibromyalgia, chronic fatigue syndromes, infectious diseases and asthma (Adam \& Gunnar, 2001; Gunnar \& Vazquez, 2001). 


\section{Conclusions about existing research}

$\checkmark$ Children are prone to altered Cortisof and $\alpha$-amylase diurnal pattern in the face of stress and adversity

口 A normal and steeper cortisol diurnal rhythm is associated with good health outcome while flatter slopes of cortisol are associated with poor health outcomes.

a-amylase is still an unknown and has yet to be determined whether it is an acute or a chronic stress response

a early childhood psychological stressors have been evidenced to affect the HPA response to cause undesirable health outcomes later in life.

Children can exhibit healthy and less than healthy adaptations to stress; they may say they are doing well when physically they are suffering significantly; and they are highly influenced by the stress response of their family.

\section{Why am I interested?}

- grave concerns about the long-term physical and psychosocial health problems these children may face when they reach adulthood.

- Need to investigate the relationship of stress and psychobiological health in Palestinian children in the midst of high rates of PTSD and psychiatric disorders.

* assessing the neurobiological contribution to resilient adaptation of children to adversity is important for implementing early prevention and treatment of potential alterations (Curtis \& Cicchetti, 2003; Hunter, 2001b)

- Since salivary a- amylase has an opposite pattern to cortisol diurnal rhythm, this assessment in conjunction with cortisol may help identify if an abnormal stress biomarkers' diurnal pattern exists. 


\section{Gaps in the literature}

- The biological contributions and implications of chronic war stress on children has been assessed in a very limited capacity.

- No studies have examined the impact of chronic war violence with the Salivary a-amylase diurnal activity.

- There is limited literature documenting the relationship between neurobiology and resilience.

- There is a lack of complementary studies on both psychological and biological dimensions of stress physiology among resilient children under chronic war stress exposure.

- My study assessed the impact of chronic war stress in Palestinian children on their psychosocial and biological responses.

\section{Theoretical Framework}

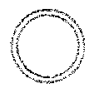

- The study was grounded in Lazarus (1994) model of stress, coping, and adaptation

○ Stress was measured by the trauma exposure scale\&PSS

o Coping was assessed by the $\mathrm{H} \& \mathrm{H}$ Resilience scale

o Biological adaptation was assessed by cortisol and aamylase levels diurnal pattern 


\section{Research Questions}

- What was the relationship of demographic variables, level of trauma exposure, perceived stress, and resilience, with cortisol diumal activity in Palestinian children, ages 10-12, exposed to chronic war violence?

What was the relationship of demographic variables, level of trauma exposure, perceived stress, and resilience, with a-amylase diumal activity in Palestinian children, ages 10-12, exposed to chronic war violence?

What was the relationship of demographic variables, level of trauma exposure, and perceived stress with resilience and resilience skills levels of Palestinian children, ages 10-12, exposed to chronic war violence?

What was the relationship between parents' and their child's perceived stress scores?

\section{Methodology}

$\checkmark$ Participants(150 children and 300 parents recruited to attend workshops

\section{口 Measures:}

$\therefore$ Demographic Questionnaire(age, gender, schooling, income)

* Level of Traumatic Exposure(LTE): Modified Gaza Traumatic Exposure Checklist with original reliability coefficient .90 and .80 in this study.

* Child\& parents perceived stress: Cohen Perceived Stress Scale(PSS) original reliability coefficient is .85 was and was $.63, .77$, and .68 for the CPSS, FPSS and MPSS respectively, congruent with $r=.68$ by Watson\& colleagues, 2008).

* Child Resilience(CR): H\& H Resilience Screening instrument original reliability coefficient is .91 and .87 when piloted in 2008 . For this study $r=.86$. 


\section{Methodology}

口 Salivary Biomarkers: Two samples (Kraemer,2006), within 10 minutes from awakening waking \& one hour prior to bedtime * Salivary cortisol measurement(Salimetrics, State College, PA)

* Salivary a-amylase Measurement (Salimetrics, State College, PA).

* Assay methodology by Salimetrics \& Granger (2006)

$*$ Norm range by Salimetrics AM cortisol=0.08-0.83 $\mu \mathrm{g} / \mathrm{dl}$ or (2.2- 22.9) $\mathrm{nmol} / \mathrm{L}$.

150

\section{Data Analysis}

$\checkmark$ SPSS version 15.0: Descriptive statistics \& Inferential statistics

$\because$ Research question \#1 answered (T-tests, ANOVA\& Pearson correlations)

$\therefore$ Research questions \#2 answered( T-tests, ANOVA\& Pearson correlation)

$*$ Research questions \#3 answered(T-tests, ANOVA\& Pearson correlations)

$*$ Research questions \#4 answered by (Pearson correlations).

口Cortisol\& a-amylase(T1 AM level- T2 PM levels) 


\section{Results}

\section{Subjects}

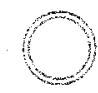

口 Participants were122 children ( 58 girls [47.5\%], 64 boys [52.5\%]), with a mean age of 11.2 years (Table 1); $79 \%$ were doing well in school and $67 \%$ came from families with moderate incomes.

$\checkmark$ All children completed the demographic, perceived stress, trauma exposure, and resilience questionnaires

$\square$ perceived stress scores were also obtained from 102 fathers and 101 mothers of the children.

- Only 37 of the 48 randomly selected child participants were able to provide sufficient morning and bedtime salivary samples to assess cortisol and $\alpha$-amylase levels.

- Participants reported the delivery of morning samples within 25 minutes from awakening. Means, range and standard deviation of study variables are presented in table 1.

Table (1) Means and Standard Deviations of Study Variables

\begin{tabular}{|c|c|c|c|c|}
\hline (4) & 1. & PFing & $(1+2)$ & 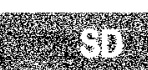 \\
\hline Child age & 122 & $10-12$ & 11.0 & .81 \\
\hline Child Stress Score & 122 & $7-51$ & 31.42 & 7.43 \\
\hline Father Stress Score & 102 & $6-46$ & 31.42 & 8.10 \\
\hline Mother Stress Score & 101 & $10-55$ & 29.94 & 7.16 \\
\hline Resilience Score & 115 & $84-188$ & 145.53 & 18.25 \\
\hline Traumatic Exposure Score & 121 & $2-24$ & 11.02 & 4.48 \\
\hline Cortisol AM Level $\mu \mathrm{g} / \mathrm{ml}$ & 37 & $.15-1.28$ & .41 & .24 \\
\hline Cortisol PM Level $\mu \mathrm{g} / \mathrm{ml}$ & 37 & $00-.11$ & .02 & .02 \\
\hline Cortisol Difference $\mu \mathrm{g} / \mathrm{ml}$ & 37 & $.13-1.24$ & .39 & .25 \\
\hline a-Amylase AM Level U/ml & 37 & $15.09-312.58$ & 86.40 & 54.81 \\
\hline a - Amylase PM Level U/ml & 37 & $12.46-243.38$ & 116.19 & 56.76 \\
\hline a-Amylase Difference U/ml & 37 & $-195.82-199.10$ & -29.37 & 74.95 \\
\hline
\end{tabular}


Table 2: Person conclations anong study variables

\begin{tabular}{|c|c|c|c|c|c|c|c|c|c|c|c|c|}
\hline He & $=4$ & 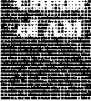 & WII & $\mid$ & Hat & 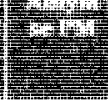 & 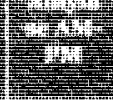 & 4 & 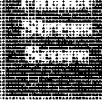 & 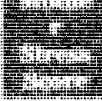 & 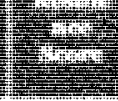 & $\sqrt{4}$ \\
\hline 1. & Cortisol AM & - & .13 & $.99^{*+*}$ & -.01 & .021 & -.17 & $35^{4}$ & .20 & $37^{*}$ & .03 & .19 \\
\hline 2. & Cortisol PM & & - & .04 & .29 & .24 & .03 & .20 & .08 & .02 & .03 & -.17 \\
\hline 3. & $\begin{array}{c}\text { Cortisol AM- } \\
\text { PM }\end{array}$ & & & - & -.04 & .19 & -.17 & $33^{*}$ & .19 & $.3^{*}$ & .03 & .21 \\
\hline 4. & Amylase Am & & & & - & .09 & $.66^{* * * 4}$ & .08 & .09 & .22 & .03 & -.18 \\
\hline 5 . & Amylase PM & & & & & - & |.69".6" & .25 & -.18 & -.15 & -.15 & -.18 \\
\hline 6. & $\begin{array}{l}\text { Amylase AM- } \\
\text { PM }\end{array}$ & & & & & & - & -.14 & .21 & .26 & .14 & .04 \\
\hline 7. & $\begin{array}{l}\text { Child Stress } \\
\text { Score }\end{array}$ & & & & & & & - & $36^{*+\cdots}$ & $36^{\circ+0 *}$ & -.04 & $.39^{2004}$ \\
\hline 8. & $\begin{array}{l}\text { Father Stress } \\
\text { Score }\end{array}$ & & & & & & & & - & $.65^{*+* *}$ & .08 & $33^{* *}$ \\
\hline 9. & $\begin{array}{c}\text { Mother } \\
\text { Stress Score }\end{array}$ & & & & & & & & & - & .02 & $.41^{* 6 * *}$ \\
\hline 10 & $\begin{array}{l}\text { Resilience } \\
\text { Score }\end{array}$ & & & & & & & & & & - &. .05 \\
\hline 11. & $\begin{array}{c}\text { Trauma } \\
\text { Score }\end{array}$ & & & & & & & & & & & - \\
\hline
\end{tabular}

Question(1): What is the relationship of demographic variables, level of trauma exposure, perceived stress, and resilience, with cortisol diumal activity in Palestinian children, ages 10-12 exposed to chronic war violence?

$\square$ Significant correlation found between child perceived stress scores (CPSS) and AM cortisol $(r=.35, p<.05)$ and between CPSS and positive cortisol difference, $r=.33, p<.05$.

- All participants demonstrated positive cortisol difference +(AM- PM) indicating their overall normal diurnal pattern meaning children in the face of war trauma appeared to be adapting biologically fairly well .

- Three male participants' (8.1\%) had AM cortisol levels exceeding the manufacturer Salimetries (2009) and other expected range; and, though not statistically significant, these three children also had high scores for CPSS, trauma exposure, high MPSS and FPSS scores

$\checkmark$ There were no overall significant associations between AM cortisol or cortisol difference with CRS, LTE, FPSS, gender, age, schooling achievement and household income. 
Question(1): What is the relationship of demographic variables, level of trauma exposure, perceived stress, and resilience, with cortisol diurnal activity in Palestinian children, ages 10-12, exposed ta chronic war violence? (cont'd)

$\square$ A significant correlation between child's AM cortisol levels and MPSS ( $r=.37, p<.05)$, as well as between positive cortisol difference and MPSS $(r=.38, p<.05)$ were found.

$\square$ There was a significant gender difference on PM cortisol $(t$ $=3.04, \mathrm{p}<.01,95 \% \mathrm{CI}=.01-.03)$.

$\square$ Boys had higher mean PM cortisol level $(M=.03, S D=$ .029) than girls $(M=.01, S D=.009)$.

$\square$ There was no significant PM cortisol difference with other variables.

Question 2: What is the relationship of demographic variables, level of trauma exposure, perceived stress, and resilience, with a-amylase diumal hythm in Palestinian children, ages 10-12, exposed to chronic war violence?

Though within normal range, $38 \%$ of the participants had positive $\alpha$ amylase difference. These participants demonstrated higher AM than PM a-amylase levels enough to cause reversed diurnal pattern. Was it because of stress or methodological error?

- The overall mean difference of $-29.37 \mathrm{U} / \mathrm{ml}$ indicates the normal $\alpha$ amylase pattern in the rest of participants.

Morning amylase levels were also found to significantly differ across age groups $(F(2,34)=3.29, p<.05)$.

- Children aged 11 years had higher mean AM amylase ( $M=114.14$, $\mathrm{SD}=75.16)$ than children aged 10 years $(M=61.13, S D, 33.44)$ and children aged 12 years ( $M=86.05, S D, 36.99)$. Additionally $60 \%$ of the participants 11 years of age exhibited this reversed diurnal pattern. 
Question 2: What is the relationship of demographic variables, level of trauma exposure, perceived stress, and resilience, with a-amylase diumal ihythm in Palestinian children, ages 10-12, exposed ta chronic war vlolence? (cont'd)

There was no significant difference between a-amylase with gender, schooling achievement and household income or significant relationship with CRS, CPSS, MPSS, FPSS, or LTE.

Results of a-amylase shows that a good percentage of these Palestinian children had altered a-amylase patterns mainly among 11 year old children which may be related to stress/trauma exposure ?acute or chronic stress response is unknown? higher stress demands exerted on this specific age group ? methodological error? or normal individual diurnal variation associated with puberty?

\section{Was there an association of cortisol and $\alpha$-amylase results?}

- There were no significant correlations found between a-amylase AM, PM and difference with cortisol AM, PM or cortisol difference.

- However, higher AM cortisol and positive cortisol difference was associated with lower AM $\alpha$-amylase levels and increased negative AMPM a-amylase difference.

o This reflects that both biomarkers' exhibited a normal diurnal pattern and confirmed their distinct relationship.

- No significant relationships were evident between participants with reversed $\alpha$-amylase pattern and cortisol diurnal rhythm.

- The presence of reversed $\alpha$-amylase diurnal pattern but not for the cortisol pattern indicates that $\alpha$-amylase enabled us to capture potential stress responsitivity among participants not depicted by the cortisol. 
Question 3: What is the relationship of demographic variables, level of trauma exposure, and perceived stress with resilience of Palestinian

$$
\text { children? }
$$

- Children's resilience scores (CRS) were significantly associated with gender $(\mathrm{t}=2.76, \mathrm{p}<.01,95 \% \mathrm{CI}=\mathbf{2 . 5 6 - 1 5 . 6 8 )}$.

- Boys had higher mean resilience scores $(M=150.05, \mathrm{SD}=$ 16.09) than girls $(M=140.93, S D=19.29)$. Though both groups had healthy resilience scores, boys appeared to be adapting to the war trauma better than girls.

- No other correlations found between CRS and study variables.

- Children reported high LTE scores $(M=11.02, S D=4.48)$ and High CPSS (31.42, SD=7.43).

- There was a strong and significant association between child stress (CPSS) and level of traumatic experiences (LTE) $(\mathrm{r}=.39, \mathrm{p}<.001)$.

\section{Question 4: What was the relationship between parents and their child's perceived stress scores?}

- Results showed a strong positive strong association between CPSS and LTE with FPSS $(r=.36, p<.001 ; r=.33, p<.01)$ and with MPSS ( $\mathrm{r}=.36, \mathrm{p}<.00 ; 1 \mathrm{r}=.41, \mathrm{p}<.001)$ respectively.

- Father and mother perceived stress were also strongly and significantly correlated $(\mathrm{r}=.65, \mathrm{p}<.001)$.

- This appears to indicate that children's response to trauma is greatly affected by their parent's response. 


\section{Discussion}

C Cortisol diurnal patterns remained normal in all participants despite of the higher morning levels' association with higher perceived stress scores and presence of some outliers.

- Those three boys had significantly high Am cortisol levels in conjunction with high perceived stress scores, high trauma scores, high parental perceived stress scores.

- Were these the results of war stress that threatens the current and future physical \& psychosocial health or were they possible methodological errors?

- Higher levels of Am cortisol in some participants could be related to normal individual variation in AM cortisol production influenced by the individual's adrenal sensitivity, capacity, cortisol binding, or methodological difficulties in assessing perceived stress, (Hallhammer et al., 2009. The levels could also be affected by the day of the week, time of measurement since awakening (Kelly et al., 2008).

\section{Discussion}

$\checkmark$ a-amylase patterns appeared to be also with normal pattern in majority of children except for the $38 \%$ of participants.

$\checkmark$ Highest AM a-amylase levels and reversed diurnal pattern were among 11year-olds. NO correlations found with CPSS.

$\checkmark$ Rare studies to compare with(Shame, Asthma)

o Could this finding also be related to methodological error (PSS)? Nater (2007) reported that the CSSS is a better measure than the PSS.

$\circ$ Food ingestion prior to testing

- Acute or chronic stressors that were not uncovered in this study? children were feeling stressed more than originally perceived?

o Could it be a normal individual variation in puberty? 


\section{Discussion}

$\checkmark$ Children facing war trauma appear to be adapting better than originally assumed

- Resilience scores were in the healthy range despite high trauma and perceived stress scores.(Quantitative vs. Qualitative approach? Methodological error?

- Boys perceived themselves as more resilient than girls this contradicts with other Palestinian studies and other international studies (Brajša-Žganec, 2005; Garbarino \& Kostenly, 1996; Hunter, 2001)? What are those gender/role expectations that might contribute to this?

\section{Discussion}

Children appeared to be influenced by the perceived stress of their parents; most often by their mother's stress.

* child perceived stress scores (CPSS) were strongly correlated with parental stress and trauma exposure.

* Mothers' perceived stress response had greater negative impact on the children's AM cortisol than the fathers'. This may be related to longer periods of contact children had with their mothers every day thus aiding in the child's ability to see and feel the mother's anxiety.

FPSS and MPSS was also strongly correlated as well as with level of child traumatic exposure

* Appears to indicate the strong impact of war violence on both parents, potentially causing aggravation of stress levels in children. 


\section{Original Theoretical Framework Lazarus (1994) Revised model of stress, coping\& adaptation}

The adapted model to reflect variables in this study is:

Antecedents

Person:

- Goals, beliefs

- Resources

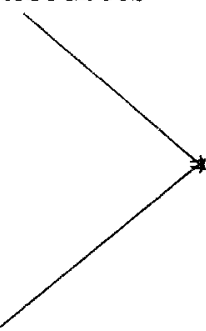

Environment:

- Harm/losses, threats

- Challenges, benefits

\section{Processes}

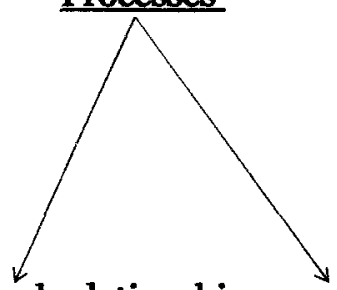

appraisal relationships $\rightarrow$ coping $\rightarrow$ emotional effects, morale
Outcomes social functioning\& health

\section{Study adapted Theoretical Framework}

Lazarus (1994) Revised model of stress, coping\& adaptation

The adapted model to reflect variables in this study is:

Antecedents

Person:

- Demographic

- Resources

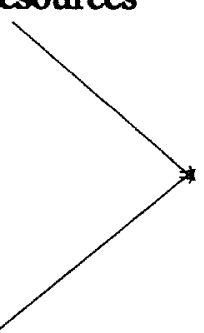

Environment:

- Traumatic exposure

- Parental stress/support

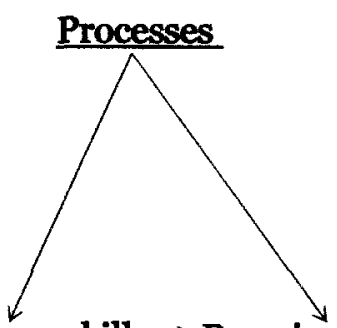

Resilience skills $\rightarrow$ Perceived stress $\rightarrow$ Biologic response in cortisol/ a-amylase diurnal activity and psychosocial 


\section{Conclusion}

- War adversity has potential impact on increased morning cortisol secretion.

- The association of our subjects with reversed a-amylase pattern with normal cortisol diurnal pattern suggests that studying $a$-amylase is an important to consider in future stress related studies.

- The overall study results revealed that Palestinian children in this sample were adapting fairly well physically and psychosocially to their chronic exposure to war and violence.

- Parental stress has significant impact on children stress.

\section{Implications}

- Publications

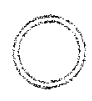

- First article "Research in a war zone: Implications for nurse researchers". Advances in Nursing Science, Nursing\& Migration 33:2.

- Second article "Literature review". SON Journal. In process

○ Third article "Relationships of traumatic exposure, perceived stress, and resilience with cortisol\& a- amylase diurnal pattern in Palestinian children" Biological Research for Nursing. In process.

- Research: This research study findings support previous research work that war adversity has potential impact on stress biomarkers diurnal secretion.

- Practice: providers need to assess war impact but it appears children are adapting better than expected (more work is needed to verify) and parental stress has an impact on the child's stress response

- Education: greater emphasis on family dynamics and relation between parent and child in their stress reactions/adaptation, greater sensitivity to gender roles across cultural groups and the effect of stress, greater content related to biological and psychological interaction effect 


\section{Limitations of the study}

- The cross-sectional design with the limited number of participants and cortisol sampling can limit the study's validity and generalizability;

- Low reliability for the child perceived stress instrument. Pilot testing a revised version of the CPSS tool for utilization with Palestinian children may be helpful;

- Uncontrolled home setting for participant's delivery of salivary sampling lead to the loss of 11 salivary samples and caused potential misinterpretation of the results.

\section{Recommendations}

- Further research among Palestinian children is obviously necessary to ascertain whether cortisol outliers and reversed a-amylase diurnal pattern really reflected the negative physical and psychosocial response to war stress or was it a methodological error.

- Further longitudinal studies, with a larger sample, more reliable screening instruments and with more controlled methodologies, is needed to explore the SNS and HPA responsitivity of children, across various ages 


\section{Thank You All}

- I had the honor to work with all you, as a result I have grown to become competent:

- Professionally: Teacher and researcher in the field of stress psychobiology. Participate in policy making related to traumatized Palestinian children

- In Practice: developing psychobiological screening tools (resilience/adaptation, war PSS across age groups, cortisol\& aamylase\&) for early detection and management of deviants.

- My next goal is to expand this research study to include other biomarkers such as the DHEA, norepinephrine and neuropeptide $Y$ related to the study subject; repeat the study under more controlled environment with a large sample size and more reliable instruments 